\title{
Samoan Educators' Perceptions and Experiences of In-service Training in Implementing Curriculum Reform
}

\section{by}

Maimoana Janine Petaia

\author{
A thesis \\ submitted to the Victoria University of Wellington \\ in fulfilment of the \\ requirements for the degree of \\ Master of Education
}

Victoria University of Wellington 2009 


\section{ABSTRACT}

This research study was undertaken in Samoa, a self-governing island nation in the Pacific. The main purpose of the study was to investigate the effectiveness of in-service training in implementing new curriculum reforms for senior history. This study sought to identify the barriers and facilitators of in-service training (INSET) workshops so that planning for future workshops can better equip teachers with the knowledge and skills to implement a curriculum. It also sought to obtain educators' views and understanding on any professional development policies. This study adopted an interpretive phenomenology methodology using a case study approach. Purposeful sampling was used to select the history teachers and Ministry of Education personnel for the study. Data was collected through the use of in-depth, semi-structured face-to-face interviews. Thematic analysis of the interviews revealed that although the teachers found the INSET to be effective, there were several barriers that prevented teachers from fully implementing the training into classroom practice. One of the notable barriers was the lack of support offered to teachers from principals and heads of departments in the critical stages of implementation. Another notable barrier, both at the school level and national level, was the lack of monitoring and evaluation of the in-service training. Teachers felt that there needed to be continuous and consistent monitoring and evaluation carried out by principals and Ministry of Education staff to ensure that the programme was being implemented effectively within the classrooms. The lack of monitoring and evaluation resulted in teachers reverting to traditional styles of teaching and learning. Another notable barrier was teacher quality. The success of any reform programme is heavily dependent on teachers and their willingness to fully and effectively implement a programme. This study found that teachers' lack of interest and motivation resulted in the curriculum not being implemented effectively into classroom practice. In trying to minimise the various problems and difficulties of centrally-planned INSET and professional development activities, the local policy on teacher training is a shift towards school-based training. This study found that teacher's professional development was more 
effective and relevant if it focused on developing their training needs within their own environments. 


\section{ACKNOWLEDGEMENTS}

First of all I would like to thank our Heavenly Father for giving me the knowledge, the wisdom and the commitment to complete this research study.

This research would not have been possible without the assistance of many educators in New Zealand and Samoa, who willingly gave their time, wisdom and support to enable me to complete this thesis. Faafetai tele lava. Without your support and guidance this research would not have been completed.

Dr Lex McDonald, Postgraduate Director of Education, Victoria University of Wellington, was my supervisor for this research study. From the very first day he ably offered scholarly advice and assistance in a research area he has pursued with passion and interest. I shall forever be indebted to him for his support, advice and encouragement to get this thesis completed. Faafetai tele lava.

I would like to thank my parents, my sister and brother for their never-ending support, prayers and words of encouragement. I would also like to thank my grandparents, all my aunties, uncles, cousins and friends for their support and prayers. Without it, I would not have been able to complete this thesis.

Last but not least, I would like to thank my husband and my two children, Helena-Marie and Aidan Samuelu for being very patient with my long absences and neglect of other duties while I worked on my thesis. Thank you for being supportive and understanding. It wasn't always easy but we made it!

May the good Lord continue to richly bless and guide you all always. 


\section{ABBREVIATIONS AND ACRONYMS}

APEC Asia Pacific Economic Cooperation

CEDAW Convention on the Elimination of All Forms of Discrimination against Women

CMAD Curriculum Materials and Assessment Division

DOE Department of Education

INSET In-service training. Usually undertaken in an environment external to the organisation. (For example in a training centre)

JSS Junior Secondary School

MESC Ministry of Education Sports and Culture

NUS National University of Samoa

NZAID New Zealand Aid

NZODA New Zealand Overseas Development Aid

OECD Organisation for Economic Cooperation and Development

ONSET on-service training. Usually undertaken within an organisation. (For example in a school)

PSSC Pacific Senior Secondary Certificate

SOD School Operations Division

SPBEA South Pacific Board for Educational Assessment

SRO School Review Officers

SSECRP Samoa Secondary Education Curriculum and Resources Project

SSS Senior Secondary School

USP University of the South Pacific 


\section{LIST OF FIGURES}

Title page

Figure 1: $\quad$ Map of Samoa 5

Figure 3.1: A model of the Process of Teacher Change 30

Figure 3.2: Transfer Process 32

Figure 3.3: Model of the Transfer Process

Figure 3.4: Role-taker / Time Differentiated Integration of Transfer Strategies Model 36

Figure 3.5: A Multi-level Transfer Model 


\section{Table of Contents}

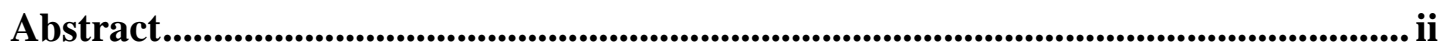

Acknowledgements ............................................................................................................. iv

Abbreviations and Acronyms ............................................................................................ v

List of Figures.............................................................................................................. vi

Chapter 1 ........................................................................................................................... 9

Overview of the Research Problem ........................................................................... 9

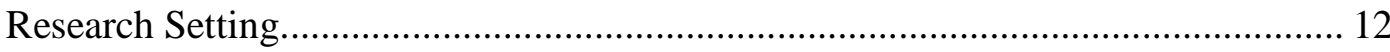

Description of Samoan Islands ................................................................... 12

Historical and Political System ..................................................................... 12

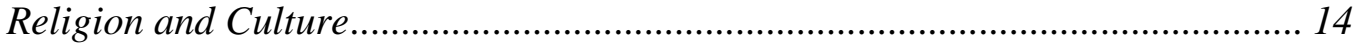

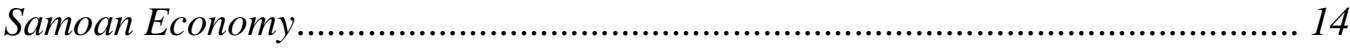

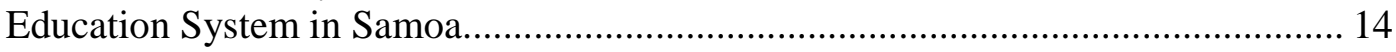

School Management and Organisation ……………………………………….... 15

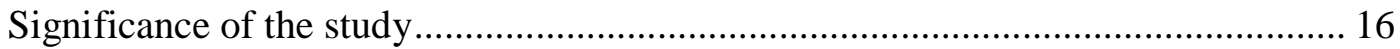

Research Questions .............................................................................................. 16

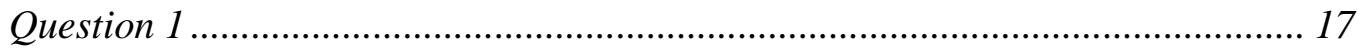

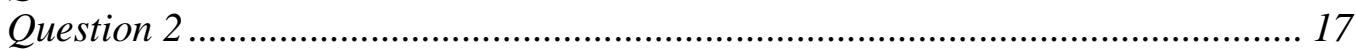

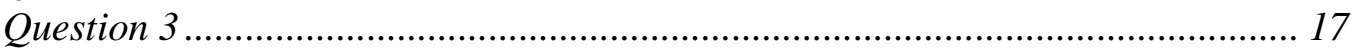

Organisation of the thesis.................................................................................. 17

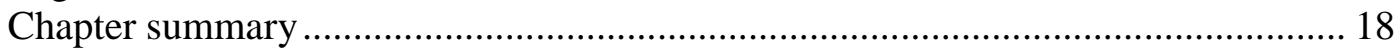

Chapter 2: Samoa Education System - setting the context.......................................... 19

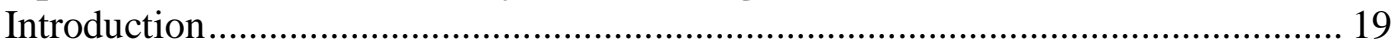

Samoa Secondary School Education Dual System - An overview ……………….... 19

Background to Samoa Secondary Education Curriculum and Resources Project -

Phase 2 (SSECRP-2) ......................................................................................... 22

Chapter Summary …………………………………………………….... 23

Chapter 3: Literature Review............................................................................................... 25

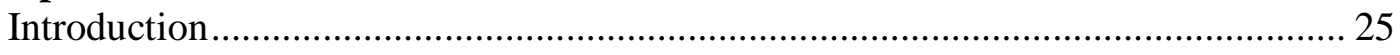

In-service teacher training and professional development workshops ...................... 25

Challenges and limitations of INSET ………………………………………. 28

School based training or site-based professional development ................................. 32

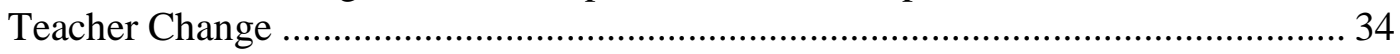

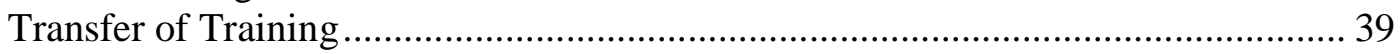

Models of Transfer.............................................................................................. 43

Effective pedagogies in teaching history ............................................................ 45

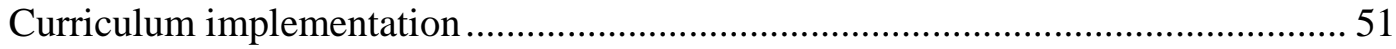

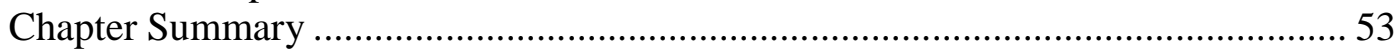

Chapter 4: Methodology............................................................................................................. 55

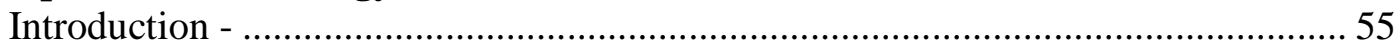

'Locating oneself' in the study ............................................................................ 55

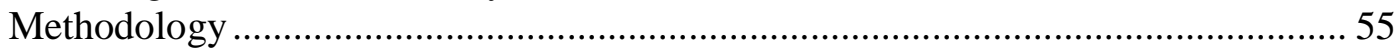

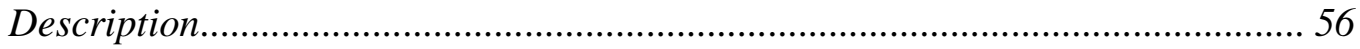

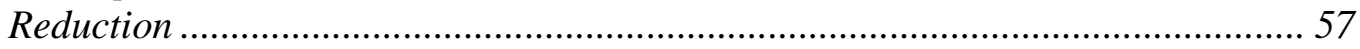




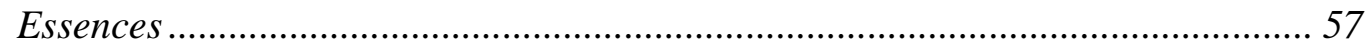

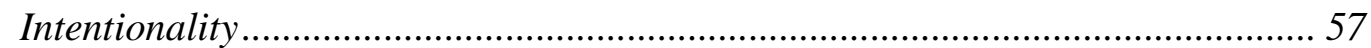

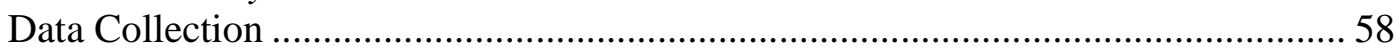

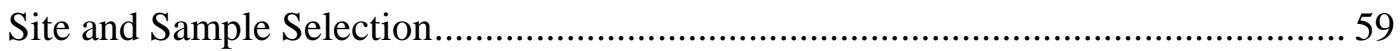

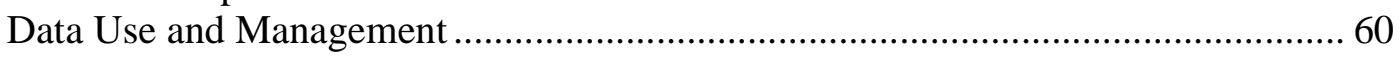

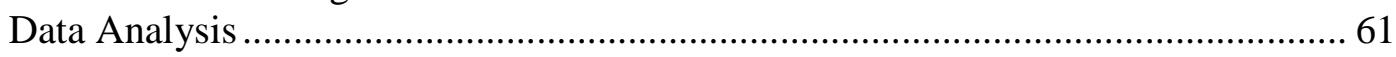

Credibility and Trustworthiness in Qualitative Research ..........................................6 62

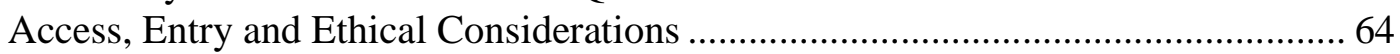

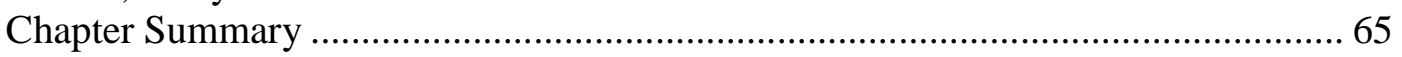

Chapter 5: Results and Discussion: Facilitation of Transfer..................................... 67

Effectiveness of Approaches and Strategies used in the training ..............................67 67

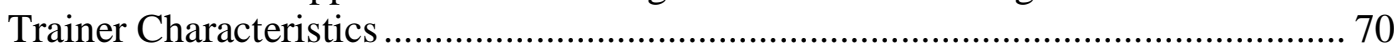

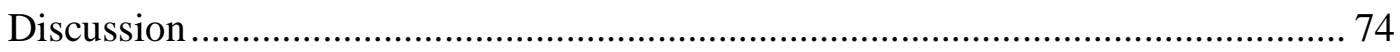

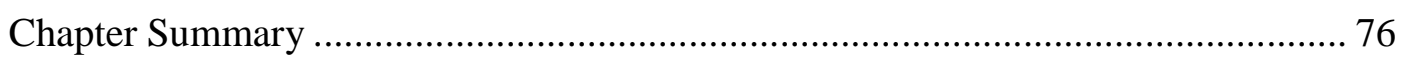

Chapter 6: Results and Discussion: Barriers of Transfers ............................................. 77

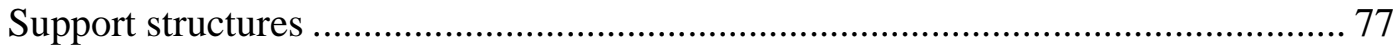

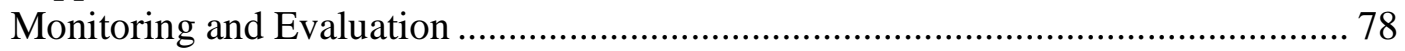

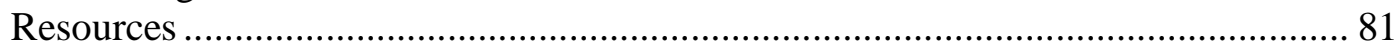

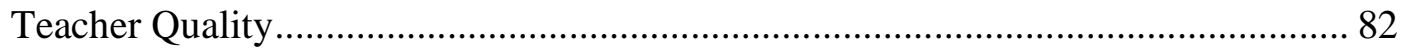

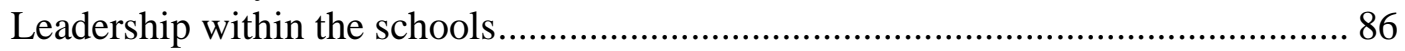

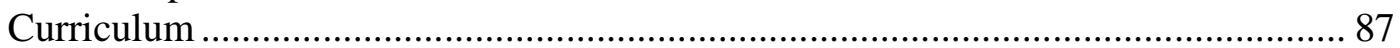

Network

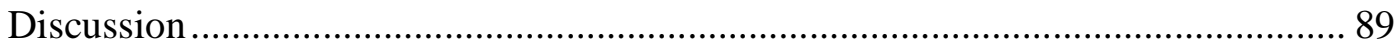

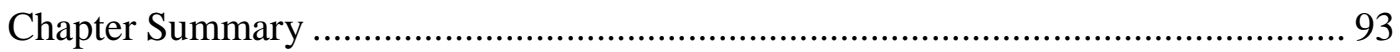

Chapter 7: Results and Discussion. Question Three....................................................... 95

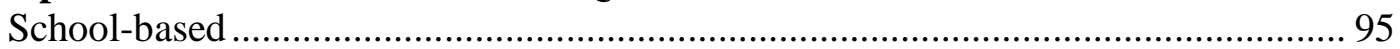

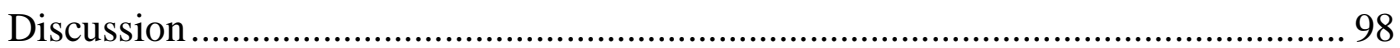

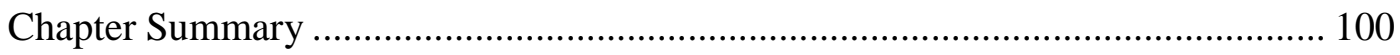

Chapter 8: Conclusion and Recommendations ....................................................... 101

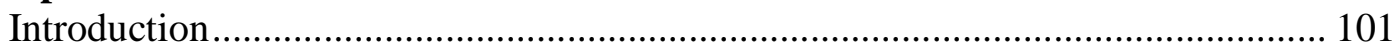

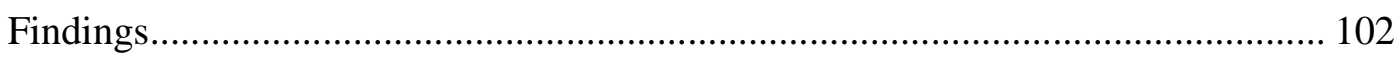

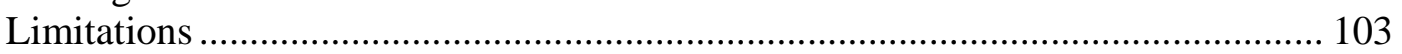

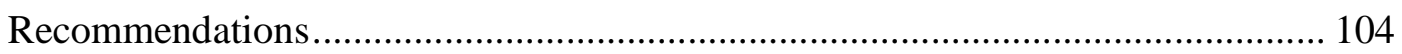

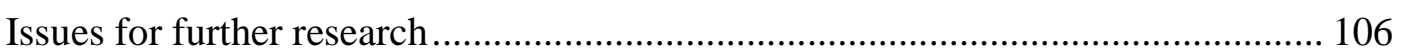

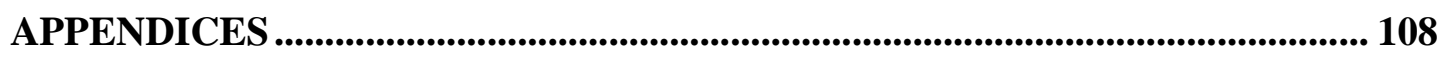

Appendix One: Participant Information Sheet.................................................... 108

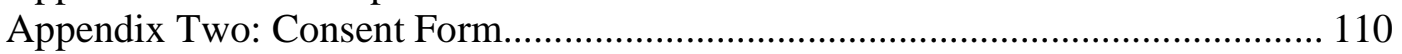

Appendix Three: Pre-interview Information Sheet............................................... 111

Appendix Four: Consent form - Interview........................................................... 113

Appendix Five: Application letter to carry out research in schools......................... 114

REFERENCES.......................................................................................................... 116 


\section{CHAPTER 1}

\section{Overview of the Research Problem}

Teacher professional development plays an important role in changing teacher's pedagogical skills, knowledge and attitudes which in turn has a positive impact on student learning (Borko \& Putnam, 1995; Cohen \& Hill, 1997; Falk, 2001; Lam, 1998; Lamie, 1998; Sabri, 1997; Schober, 1984; Supovitz, Mayer \& Kahle, 2000; Supovitz \& Turner, 2000; Zeegers, 1995). But despite this claim, a high number of studies have also shown that professional development does not necessarily equate to enhanced teaching and learning practices (American Educational Research Association, 2005; Day, 1999; Garet, Porter, Desomine, Birman \& Yoon, 2001; Gravani, 2007; Lieberman, 1996; Loucks-Horsley, 1997; OECD, 1998; Ogletree \& Allen, 1976). There is significant and mounting evidence to suggest that professional development and INSET workshops do not always adequately prepare and equip teachers with the required knowledge, skills, attitudes and capabilities to effectively deliver a programme (Gravani, 2007; Kieviet, 1990; Lieberman, 1996; OECD, 1998; Ogletree \& Allen, 1976; Sabri, 1997; Vonk, 1995). There are wider contextual and structural issues that determine the success and /or failure of any professional development activity (Baldwin \& Ford, 1988; Broad and Newstrom, 1992; Foxon, 1993; Hynds, 1997; McDonald, 2002; Sabri, 1997; Stronkhorst \& van den Akker, 2006; Subedi, 2004; Taplin, et al., 2007; Vonk, 1995; Zeegers, 1995). There is also the issue of whether the skills and knowledge obtained from professional development and INSET workshops are being transferred into the classroom and to what extent (Foxon, 1993; McDonald, 2002).

While the hope is that transfer of training occurs, numerous studies have found that this is not always the case (Williams et al cited in Leberman, McDonald \& Doyle, 2006). There are wider contextual issues and processes such as training programme (Sabri, 1997; Stronkhorst \& van den Akker, 2006; Vonk, 1995), personal characteristics of the trainee (Wlodkowski, 1985) and workplace support (Baldwin \& Ford, 1988; Broad and Newstrom, 1992; Hynds, 1997; McDonald, 2002; Taplin, et al., 2007; Tufue, 1998; Zeegers, 1995) that act 
either as facilitators or barriers to the transfer of training. Perry (1990), Foxon (1993) and Lewin (1951) emphasise that barriers to transfer within the organisation need to be identified in order for transfer to occur. Lewin (1951) argues that if the inhibiting or restraining forces are greater than the facilitating forces than transfer is not likely to occur. For example, with regard to history teachers and professional development, the literature suggests that the training programme needs to focus upon the practical needs of history teachers in the classroom if any transfer is to occur (Pendry, Husbands, Arthur \& Davison, 1998). There have also been studies to suggest in terms of organisational support that the history department plays the biggest role in helping teachers to transfer what has been learned in training into the classroom (Hill, 1995; Pendry et al, 1998).

Given this understanding of the wider contextual issues and processes that act as barriers to the transfer of training into the classroom, there have been calls for changes to how INSET is approached (Fullan cited in McDonald, 2002, p. 96). A shift away from the traditional system of training where a top-down approach was adopted to a standard base system or a bottom-up approach (Ingvarson, 1998a) where training is designed around the practical needs of classroom teachers. There has also been a widespread shift towards school based professional development (Lieberman, 1996; Saito, Hendayana, Imansyah, Ibrohim, Isamu \& Hideharu, 2006). Research has shown that this shift towards school based professional development has many benefits for teachers (Darling-Hammond, 1998a; Hargreaves \& Fink, 2000; Lam, 1998; McLaughlin \& Zarrow cited in Villegars-Reimers, 2003 ).

In Samoa, efforts by the Government through its Ministry of Education, Sports and Culture (MESC) to reform the education system, with the implementation of a new single-stream curriculum and the training of teachers has noted that despite continuous and on-going professional development workshops and training, not much has changed in teachers pedagogical practices (MESC, 2006). This concern has also been highlighted in an Asian Development Bank Education Sector Report (ADB, 2005) and a joint report by the governments of Samoa, Australia and New Zealand (Government of Samoa, 2006), in which 
teaching quality and practices remain low. However, Afamasaga (2002) argues that the training of teachers for the new single-stream curriculum needs to be well in - serviced and adequately resourced. This implied that the training should adequately prepare teachers to teach the newly implemented curriculum.

Given this predicament, this study focused on obtaining Samoan educators' perceptions and experiences of INSET and professional development programmes in helping teachers to implement the new reform changes in curricula, with an emphasis on history teachers. It sought to obtain educator's perceptions on the facilitators and barriers to the transfer of skills learnt in training into the classroom. It is noted in the literature that student records alone should not be used as an indicator to measure training effectiveness (Fletcher \& Barufaldi, 2002) but rather more research should be conducted with teachers, by means of working backwards to identify which specific characteristics of professional development work well, which aspects don't work well and why (Guskey, 1997). Ingvarson, et al., (2003) argue that a certain amount of confidence should be placed on teacher surveys on the impact of professional development activities on their practices. They go on to state that that there is no reason to question teacher responses on the impact of professional development activities as teachers tend to be forth-coming when it comes to assessing its value and worth. Fletcher and Barufaldi (2002) have also noted that teacher opinion, as an indicator, will prove useful in the future for the direction of effective professional development. Ingvarson (1998b; 2002) argues that obtaining teachers views on the quality and impact of professional development programmes in changing their practices should be of paramount importance. He goes on to state that the success of any professional development programme should not be measured against the developers objectives but rather on the impact of the programme on teachers teaching practices. Corcoran (1995) adds to this by stating that the success or the failure of any educational reform initiative will depend on the efficacy and efficiency of teachers to perform and consequently professional development has become a major focus of any reform initiative. 


\section{Research Setting}

Description of Samoan Islands

The Samoan archipelago is a group of volcanic islands covering 2,934 square kilometres in land area and lies south of the Equator and bounded by the latitudes of 13 degrees and 15 degrees south and longitudes of 168 degrees and 173 degrees west (Ministry of Finance, 2008). Samoa consists of nine islands, Savaii, Upolu, Manono and Apolima, which are inhabited and the uninhabited islands of Fanuatapu, Namu'a, Nu'utele, Nu'ulua and Nu'usafee (Figure 1). Apia, on the northern coast of Upolu, is the business and economic centre of the islands; it has the seat of government and is where the majority of the population is situated. Samoan is the national language but English is the language in government, education and commercial businesses. The preliminary census counts for 2006 showed the total population at 179,186, of which 92,961 were males and 86,225 females, a 1.4 increase since the 2001 census.

\section{Historical and Political System}

Samoa became a German colony in 1899. On the outbreak of World War 1 in 1914, Samoa became a mandated territory of New Zealand pursuant to the League of Nations. After World War II New Zealand continued to administer Samoa as a United Nations Trust Territory. In 1962, Samoa became the first nation in the Pacific to gain political independence, and in 1970 became a member of the Commonwealth.

Samoa has a democratic parliamentary government that blends both western and local traditions. A Head of State is elected by the fono (Legislative Assembly) for a five-year term. Executive power lies with the Cabinet headed by a Prime Minister and supported by the majority of the 49 members of the fono, with a five-year term. Ministers are selected by the Prime Minister from the fono in the Legislative Assembly. Two members are directly elected by the country's non-Samoan and mixed ethnic groups. 


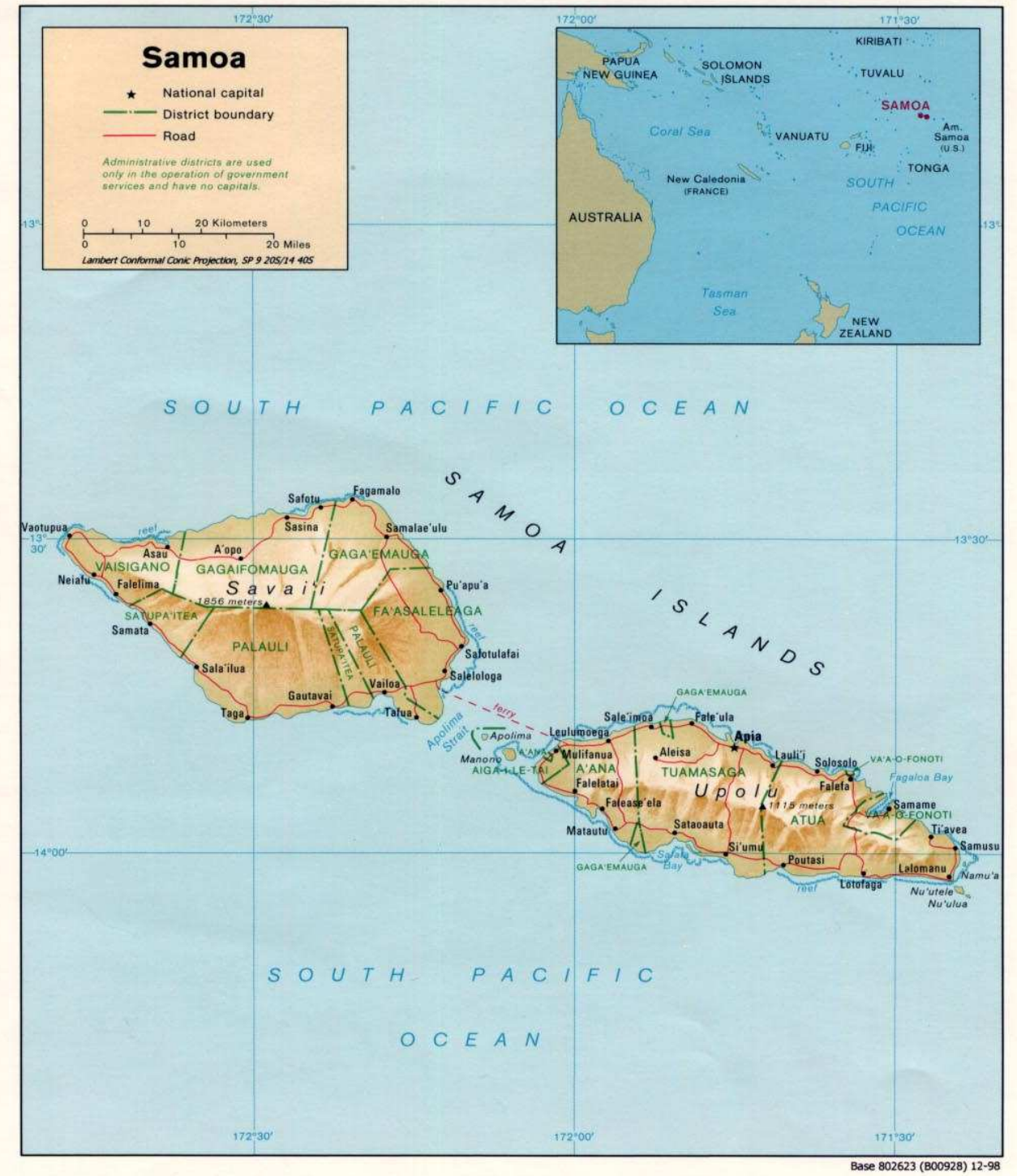

Figure 1 Map of Samoa

(Source: www.lib.utexas_edu/maps/samoa.html cited in Ministry of Finance, 2005, p. iii)

The remaining 47 seats are elected from amongst the matai (Chiefs) from the 47 Samoan constituency districts. Prior to 1990, members of the Legislative Assembly were elected into Parliament by matai suffrage, where only those holding chiefly titles were able to vote. In 1990, universal suffrage was introduced and those 21 and over are now obligated by law to vote in the country's general elections which are held every five years. 


\section{Religion and Culture}

Religion plays a very important part in the lives of the Samoan people with $99.7 \%$ of the population being Christians across a range of denominations. It is intertwined with the fa'asamoa (Samoan way of life). The fa'asamoa is unique in the way it is structured. The villages are run and controlled by the faamatai (chief system) and is comprised of a group of extended families. The Samoan matai is the head of the family and represents the family at the village council meetings, where the matai deliberate over and discuss matters pertaining to their village. It is also at the council meetings where the matai are responsible for making village laws so as to ensure peace and order in the villages. The pulenuu (village mayor) is responsible for ceremonial ceremonies and ensures that law and order is maintained in the villages.

\section{Samoan Economy}

Samoa's economy is small and agriculturally based, relying heavily on foreign aid (Ministry of Finance, 2005). The country's major agricultural crops are coconut or copra, taro, bananas and nonu fruit. Since the 1990's economic growth has also come from fisheries and tourism, with fish being Samoa's largest export followed by nonu juice, beer and coconut cream. Samoans are also heavily dependent on overseas remittances from relatives in New Zealand, Australia and the United States of America. Samoa's currency is the Tala, which is abbreviated to SAT, meaning Samoan Tala.

\section{Education System in Samoa}

The government provides primary and secondary education in Samoa in partnership with village based school committees, mission schools and the private schools. Primary education is compulsory for children aged between 5 and 14 years. At the end of Year 8, students sit a national examination to determine entry into secondary schools. The secondary programme covers a 5 -year period. Prior to 2005, secondary education in Samoa was operated on a dual-stream education system (explained in Chapter 2), where the high achieving students went directly to senior secondary schools for years 9 to 13 while the majority of students went to junior secondary schools offering 
programmes from Year 9 to 11. The National University of Samoa (NUS) and the University of the South Pacific (USP) provide tertiary education.

The government of Samoa spends a large amount on education (Ministry of Finance, 2005). It is defined as one of the six priority areas for development under the government of Samoa's Strategy for the Development of Samoa. The goal of the education strategy is to provide "improved student learning outcomes with specific emphasis on raising numeracy and literacy levels" (Ministry of Finance, 2005, p. 10). The strategies outlined in the SDS for attaining these goals are:

- Strengthening community support in teacher education

- Improving teacher quality

- Improving curriculum and assessment materials

- Improving teaching materials

- Improving school facilities and equipment

- Strengthening MESC

- Developing sports

\section{School Management and Organisation}

Government schools in Samoa are controlled and managed by both the government and the village communities. The government through MESC appoints the principal and the teachers. The government pays the teachers salaries and provides stationery and the curriculum materials for the school. The village communities on the other hand provide the school buildings, furniture and equipment for the school. The village committees are also responsible for school maintenance.

There are 21 School Review Officers (SRO). The SRO act as liaison officers between the Ministry and the school, and maintain an effective relationship with the village committee on behalf of the Ministry. The SROs duties include: (1) monitoring the performance of the school; (2) ensuring the effective operation of the school committees; (3) helping and advising the school committees on issues pertaining to the social and academic welfare of both students and staff; 
(4) offering administrative support to school principals; and, (5) ensuring teachers are supplied with adequate teaching and learning materials (MESC, 1995).

\section{Significance of the study}

While there have been numerous studies undertaken in the areas of teacher INSET, professional development, transfer of training, curriculum implementation and effective teaching pedagogy, it has always been from a Eurocentric and Western point of view. A study of this nature can only add to the very limited research available on the Pacific (McDonald, 2002), and specifically the direction for Samoa on future teacher professional development and INSET. The focus and findings of this research will be of significance in Samoa given that teacher development and the quality of teaching and learning are priority areas highlighted in the Government of Samoa Strategic Development Plan (Ministry of Finance, 2005). Also, Samoa's education system has been undergoing reform and it is imperative that research is carried out to determine what kinds of professional development are more effective for an island setting especially during the implementation of a new curriculum. Penuel, Fishman, Yamaguchi and Gallagher (2007) on the implementation of a new history curriculum, argue that new research is needed to illuminate how particular professional development programmes impact on teacher practices during the implementation of a new curriculum. Penuel et al (2007) argue that while there have been numerous research findings (Garet, et al., 2001; Supovitz \& Turner, 2000) to prove that professional development activities impact and influence teacher practices, there is still limited and somewhat fragmented research on what is seen as effective professional development for history curriculum implementation.

\section{Research Questions}

This study sought to obtain educator's perceptions and experiences of INSET in implementing new curriculum reforms, with an emphasis on history teachers. Initial reviews of the literature and personal interest have facilitated the formulation of the proposed research questions. The questions revolve around 
the identification of the facilitators and barriers associated with the implementation of the history curriculum in the classroom.

\section{Question 1}

What are the strategies, techniques and approaches used in the INSET to help teachers improve their content knowledge and pedagogical skills in implementing the new Samoan history curriculum document into classroom practice?

\section{Question 2}

What are some of the barriers impeding the successful implementation of the history curriculum document into the classroom?

\section{Question 3}

What are teacher's views or understanding on any policies or structures in place to ensure on-going professional support while implementing the new curriculum changes?

\section{Organisation of the thesis}

Subsequent chapters in this study cover: (2) the Samoan education system, setting the context; (3) literature review; (4) methodology and data analysis; (5) results and discussion question one; (6) results and discussion question two; (7) results and discussion question three; and, (8) conclusion and implications.

Chapter Two provides an overview of the education system in Samoa with the merging of the secondary school dual-system of education into a single-stream system of education. This chapter sets the context for the study as the newly implemented curriculum and subsequent INSET took place as a result of the merger.

Chapter Three situates the study in its theoretical framework; it provides an overview of the international literature on different aspects of the research 
study. It provides an overview of the challenges and limitations of INSET and looks at the positive benefits of training in helping teachers to implement a programme. This section also discusses transfer of training and the impact this has on teacher change. The chapter touches on what constitutes an effective history lesson as the study focuses on the perceptions and experiences of history teachers. It also provides a brief section on the problems associated with curriculum implementation.

Chapter Four covers the research orientation, the data collection and analysis procedures used in this study. Chapters' Five to Seven discuss the results for the three main questions.

Chapter Eight summarises the main findings from chapters 5-7 and then discusses them in relation to INSET and curriculum implementation. This chapter also discusses the implications of the findings. The study ends with recommendations on the direction for INSET and professional development in Samoa.

\section{Chapter summary}

This chapter has provided a brief overview on the significance and impact of professional development and INSET workshops on teachers. However, it also sheds light on the on-going problems surrounding the training of teachers and its impact on changing teacher beliefs, attitude and practices, and the issue of whether training is transferred into the classroom setting and to what extent. Thus this research is concerned with obtaining teacher's perceptions and experiences on the impact of INSET in helping them to implement curriculum reform so that future training programmes can be designed to meet the needs of teachers in a Pacific Island setting, namely Samoa, a small island in the South Pacific. 


\section{CHAPTER 2: SAMOA EDUCATION SYSTEM - SETTING THE CONTEXT}

\section{Introduction}

This chapter considers the background to the Samoa Secondary Education Curriculum and Resources Project (SSECRP). It provides a historical overview of factors that led to the project and reasons behind the need to restructure the education system of Samoa.

\section{Samoa Secondary School Education Dual System - An overview}

A World Bank review on the education system of Samoa in the 1990's resulted in the 'Western Samoa - Rebuilding the Education System: Education Sector Review' (World Bank Report, 1992) report. This report highlighted a number of issues with the dual-stream education system in Samoa including: a) the inequalities [and inefficiencies] in educational opportunities for the children of Samoa; b) underperformance of both primary and secondary schools resulting from problems with the quality of teaching and learning; and, c) a curriculum that lacked relevance and significance (Scott, et al., 2004, p. 1).

The problems and implications highlighted in the World Bank report were considered under an Education and Planning Development Project, funded by the then New Zealand Official Development Assistance Programme (NZODA). The outcomes of this project resulted in two key national planning documents for the development of the education sector in Samoa, Education Policies 1995 - 2005 and Education Strategies 1995 - 2005.

The Education Strategies and Policies handbooks provide a policy framework and strategic plan for the development of education in Samoa and include sections on early childhood, primary and secondary education, teacher education and inclusive education, along with sections on departmental and school management, and post school education and training. Since the adoption of the policy and strategic plans in 1995, the government of Samoa 
(GoS) has sought assistance from overseas donors to implement the various projects outlined in these documents.

NZODA in collaboration with the Samoa Department of Education (DOE), now known as the Ministry of Education, Sports and Culture (MESC) undertook the task of developing and implementing a comprehensive single stream curriculum for secondary education in Samoa. The intention was to ensure that the "same curricula and assessment requirements will apply to all students" (DOE, 1995, p. 6).This project was entitled 'Samoa Secondary Education Curriculum and Resources Project' (SSECRP). The main goal was to "improve the quality of secondary education in Samoa by developing a comprehensive single stream curriculum for secondary education for Year 9 to 13 in accordance with Government of Samoa policies" (National University of Samoa, 2004, p. vii). Apart from changes to the curriculum, changes were also made to Samoan secondary schools administrative and structural systems.

Prior to the commencement of SSCERP, Samoa's education system was characterised by a dual - stream education system. It was comprised of an 8year primary education system, which was made compulsory in 1994 for all children ages 5 to 14 and a 5 -year secondary education programme (DOE, 1995). Secondary education was based around a dual system of junior secondary schools (JSS) providing education for years 9 to 11 while the senior secondary schools (SSS) catered for years 9 to 13 or in some schools, years 12 and 13 , where students went directly from year 10 to 12 . The JSS were mainly government schools while the SSS were either mission, private or government owned.

Entrance and selection into the secondary schools depends on three external examinations. The Year 8 national examination determines those who enter secondary schools. The highest achievers are enrolled in well-regarded Government schools while the rest are placed in other schools (National University of Samoa, 2004). The next external examinations are held at Year 11, within the JSS to determine entrance into Year 12. Those who pass continue onto year 12 in either a JSS or SSS, where they sit the Year 12 school 
certificate examinations. The last of the external examinations is held at Year 13 where students sit the Pacific Senior Secondary Certificate (PSSC) examination conducted by the Pacific Board of Educational Assessment (SPBEA). Success at the PSSC level provides entry into the University Preparatory Year (UPY) at the National University of Samoa (NUS).

The decision by the DOE to mainstream the secondary education system was because the dual - stream structure was "inequitable and inefficient" (DOE, 1995, p. 23). The dual system was characterised by an education system that was "still limited and highly selective" (Scott, et al., 2004, p.2) and which at most, disadvantaged and limited access for rural school children to SSS (National University of Samoa, 2004). This was further complicated by the lack of resources and inadequate teaching staff at JSS.

Other problems noted by the DOE (1995) in the rationale for adopting a mainstream system for secondary education are explained below:

a) A high percentage of students do not pass Year 11 examinations, which means that a large number of students (about $75 \%$ of the total age group) do not complete secondary education (National University of Samoa, 2004). This causes a major concern as those not completing secondary education have difficulty in the labour market because companies prefer to employ those with a Western Samoa School Certificate qualification or higher.

b) A high turnover of teaching staff. Fifty percent of teachers in the JSS were primary trained leading teachers to teach subjects which were not their own. In the SSS, there was difficulty in trying to obtain teachers to teach certain subjects, namely science, mathematics, English and accounting.

c) Inadequate teaching facilities and resources for both SSS and JSS. Facilities such as science laboratories, libraries, home economics and industrial classrooms were either non-existent or not adequately 
supplied. Lack of resources to enable the effective teaching of applied subjects led to a more theoretical and less practical knowledge of much needed skills for the labour market

d) It was also noted that the JSS curriculum lacked relevance and applicability to the labour market. The SSS curriculum placed a heavy emphasis on future white collar or professional employment. The skills needed to survive in the workforce were either not sufficiently taught or were not taught at all.

Given the above problems with the dual-education system, the adoption of the single-stream education system was perceived as a significant and important development for the Samoan secondary education system. Adopting this single-stream system would allow the Government of Samoa (via the DOE) to address the issues of equity, quality, relevance and efficiency (DOE, 1995).

\section{Background to Samoa Secondary Education Curriculum and Resources Project-Phase 2 (SSECRP-2)}

The Samoa Secondary Education Curriculum and Resources Project (SSECRP) began in 1998 and was implemented in two phases: phase 1 from 1998 to 2001 and phase 2 from 2001 to 2004 (Scofield, 2004). This project was funded by NZODA, which is now known as New Zealand Aid (NZAID).

The goal of the SSECRP was to:

- Develop a single stream curriculum framework for years $9-13$

- Develop and publish curriculum statements for years 9-13

- Develop and publish resource materials to support curriculum statements

- Design and conduct INSET for teachers, school principals and SROs to introduce the single stream curriculum and resource materials

- Transfer skills and knowledge to DOE Staff (Scott, et al., 2004) 
As a result of SSECRP, specialised INSET workshops were conducted for teachers in the different subject areas to assist them in implementing the new single-stream curriculum. Training was also conducted for top management, principals and SROs to assist them in helping teachers to implement the curriculum. Four years on since the introduction of the new curriculum, it is imperative that research be conducted to evaluate the impact of the INSET on implementing curriculum reform.

Under the Education Sector Project, INSET materials were also developed for each subject. Train the trainers workshops were carried out for selected 'expert' teachers for the delivery of INSET to classroom teachers. The INSET programme was designed to support the introduction and implementation of the new curriculum by concentrating and addressing the training needs of teachers arising from the single-stream curriculum.

Prior to the commencement of INSET, a training needs analysis was undertaken to identify the weaknesses in the teaching service. The analysis identified two main weaknesses. One weakness was the limited awareness of the variety of teaching approaches that could be used to deliver the curriculum; the other weakness identified in the analysis was the inadequate content knowledge teachers had. As a result, the INSET programme was designed to refine and expand teachers' content knowledge and pedagogical skills. Subject advisors and consultants held workshops in each subject area. Modules were developed to address both the subject content and pedagogical skills. The consultants then modelled their use with the pool of teachers selected as trainers. The trainers in turn used the modules for the subsequent INSET offered to all teachers.

\section{Chapter Summary}

This chapter has provided an overview on the education system of Samoa and the rationale for restructuring the old secondary education system, which was characterised as being inequitable and inefficient to meet the needs of Samoan students. As a result of this need for reform, the single-stream education 
system was introduced, where the same curriculum and assessments were applied to all secondary school children. Central to this merger has been the review, design and development of curriculum statements across all subject areas, and the training of teachers through regular in-service and teacher professional development programmes. 


\section{CHAPTER 3: LITERATURE REVIEW}

\section{Introduction}

This chapter details the theoretical framework that has guided the study. It is divided into different sections having a bearing on the phenomenon that is being researched. It highlights the research under taken on INSET, the phenomenon of transfer of training, effective teacher pedagogies in the teaching of history, and on teacher change and curriculum implementation.

\section{In-service teacher training and professional development workshops}

In the last decade there has been an upsurge of interest on in-service teacher training and what is considered an effective training workshop (McDonald, 2002; Organisation for Economic Cooperation and Development [OECD], 1998; Timperley, Wilson, Barrar \& Fung, 2007; Villegas-Reimars, 2003). The reasons for this interest in INSET and teacher professional development vary from increased funding from donor agencies to improving teacher education to Government bodies who view teacher education as a key component for economic development (Cobb as cited in Villegas-Reimars, 2003). There is also an increase in support from national and international organisations such as the Asia Pacific Economic Cooperation (APEC) which views teacher education as the key to economic and social development within a country. Increased interest in INSET and teacher professional development is also due to widespread and continuous reforms in education where teacher training is considered to be a key element in the change process (Harris \& Fasano, 1988).

What is in-service training? According to the OECD (1998) in-service education and training refers to the identifiable learning activities in which practising teachers participate. The intention of such training is to increase and improve the professional knowledge, skills, attitude and capabilities of teachers in a defined area in order for them to educate children more effectively (Bolam, 1982; Education Review Office, 2000). There are also those who note that INSET, especially in developing countries is the only form of preparation some 
teachers gain without being qualified (Villegas-Reimars, 2003). He also indicates that the definition of INSET varies from one country to another depending on the type of training. Gardner (1995) adds to this by stating that INSET should be seen in terms of a scale; on one end of the scale is training that occurs in an environment away from school specifically set up for training and which he refers to as 'in-service' (INSET); on the other end of the scale is training that takes place within the school, in teacher's practical environment, which he refers to as 'on-service' (ONSET) training. She goes on to explain that in between the two "poles of the continuum might be a series of training and practices that provide training to a greater or lesser extent in or out of school". (Gardner, 1995 p. 628).

The term in-service training has also been used synonymously with teacher professional development. While the OECD (1998) refers more specifically to INSET as learning activities in which practicing teachers are involved, professional development signifies any activity that develops teacher's knowledge, skills, practical expertise and characteristics as an effective teacher. One can claim that INSET is part of a teacher's professional development and only adds to their repertoire of teaching skills, knowledge, expertise and the characteristics of the teacher. However, Villegas-Reimars (2003) has noted that there is no clear distinction on differences between INSET and professional development. Benejam and Espinet (1992) support this by stating that in the United Kingdom and Spain, INSET is described as a different model of professional development which puts strong emphasis on action-research, group activities and interactions, and problem-solving techniques. But Showers, Joyce and Bennett (1987), in conducting metaanalysis research on professional development, found that workshops that adopted and used theoretical components were more effective than training that merely concentrated on teaching new techniques (Villegas-Reimars, 2003). Others (Karagiorgi \& Symeou, 2006; OECD, 1998; Sabri, 1997; VillegasReimars, 2003) argue that those workshops which concentrate on theoretical aspects while neglecting teaching skills and the techniques of teaching also fail to have any positive impact. Thus it is clear from the literature that the dividing line between the two terms, in-service training and professional development, 
remains unclear. Based on this the literature review will use the terms interchangeably to describe all professional activities and learning that teachers are involved in.

While there continues to be ongoing discussion and disagreement on the term INSET and the distinction between INSET and professional development, most would agree that INSET takes place for one of the four reasons categorised by Greenland (1983):

- In-service training is carried out for those teachers who have not been qualified

- In-service training takes place to upgrade teacher's knowledge and skills. This is particularly true for older experienced teachers who need training to upgrade teaching techniques (OECD, 1998). They add to this by stating that training takes place to assist teachers to avoid the burnout syndrome.

- In-service training takes place to prepare teachers for new roles such as principals or education trainers. Others (Education Review Office, 2000) also go on to note that INSET also takes place in order for teachers and educators to obtain promotion. This is the case in Korea where teachers must undertake 180 hours of training in order to receive promotion

- In-service training takes place during a reform period, especially when a new curriculum is implemented (Harris \& Fasano, 1988; OECD, 1998) and takes place during technological advancement.

Apart from the reasons categorised above, the OECD (1998) also states that INSET takes place for the 'feminisation' of the profession (p.21). They highlight the disparities in the profession with men holding higher positions despite being outnumbered by women. They go on to state that INSET has a role to play in assisting and encouraging women to apply for higher positions. One such example of this is when Samoa acceded to the Convention on the Elimination of All Forms of Discrimination (CEDAW) against Women convention in 1992. Under this convention, the Government of Samoa acknowledges the objectives contained in this agreement relating to the elimination of gender discrimination by ensuring that women had access to training and continuing education amongst other objectives. 


\section{Challenges and limitations of INSET}

Studies conducted to evaluate the effectiveness of INSET have shown that teachers who attend training show a marked improvement in their classroom practices, skills, beliefs and attitude as opposed to those that do not attend (Cohen \& Hill, 1997; Lam, 1998; Lamie, 1998; Schober, 1984; Stronkhorst \& van den Akker, 2006; Supovitz \& Turner, 2000; Zeegers, 1995).

Studies conducted by le Roux and Ferreira (2005) and Ha, Lee, Chan and Sum (2004) show those teachers who attend professional development workshops were satisfied with what was learnt in the training. Teachers in these workshops showed that training that concentrated on improving their subject content knowledge was more relevant and useful as opposed to those that merely concentrated on teaching styles and methods ( $\mathrm{Ha}$, et al., 2004; le Roux \& Ferreira, 2005). Cohen and Hill (2000) and Ingvarson et al. (2003) support this by stating that professional development and INSET workshops that increase teachers content knowledge about their subject area is more likely to lead to improved student learning as the teachers become more competent to present it in a more meaningful way. This is further supported by the American Educational Research Association (AERA, 2005) which stated that the focus on content knowledge in training workshops was one of the most effective elements in changing teacher instructional practices. But other studies conducted by Sabri (1997) and Lam (1998) showed that workshops should also concentrate on elements of delivery and teaching styles as this enabled teacher's to deliver the curriculum in more meaningful ways. In regards to professional development for history teachers, Bain (2003) and Hootstein (1994) stress that the main concern for these teachers is not so much understanding subject matter but how to deliver history in a more meaningful way. Given this concern, Cole and Barsalou (2006) stress that pedagogy should take precedence over training on subject matter as there is an urgent need to address how to teach. Whatever the differences are, the AERA (2005) noted that professional development workshops should ensure that there is coherence or the linkage to the past. Following this, ideas should be presented so teachers are better able to grasp what they already know and any new ideas shown in the training, so to ensure changes in teacher instructional practices. 
Gravani (2007) in another study stressed that training workshops should include sessions on the use of new technology given the widespread introduction of the use of technology and multi-media in the current curriculum.

Perhaps one of the most encouraging elements of professional development and INSET workshops is the forming of professional circles and fostering of professional relationships amongst teachers (AERA, 2005; Barak \& Waks, 1997; Garet, et al, 2001; Gravani, 2007; Karagiorgi \& Symeou, 2006; OECD, 1998; Sabri, 1997). Lieberman (1996) states that these organisations are powerful and enriching as they offer teachers something "different in quality and kind" than those available in their own schools and environment (p. 200). This is particularly true for the group of history teachers in Stoskopf's (2001) study, who noted the advantages of professional circles in developing rich and vigorous content and pedagogy for the teaching of history. Lieberman (1996) goes on to note that these relationships give teachers the time to discuss and share teaching experiences which in turn help them to reflect on their own practices. This networking of teachers is particularly strong in the United States and Japan where teachers observe and provide feedback on colleague performances, which helps to enhance teaching practices (OECD, 1998) and in Switzerland, teachers are used as trainers for professional development workshops to increase their confidence.

There is also significant and mounting evidence to suggest that INSET does not always adequately prepare and equip teachers with the required knowledge, skills, attitude and capabilities to effectively deliver a programme (Kieviet, 1990; Sabri, 1997; Vonk, 1995;). Teachers argue for example that one-shot workshops (Loucks-Horsley, 1997) do not always cater to the needs of teachers and do not identify their weaknesses (Slater, 2006; Stronkhorst \& van den Akker, 2006). Numerous studies (Day, 1999; Gravani, 2007; Ogletree \& Allen, 1976) have found that INSET workshops adopt a lecture-like approach as opposed to a participatory interactive approach. Teachers argue that these workshops adopt a top-down approach, are administratively organised with little or no teacher input (Gravani, 2007; OECD, 1998; Ogletree \& Allen, 1976). Kennedy (2001) suggests that ignoring teacher's autonomy, credibility and 
control over their training needs limits their professionalism and security as educators. This is further supported by Ogletree and Allen (1976) who state that teachers should have greater control of their training needs otherwise they will be psychologically absent from the training workshop.

Teachers have also noted that INSET workshops bear no relevance to classroom practice (Lieberman, 1996; Ogletree \& Allen, 1976). Lieberman (1996) and others (Karagiorgi \& Symeou, 2006; OECD, 1998; Stronkhorst \& van den Akker, 2006) argue that workshops were unattached to what was actually happening in the classrooms. This claim is supported by other studies (Garet et al, 2001; Gravani, 2007; Karagiorgi \& Symeou, 2006) that have found professional development activities allocate too much time to the theoretical aspects of teaching and learning and not enough time on practical activities that can assist teachers when they return to their classrooms. Garet et al. (2001) concluded, in their large scale study of professional development activities, that professional development activities that adopt a more practical approach to training are more effective and relevant for teachers. Pasikale (1996) in her study on Pasifika teachers noted that preference for practical approaches in professional development workshops was evident.

Perhaps one of the strongest criticisms about professional development activities is the lack of evaluation and follow-up after the training $(\mathrm{Ha}$, et al, 2004; Huberman \& Miles, 1984; Ingvarson, et al., 2003; OECD, 1998; Ogletree \& Allen, 1976; Slater, 2006). The OECD (1998) claims that evaluations are poorly conducted, analysed and disseminated which in part leads to models of best practice not being readily available to policy makers. In a study conducted by Ingvarson, et al., (2003), few participants received any constructive feedback during the critical and often difficult implementation phase of trying out new ideas learnt in the training. Slater (2006) claims that not observing a teacher upon return to the classroom, leads to top management and workshop facilitators not being able to identify gaps or needs in teacher knowledge and practices. 
There has also been widespread criticism for the lack of support teachers receive upon return to the classroom after a professional development training workshop (Barak \& Waks, 1997; Huberman \& Miles, 1984; Lamie, 1998; Zeegers, 1995). Fullan (1982) argues that follow-up for teachers upon their return to the classroom and during the implementation phase of change is recognised as a critical element to ensure change in their practices. Showers, et al. (1982) go on to note that support for teachers is critical to ensure that teachers continuously develop new skills and integrate them into their teaching practices. Slater (2006), Ha, et al. (2004) claim as a result of their research into teacher support following training, note that support structures need to be reinforced and continuous from principals, facilitators, top management and other colleagues. Lieberman (1996) notes that support for teachers can also come from parents and the community as a whole. She argues that involving the whole community in supporting teachers will lead to continuous learning and changed practices on the teacher's part.

There are other criticisms made against INSET that can be referred to as 'house-keeping complaints' as they deal with issues such as timing of workshops, compensation for attendance, catering and accommodation. Studies carried out by le Roux and Ferreira (2005) and Willink (1959) found that teachers complained about the timing of workshops which was usually conducted around exam times or at times when teachers had a busy workload. There were other studies (Lamie, 1998) in which teachers requested to have longer professional development workshop days as opposed to the one-shot workshops teachers were accustomed to (Loucks-Horsley, 1997). le Roux and Ferreira (2005) in their study also found that teachers wanted to see an improvement in accommodation and catering. In another study by Ogletree and Allen (1976) teachers raised the issue of compensation for attending workshops. While these 'house-keeping' issues of INSET might not be significant, it is important that all conditions surrounding workshops are improved as it contributes to the overall effectiveness of the training.

There are also studies (e.g., McDonald, 2002) indicating that transfer of ideas to the classroom is problematic - INSET may have improved teacher 
knowledge and skills but what about the impact? Studies have shown that continuous and intensive professional development workshops are more effective than short term workshops (Darling-Hammond, 1998a; Garet et al, 2001; Hargreaves \& Fullan, 1992; Lieberman, 1996) and it will to a certain extent ensure transfer. Fullan (1991) stresses that INSET workshops have to adopt a long-term commitment and be organised on a continuous basis in order for changes in teachers practices to be evident. Weiss, Montgomery, Ridgeway and Bond (1998) argue that traditional approaches to professional development workshops do not encourage nor deepen teacher's skills and knowledge base which in turn does not change their classroom practices. Studies (e.g., Garet et al., 2001) have also shown that linking teacher's prior knowledge to new knowledge will ensure changes in their practices which will lead to it being transferred into classroom practice.

\section{School based training or site-based professional development}

Due to the many problems and issues with centrally planned INSET and professional development workshops, there has been a widespread move towards school-based or site-based professional development. Site-based professional development provides guidance and assistance at the school level, in the teachers' environment, using approaches such as coaching, collaboration, inquiry and reflection (Veenman \& Denessen, 2001). This approach to professional development gives teachers the opportunity to identify their own learning needs in their own environment, in what is referred to as a bottom-up approach (Saito, et al., 2006). Lieberman (1996) argues that this approach gives teachers the support they need from principals or top management. Hargreaves (1997) stresses that strategic policies should develop guidelines or procedures to assist staff to design, implement and evaluate teaching and learning programmes for their schools.

Educators (Darling-Hammond, 1998a; Hargreaves \& Fink, 2000; Lam, 1998; McLaughlin \& Zarrow cited in Villegas-Reimers, 2003,) argue that a move towards school-based professional development has many benefits for teachers. It provides a forum for teachers to critically reflect on their role, their 
existing professional views and the conditions in their own classroom and school (Hattam \& Mclnerney, 2000). There is strong collegial support amongst the staff and it will foster and encourage collective learning (Lieberman, 1996; Saito, et al., 2006). Lieberman (1996) argues that fostering and encouraging collegiality amongst staff is the most important step in making "professional learning an accepted norm in the life of the school" (p.200). This is further supported by Guskey (1995) and others (Darling-Hammond, 1998a; Lam, 1998; McLaughlin \& Zarrow cited in Villegas-Reimers, 2003) who stress the importance of conducting professional development workshops in teachers immediate environment so that the optimal mix can be achieved. This will also ensure greater autonomy, networking and ownership among teachers (Karagiorgi \& Symeou, 2006)

Others (Karagiorgi \& Symeou, 2006; OECD, 1998; Lam, 1998) note that school based professional development offers a forum for teachers to integrate their professional needs with school improvement efforts. For example, in Germany and the Netherlands, professional development workshops are planned and designed to meet teachers' professional needs and school improvement efforts (OECD, 1998). This approach also ensures and encourages a quality assurance system within the school context (Education Review Office, 2000).

While there are numerous research findings to support the significance of school based professional development workshops, there are issues that need to be recognised to ensure that the workshops are effective. One of the most crucial elements to ensure that school based professional development work is to have 'effective leadership' or the existence of a key person within the school (Hattam \& Mclnerney, 2000; Saito, et al. 2006). There also needs to be a strong collaboration among teachers (Hattam \& Mclnerney, 2000). Saito, et al. (2006) stress that this collaboration has to involve teachers from all subject areas to ensure that school improvement efforts are recognised and fostered by all. This will ensure that professional development is effective as teachers and principals will be pursuing school issues and problems together while at the same catering to their own professional needs (Barth, 1990; Hargreaves \& Fink, 2000). 


\section{Teacher Change}

While the hope is that professional development workshops and INSET will lead to changes in teachers classroom practices, this is not always the case. Fullan (1985), well known for his theories and studies into educational change, has noted that in-service teacher programmes should lead to changes in education, but there also needs to be an understanding of the justification for change. Fullan (cited in McDonald, 2002) states that "change requires some active initiative and participation, the need for support needs to be evident, [and as a result], ownership for change will develop slowly" (p. 106). But both Fullan (1982, 1988) and others (Borko \& Putnam, 1996; Thompson, 2001) also emphasise that teacher change is a long term process, "with implementation occurring gradually and incrementally over a period of two or more years" (Fullan, 1982, p.204). This is substantiated with findings by Donovan, Sousa, Walberg (1987) and Ben-Chaim, Freski, Carmeli (1998) who have stated that it takes several years for a programme to have any educational impact. Both studies suggest that it takes a minimum of 3 years to fully apply in the classroom what has been learned during training. Guskey (1995) argues that any significant change in teacher beliefs, attitude and practices will occur after programme implementation. This is further supported by Backhouse (1987) who states that teachers will change their approach to their practices and beliefs if there is motivation and support from lead teachers and colleagues. Fullan (1982) states that for change to occur, organisational support is the most essential ingredient for teacher change.

Showers, et al. (1987) in their model of teacher change state that teachers go through three different phases before change actually occurs. The first phase is the awareness phase where individual concerns control their way of thinking and doing things. During this phase teachers start to observe and form their perceptions of things. The second phase is the implementation phase where concerns about the implementation of a training programme become more intense. This is the phase in which teachers decide whether or not to accept the changes to a programme. This phase, according to Hargreaves (1995), is when a teacher undergoes a period of uncertainty and confusion in trying to implement new teaching practices. He cautions that this emotional adventure 
should be considered when planning professional development workshops. The third phase is the impact period where teachers become somewhat anxious and worried with the consequences of change in implementing a programme in their contextual environment. Gewirtz (1997) argues that it is in this phase that teacher's autonomy and credibility can be damaged, as they will be more concerned with 'outputs' rather than the 'processes' of teaching and learning.

Showers, et al. (1987) model of teacher change is somewhat similar to Fullan's (1993) four core capacities for change. Fullan (1993) states that personal-vision building, inquiry, mastery and collaboration become important skills for teachers for change to occur. With personal-vision he states that teachers are able to reflect on why they entered the teaching profession in the first place and thus visualize required changes that should take place to further enhance their teaching practices, beliefs and attitude. This capacity involves their emotions and how they feel. Loucks-Horsley (1997), Hargreaves and Fullan (1992) and Weissglass (1994) urge that any professional development workshop that aims to change teacher practices should incorporate the emotions and needs of the teachers. Hargreaves (1995) states that professional development workshops tend to ignore the emotions of the teachers and as Weissglass (1994) cautions, ignoring the emotional needs of teachers causes obstacles to changing their practices.

By inquiry, Fullan (1993) means continuous and constant questioning with teachers "internalising norms, habits and techniques for continuous learning" (p. 2). He states that continuous learning through on-going research will enable teachers to create new knowledge, skills and ideas that can only add to their repertoire of teaching skills. This is supported and highlighted by Lieberman (1996) and others (Day, 1999; Mayer, Mitchell, Macdonald \& Bell, 2005) who argue that continuous and constant inquiry by teachers into their own practice make them aware of further skills, knowledge and techniques they need to grasp to be able to work more effectively and efficiently with their students. Mayer, et al. (2005) stress the importance of inquiry and research to ensure professional growth of teachers and for any school reform programme to be successful. But Lieberman (1996) cautions that replacing old ideas with new 
ones is both difficult and challenging and highlights the need for teachers to work collaboratively in order for changes to occur.

Fullan (1993) states that mastery is the process in which a teacher investigates a topic through the process of inquiry and then ensures complete understanding of this topic. This process involves the teacher in a continuous cycle of trialling and modifying to ensure complete and thorough understanding. The last core capacity in his change cycle is that of collaboration. He states that the "ability to collaborate on both a small and large scale is becoming one of the core requisites of post-modern society" (p. 3). Numerous studies have also highlighted the importance of professional circles in enhancing individual teacher's practices and beliefs (AERA, 2005; Barak \& Waks, 1997; Garet, et al., 2001; Gravani, 2007; Karagiorgi \& Symeou, 2006; OECD, 1998; Sabri, 1997). Moreover, as Lieberman (1996) states, these organisations are not only powerful but also enriching as they offer teachers something "different in quality and kind" than those available in their own schools and environment (p. 200).

Anderson (1997) offers another model of understanding teacher change. This concerns based model examines three different stages of teacher change: stages of concern, levels of use, and innovation configurations. During the stages of concern phase, he explains that teachers experience stages of awareness, informational, personal, management, consequence, collaboration and refocusing. During the levels of use phase, teachers use and adopt the most appropriate and relevant of teaching and learning practices to suit their classroom circumstances. During the innovation configurations phase, teachers revise, modify and adopt practices to meet their individual teaching needs. It can be argued that his concerns based adoption model is somewhat similar to both Showers, et al. (1987) and Fullan's (1993) core capacities for change cycle. The reason being, that teachers go through a period of awareness, concern and reflection, to a period of inquiry, implementation and mastery, to a period of impact and innovation before changes start to emerge.

Loucks-Horsley (1997) also offers a list of five principles that professional development workshops should incorporate into their training so as to foster 
teacher change and adoption of ideas, especially during a curriculum reform or implementation period. Her first principle is that "fundamental change occurs over time, through active engagement with ideas, understandings and real-life experiences" (p.134). This principle is supported by Borko and Putnam (1996) who stress that change in teacher practices occurs only after they have had the time to adapt to the new practices in their classroom and school environments.

Loucks-Horsley's (1997) second principle is concerned with the way in which teachers experience change. During the implementation phase, teachers go through a roller coaster of stages as they try to change their teaching practices. Included in this stage is the aspect of their emotions as they try to adapt to changes. Hargreaves (1995) states that during an implementation phase, teachers practices are at the forefront of professional development workshops, but cautions that changes will not occur unless their feelings and emotions are included in the training. Hargreaves and Fullan (1982) stress that changing teacher practices also changes the teacher so it is important that their feelings and emotions are considered during the implementation phase.

The third principle is the use and adoption of effective teaching practices. She states that training should focus on teachers practical needs. It should also focus on their current knowledge and how that can be enhanced. There also needs to be adequate resources to ensure that teachers are able to implement a teaching lesson effectively.

Her fourth principle is the use of different approaches for teacher learning such as action research. This principle ensures that a teacher is able to learn, not only through the means of attending professional development workshops, but also by undertaking action research, peer observations and exchange programmes. The fifth principle states that "professional development can only succeed with simultaneous attention to changing the system within which educators work" (Loucks-Horsely, 1997, p. 139). Fullan (1993) supports this by arguing that "clearly beyond better pedagogy, the teacher of the future must actively improve the conditions for learning in his or her immediate 
environment" (p. 6). There also needs to be organisational support structures in place to ensure changes to their practices.

The models by Showers, et al. (1987), Fullan (1993), and Loucks-Horsley (1997) attempt to explain the factors involved in teacher change. DarlingHammond (1998b) goes further and stresses that for real changes to occur, teachers must have opportunities to talk, think and try out new practices. She notes that teacher learning and change is enhanced when it is closely linked to the work they are doing with their students in an environment conducive to learning.

Guskey (1997) offers an alternative model on the process of teacher change (Figure 3.1). He argues that professional development activities fall short of achieving intended outcomes because designers fail to understand the process in which teacher change takes place. He goes on to suggest an alternative model that highlights a different cycle among the three outcomes of professional development activities: change in teachers' classroom practices, student learning and teachers' beliefs and attitudes. It is argued that change in teachers' beliefs and attitude comes after change in student learning outcomes. $\mathrm{He}$ adds that teachers will change and strive to better their performance when changes in student learning outcomes become evident. He emphasises that the simplicity of the model is not supposed to deduct from the difficulty of the issues involved nor the inherent relationships among the components of the model.

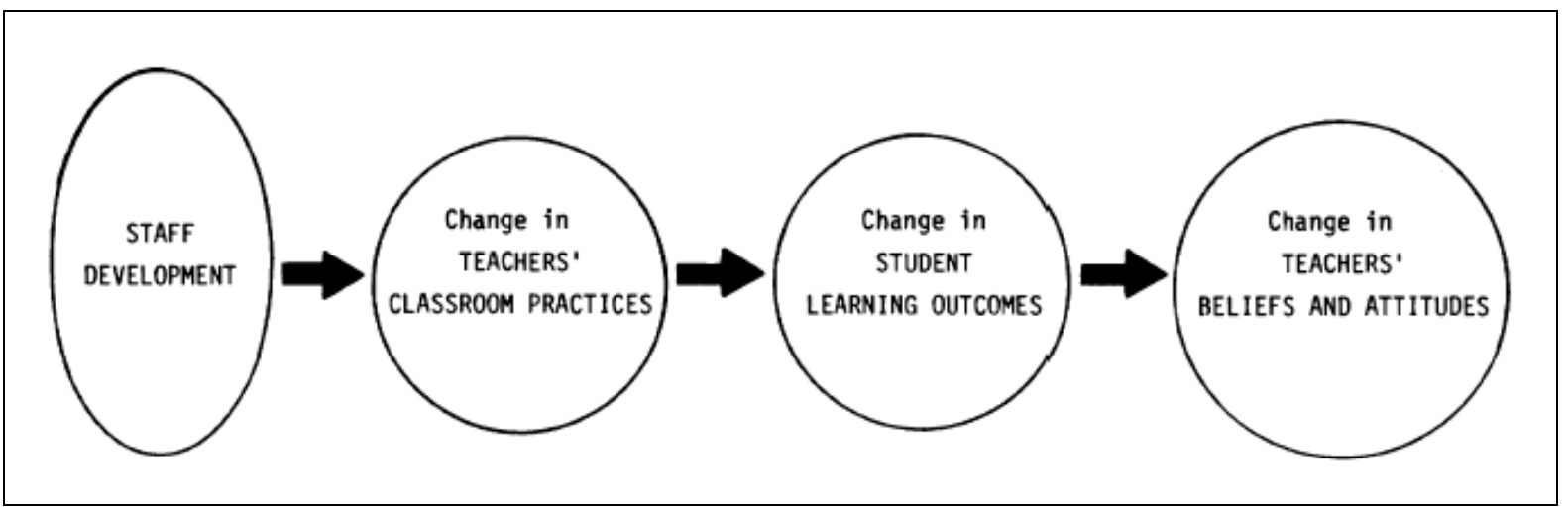

Figure 3.1 A Model of the Process of Teacher Change (Guskey, 1997) 


\section{Transfer of Training}

The terms transfer of training and transfer of learning have often been used synonymously in the literature to describe the process in which skills and knowledge learned in one setting are transferred to another. It can also mean different things. Baldwin and Ford (1988) and Subedi (2004) define transfer of training as the degree to which trainees use the attitude, skills and knowledge learned in training to improve on-the-job performance. Foxon (1993) and Broad and Newstrom (cited in Leberman, McDonald, Doyle, 2006) add to this by suggesting that "it is the effective and continuing application by trainees to their jobs of the knowledge and skills gained in training, to both on and off the job" (p.1). On the other hand, transfer of learning is seen as the ability (of students) to utilise knowledge acquired in the training (or classroom) to the 'real world'. Cordeiro, Kraus, Hastings and Binkowski (1997) have suggested that transfer of training tends to be commonly used in discussions referring to training programmes such as teacher professional development, whereas the terms transfer of learning is more widely used with reference to learning in the classroom. Cree and Macaulay (2000) support this by noting that transfer of learning has its origins in an educational context and the term is widely applied to learning that takes place in the classroom. But despite the on-going terminology debate, Cormier and Hagman (cited in Leberman et al, 2006) argue that the term "transfer of training equates to transfer of learning" (p. 2).

While all professional development and INSET workshops aspire to the transfer of skills to on-the-job application, Foxon (1993) and Subedi (2004) stress that transfer of training is a complex process. Foxon (1993) argues that along with the process of transfer, there is bound to be frequent setbacks and a relapse to previous habits. This is supported by Lewin (1951), who states that during the transfer process the participant (or teacher in this case) is exposed to a 'force field' of factors facilitating and inhabiting the transfer of training to the workplace. He states that the two opposing sets of forces, the facilitating and inhibiting factors determine whether transfer occurs or not. He further states that if the driving or facilitating forces are greater than the restraining or inhibiting forces, transfer will occur. Curry (2001) and Broad and Newstrom (1992) go on to note that if the inhibiting or the restraining forces are greater or 
of equal value to the facilitating or driving forces than transfer will not occur. Perry (1990) argues that barriers to transfer within the organisation needs to be identified in order for any chance of transfer to occur.

If transfer does occur, the question of how much is transferred cannot be measured or fixed (Foxon, 1993; McDonald, 2002) as training participants tend to revert to previous habits. Foxon goes on to note that viewing transfer as a product or outcome is extremely difficult so instead offers an alternative to transfer as a process (p. 2). The process approach (Figure 3.2) model shows what essentially happens as participants try out new skills and techniques, trial and practice the learning, stop using the skills and techniques learnt, or stop using the skills at all. She argues that this process approach enables managers and supervisors to measure transfer at various points. She emphasises the fact that each stage is a prerequisite for the next one. When participants get to the final stage, they either retain and apply the training or, for the most part, may revert to pre-training habits resulting in transfer failure. But she goes on to state that there is a high risk of transfer failure during the early stages.

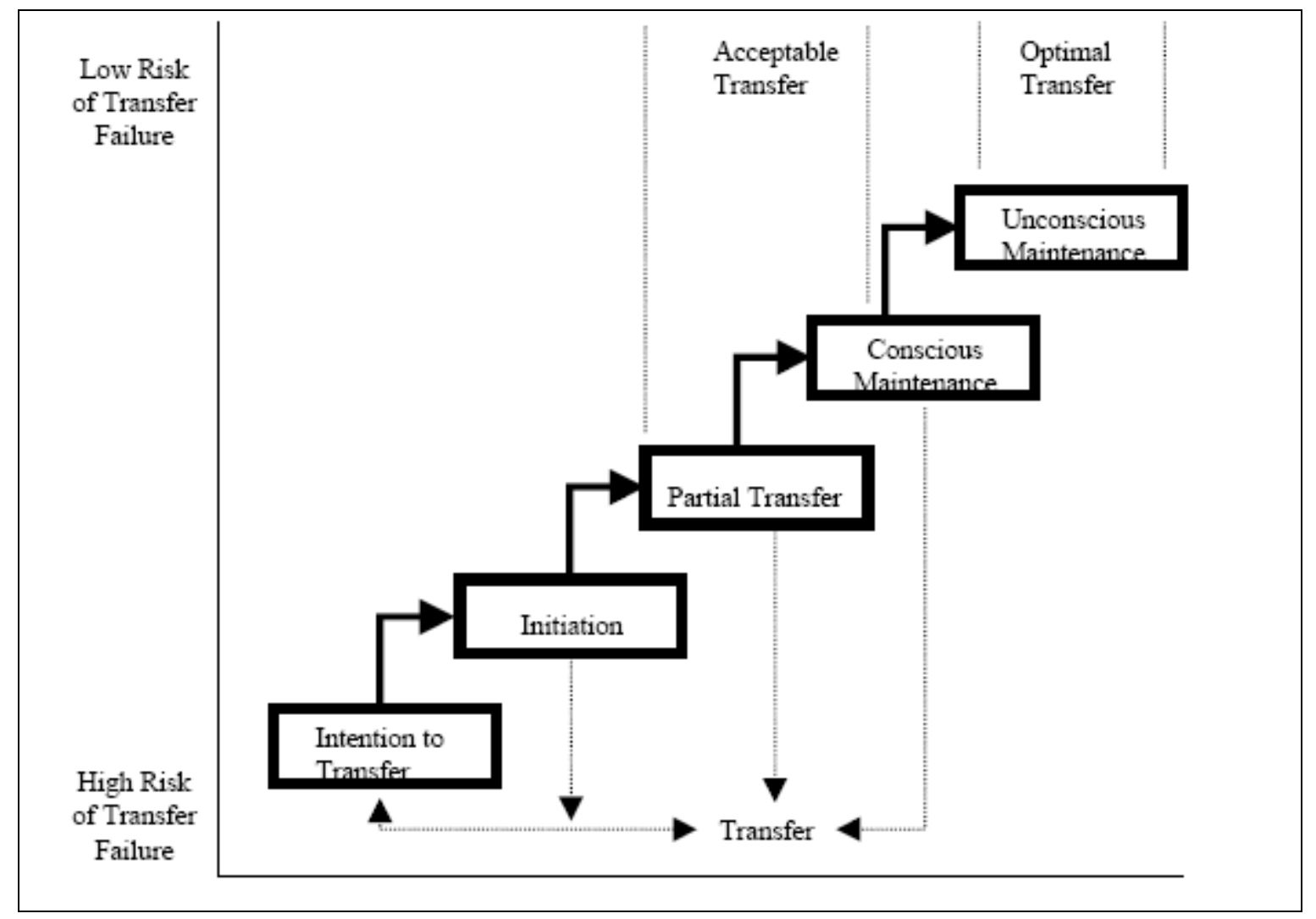

Figure 3.2 Transfer Process (Foxon, 1993) 
During the intention to transfer stage, learners are eager and motivated to try out new ideas learnt in the training. She notes that if participants leave the training workshops with low levels of motivation but with a desire to apply the training, then transfer will most likely fail. During the initiation stage, participants try out new skills, but due to various reasons such as organisational support, attempts to apply training may halt. During the partial transfer stage, participants apply some or all of the skills to the job. The last two stages, the conscious maintenance and the unconscious maintenance, are when transfer has occurred. The participant consciously and knowingly utilises the skills learnt in the training to on the job performance which over time is applied accordingly. During the unconscious maintenance stage, the learner would have fully applied the learning, hence achieving transfer of training. But she cautions that learners may still revert to old habits and ways of doing things.

In considering the difference between professional development and transfer, McDonald and Melchior (2008) indicate that transfer can be considered from a process perspective but indicate it is more - it is a process-dependent activity that ultimately must also be considered in outcome terms. Impact on-the-job, irrespective of the level of transfer, is what counts and therefore they believe that outcomes are important. They go on to add that professional development, often a related activity, is a process but an outcome-dependent activity.

Lewin (1951) and Foxon (1993) note that transfer driving and inhibiting forces can occur at any stage of the training, whether before, during or after. It is important to note that although participants attend the same training, they bring with them different experiences that will determine the level of transfer. Lewin (1951) notes that the total strength before, during and after the training will determine if transfer occurs and to what extent. But Broad and Newstrom (1992) and Kelly (1982) note that if transfer does occur, it is extremely low and it is likely that the behaviour will disappear over time. This is supported by Marx (1986) who states that transfer failure is as high as $90 \%$ for the majority of training workshops. In a study by Huczynski and Lewis (1980) less that $65 \%$ of the participants applied what was learnt in the training to improve on-the-job performance. 
Given the low level of transfer, there has been a resurgence of interest on the wider contextual issues and processes that can inhibit transfer. Foxon (1993) carried out a search of the literature and used it to conduct a content analysis on more than 30 articles and identified 128 inhibiting or restraining factors which were grouped into four categories: (1) organisational climate factors; (2) training design factors; (3) individual learner characteristics; and, (4) training delivery factors. She noted that an unsupportive organisational climate accounted for $42 \%$ of the identified inhibiting factors. The lack of support received from management to implement training was the most commonly cited factor. For example, there have also been studies to suggest in terms of organisational support that the history department plays the biggest role in helping teachers to transfer what has been learned in the training into the classroom (Hill, 1995; Pendry et al, 1998). The lack of opportunities to apply the learning, fear or failure to provide resources was also cited in Foxon's (1993) study. Work demands also inhibited the participants from applying training and as a result resorted to old ideas and ways of doing things. This inhibiting factor has also been highlighted in numerous studies that argue that the level of support offered to training participants determines to a certain extent the application of training into the workplace (Baldwin \& Ford, 1988; Broad \& Newstrom, 1992; Hynds, 1997; McDonald, 2002; Subedi, 2004; Taplin, et al., 2007; Tufue, 1998; Zeegers, 1995).

The training design accounted for $22 \%$ of the inhibiting factors according to Foxon (1993). Participants noted that the training content was too theoretical in orientation and not practical enough. Studies by Sabri (1997), Stronkhorst and van den Akker (2006), Subedi (2004) and Vonk (1995) concluded that the training design was one of the biggest contributing factors to the low levels of transfer. For the professional development of history teachers the literature states that the training programme needs to focus upon the practical needs of these teachers in the classroom for any chance of transfer to occur (Pendry, et al., 1998).

Foxon (1993) noted that individual learner characteristic accounted for $21 \%$ of the inhibiting factors. She goes on to comment that the major inhibitor to the 
transfer of skills onto the job results from a low level of learner motivation to apply the training. This can either be attributed to the difficulty for the learner to grasp the skills or knowledge from the training or simply that they did not see the relevance of the training to their job requirements. This is supported with studies by Subedi (2004) and Wlodkowski, (1985) who argue that the personal characteristics of the trainee and their lack of motivation to apply the training accounts for zero or low level of transfer. Foxon (1993) also noted that training delivery factors such as the inappropriate delivery style of the workshop accounted for $13 \%$ of the low level of transfer. The low level of credibility of the trainer was another inhibiting factor.

In general then what is known is that the individual, the training programme and the support factors are all important for transfer (McDonald, 2002). A useful approach to encapsulate this perspective has been outlined by Broad and Newstrom (1992); they have proposed that there should be a partnership between trainees, their heads of department and trainers at all stages of the training process to ensure support while the trainee undergoes training. It is a 'role $x$ time' model of the transfer process. They believe that this approach will ensure that on-the-job transfer occurs.

\section{Models of Transfer}

Numerous models have been developed to try to explain the process of transfer. Baldwin and Ford (1988) designed an organisational model of the transfer process (Figure 3.3). They explained that the training outputs were influenced by training inputs which they categorised into three categories: trainee characteristics; training design and work environment. Two of the training inputs, trainee characteristics and work environment, directly influence the job performance. This model has had significant impact upon the development of transfer of training since the 1980s. 


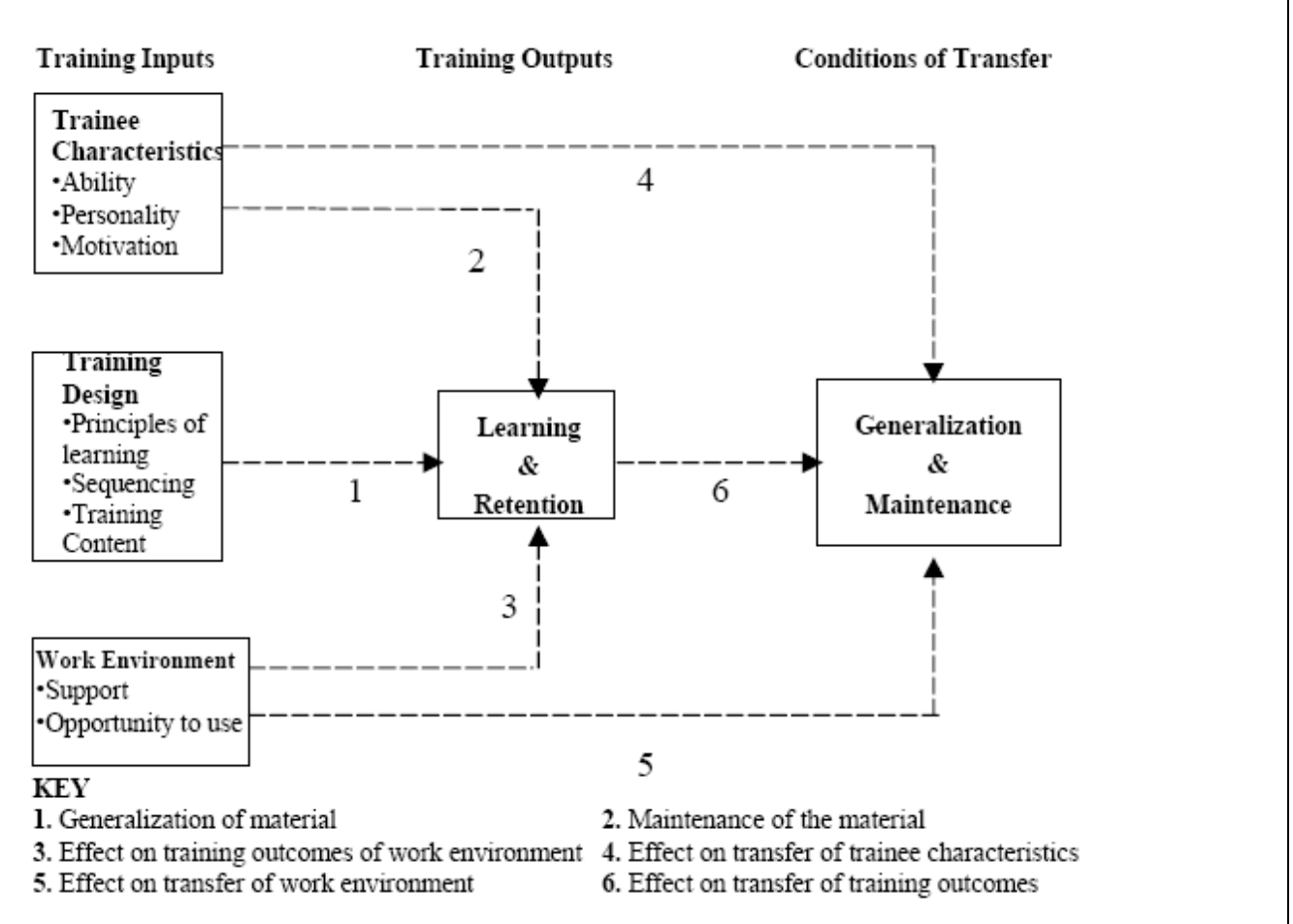

Figure 3.3 Model of the Transfer Process (Baldwin \& Ford, 1988)

As indicated above, Broad and Newstrom (1992) designed a model (Figure 3.4) to try to explain the transfer of training process. While other models focused on the contextual and theoretical processes to explain transfer, their model was based around a partnership approach between the manager, trainer and trainee and the contributing role of each to the transfer of training process.

\begin{tabular}{|c|c|c|c|c|}
\hline \multicolumn{5}{|c|}{ TIME } \\
\hline \multirow{4}{*}{$\begin{array}{l}\text { U్ } \\
\text { 옴 }\end{array}$} & & Before & During & After \\
\hline & Manager & & & \\
\hline & Trainer & & & \\
\hline & Trainee & & & \\
\hline
\end{tabular}

Figure 3.4 Role-taker/ Time Differentiated Integration of Transfer Strategies Model (Broad \& Newstrom, 1992)

A more complex model (Figure 3.5), built on the work of Baldwin and Ford (1988) was developed by Kozlowski and Salas (1997). This model places emphasis on the individual, team and organisation and the internal characteristics of each in the process of transfer. A striking feature of this model 
is the identification of organisational needs which emphasises system training requirements.

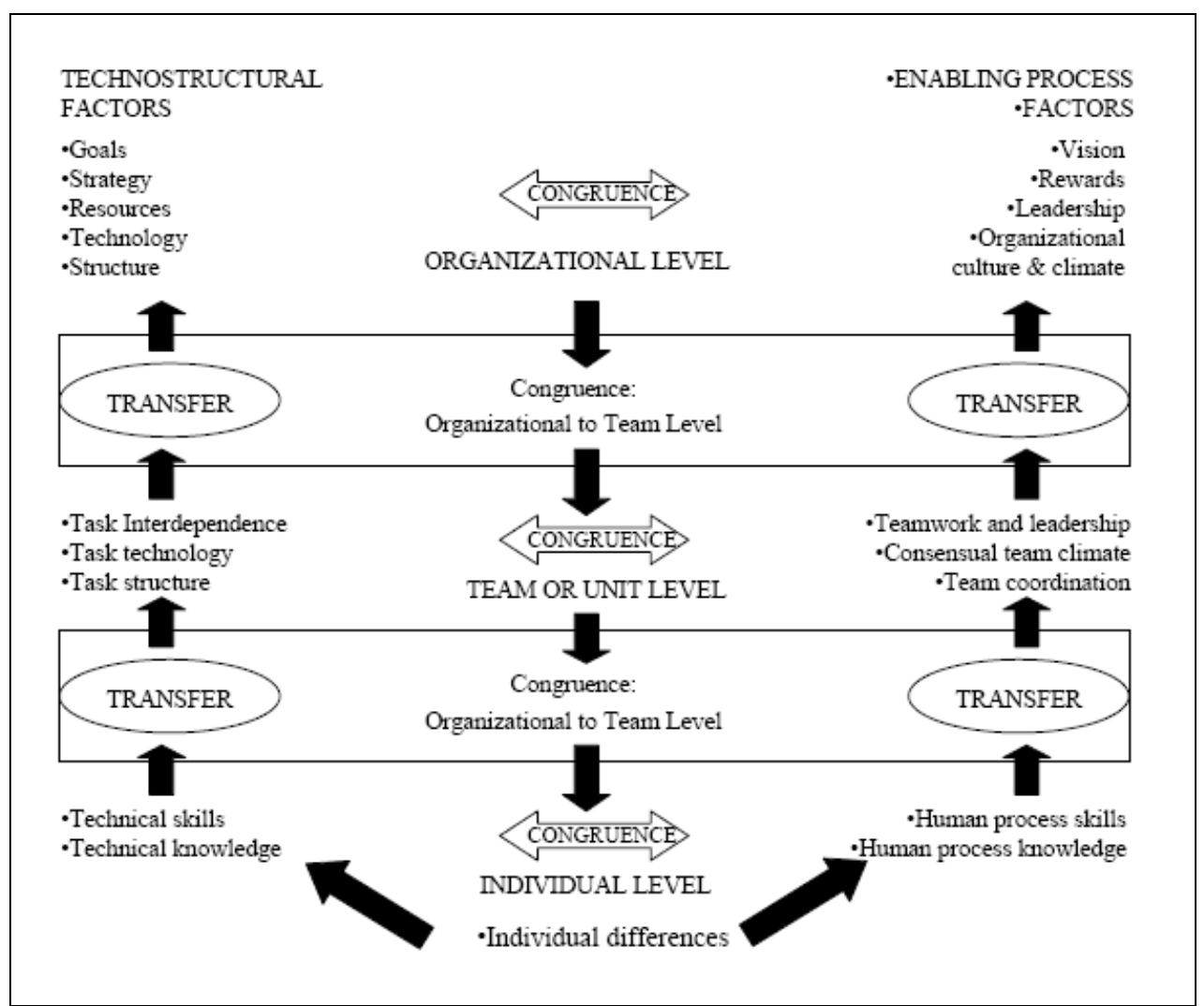

Figure 3.5 A Multilevel Transfer Model (Kozlowski \& Salas, 1997)

\section{Effective pedagogies in teaching history}

There have been numerous debates on what constitutes an effective history lesson. Research has shown that students rate their history classes as the least challenging and interesting of all the subjects offered at school (VanSledright, 1996). White (2003) goes on to note that it does not help when the core subjects such as maths, science and English take precedence over history. He goes on to argue that giving less time for history lessons leads to a shallow coverage of historical ideas, thus taking away students enthusiasm for the subject. Furthermore, the literature is also full of complaints about the poor pedagogy secondary school history teachers are adopting in their classes (Bain, 2003; Cuban, 1984; Evans, 2004; Hootstein, 1994; Stearns, Seixas, \& Wineburg, 2000; Warren, 2003). Accordingly, Bain (2003) and Hootstein (1994) state that the main challenge for history teachers in the teaching of history is 
not merely concerned with obtaining and understanding subject matter but on the techniques and methods used to facilitate the learning. This is supported by Cole and Barsalou (2006) who argue that history pedagogy should take precedence over any reforms in history curriculum. They argue that presentday history pedagogy emphasises rote learning and uncritical thinking amongst history students. Hootstein (1994) argues that many teachers are not planning history lessons thoroughly and adequately. VanSledright (2007) adds to this by stating that research into history education in the US shows that history students are not getting opportunities to practice history. What is required is the study of history via "systematically investigating evidence, reading [through] primary source documents, doing extensive research, and drawing their own conclusion from interpretations and arguments they generate" (p. 133). Instead many students are subject to traditional teaching approaches of rote learning and memorising large chunks of information from textbooks (Barton, 1996; Cuban, 1991, Seixas, 1999 and VanSledright, 2002). To complicate it even more, Wilson (2001) in reviewing the literature on the teaching of history found that there were numerous other concerns ranging from the lack of content knowledge of history teachers, an extremely broad curriculum, to no one effective pedagogical approach to the teaching of history.

VanSledright (2007) argues that present day problems with the teaching of history are related to the way history teachers were taught - large chunks of information relayed to students to memorise and recall. He goes on to note that the entire process is reinforced with tests that measure the ability of students to recall factual information rather than enhancing the skills of inquiry, questioning, and interpretation. Cantu and Warren (2003) conducted a study to find out how receptive history teachers were to using authentic historical instruction. They concluded that the problem with history teaching has much to do with how teachers were trained in college. They go on to explain that teachers were not exposed to varied historical inquiry teaching methods in college and as a result fail to recognise the value and use of such teaching methods. Their study found that the majority of teachers lacked the creativity and sophistication to teach history and given that the syllabus was centred on examinations, there was the need to cover the syllabus quickly. They also found that both males and older 
teachers were more receptive and critical than younger teachers to the use of authentic teaching methods that focused on historical investigation. Because of these traditional approaches to the teaching of history, there have been calls to change the way history is taught in schools (QCA, 2001 cited in Haydn, 2004).

What constitutes an effective history lesson? Historians note that there is no one effective history pedagogy as it is a subject that is constantly changing to ensure that students understand the world in which they live in. Most note that whatever approach teachers adopt needs to have the creativity, vibrancy and vigour that the subject demands. There are also historical skills that teachers need to include in the teaching of history (challenging but important skills to grasp). These include but are not limited to the following:

- Inquiry (a key element in history teaching / Exploring historical issues, weighing it up and reaching own conclusions

- Recognising different viewpoints or varying perspectives and interpretations

- Gathering and interpreting information (both primary and secondary sources)

- Identifying and recognising bias

- Understanding sources

- Empathetic understanding

- Conducting research (DFEE \& QCA, 1999; p. 48 cited in p. 87)

Lieberman's (1996) habits of mind principles can be adopted by history teachers to build a pedagogy that can be used when teaching history. The five principles involve: (1) critically examining evidence; (2) examining different interpretations; (3) making connections; (4) investigate and seek for alternatives; and, (5) look for meaning (by understanding the past and appreciating the present]. He believes that these principles incorporate the necessary skills for an effective history lesson, namely the skills to explore historical issues, recognise various viewpoints, gather and investigate information, identify and recognise bias and appreciate the past. 
Numerous studies have been conducted by researchers to explore the use of different methodologies that can be used to effectively teach history (Cole \& Barsalou, 2006; Combs \& Beach, 1996; Egan, 1989; Epstein, 1994; Gabella, 1994; Hootstein, 1994; Kennedy, 1998; Millan, 2000; Niemi \& Smith, 2001; VanSledright, 2007; Voss, 1998). Findings from these studies demonstrate however that there is no one correct or effective history teaching method and the literature base is growing. For example, Millan (2000), Voss (1998), Kennedy (1998) and Combs and Beach (1996) found story-telling combined with the use of visual displays was an effective teaching strategy. Millan (200) notes this approach emphasises emotions, situations and people - a very effective tool for teachers to use.

Cross-discipline techniques are increasingly being used as a means of teaching history. For example, art can be used to teach important historical skills (such as historical inquiry) through photography, paintings, poetry, music and film (Cole \& Barsalou, 2006; Epstein, 1994; Gabella, 1994; Niemi \& Smith, 2001). Gabella (1994) in her study of $11^{\text {th }}$ grade US history students found that students understanding of history increased with the aid of different forms of art. However, she also found that students still resorted to textbooks, photographs, lecture notes, and film to find the objective truth as they believed that artistic evidence was of little intrinsic value in portraying the truth. But Epstein (1994) in her study of using art to construct historical knowledge, found that students "demonstrated understandings characterised by a depth and dimension they could not have constructed from a textbook or traditional text alone" (p. 194). This is supported by Cole and Barsalou (2006) who use memorials and museums to teach history to students. They note that these are powerful sites for students to visit as they hold numerous forms of art that can only increase their knowledge and understanding of history.

Increasingly a range of strategies are being used to teach history to make it both meaningful and motivating. Hootstein (1994) found that role playing increased the motivation of students and helped them to learn about important events in history. Although the sample for his study was of teachers, he argues that role-playing increases the motivation of all students, thus enabling them to 
take an interest in learning about history. Pitt (2000) stressed the significance of using ICT to enhance student learning and understanding of history. This is supported by Niemi and Smith (2001) in their study on the impact of instructional practices on the achievement of history students. In discussing the impact of instructional practices on the achievement of history students, they argue that using a variety of instructional methods will greatly enhance student learning and increase student scores. Furthermore, they found in their study that adopting more active approaches involving student discussion and complex writing activities not only increases student understanding but is related to better results. In another study conducted by Cantu and Warren (2003) concerning authentic historical instruction, they found that teachers failed to engage students in understanding different historical interpretations they simply taught 'the facts'. The authors found that teachers' receptiveness to adopt more vigorous authentic approaches to the teaching of history was due largely to their background, interest and preparation in history. The finding by VanSledright (2007) that teachers teach as they were taught supports Cantu and Warren's (2003) work.

Another approach used by some history teachers with a high degree of success has been to let students choose their own history. While the danger in this is that the specifics of the syllabus may become obscure, Alexander (2006) argues that this is not the case. Teachers can still teach the required syllabus through the process of open inquiry and discussion, and via this process, students chose their history on what and how to learn. He argues that this progressive approach to teaching and learning enhances and motivates interest in history students.

There has been considerable discussion about the teaching of history in contexts where 'truth' is questioned. For example, while the literature abounds with strategies and techniques on how to deliver an effective history lesson, the question is whether the process of open inquiry, interpretation, recognising bias, cause and effect can be used in war torn countries? Teachers in these countries avoid enhancing the skills of historical enquiry and critical thinking for fear of their safety (Cole \& Barsalou, 2006). VanSledright (2007) states that 
history teachers struggle with teaching conflicting historical accounts and he goes on to explain that teachers are not equipped with the necessary tools or the judgement criteria for teaching such sensitive topics. Given that this is the case, Cole and Barsalou (2006) stress that teachers in war-torn countries should still be trained and equipped with the necessary skills and confidence to assist and guide students to learn about their history through the means of open inquiry and critical thinking. An example of this approach was used by a teacher in Colombia. The teacher used newspaper clippings and mission statements of the different groups involved in Colombia and then formulated questions such as: (1) Who are the bad guys? (2) Were they born paramilitaries? (3) Why would someone join such a group? From these questions the teacher then guided her students through a process of open inquiry and critical thinking but most importantly the students were encouraged to make their own judgements having viewed different perspectives. Evans (1988) states that student conceptions are shaped by teacher conceptions of the curriculum, so it is important that we let students make their own judgements about conflicting issues. At the end of the day, "it is important that the history curricula taught in schools reflect the changing world and are relevant, motivating and appropriate to students" (QCA, 2001 cited in Haydn, 2004). As Barton and Levstik (1998) state, "it is not the task of teachers to transmit official history uncritically...but to help children discover history that is useful and relevant to their lives" (p. 501). These findings could have some validity in settings such as Samoa where history is considered in Christian terms.

Present-day history curriculums are designed to move the teaching away from just telling students what happened to more innovative inter - active approaches. VanSledright (2007) argues that we need to develop a more vigorous and systematic approach to the teaching of history that offers more value to students than adopting a content approach centred around dates and events, but there has been some resistance to this move. Lawlor (1989) argues that giving students different interpretations of history will force students to choose other subjects as it will be too confusing and difficult. He continues that it would be better to just give students the facts so they master them. Tate 
(1985), in an earlier study, argued that it would be better to teach students 'an established view of the past' as opposed to giving them different interpretations. But, others in turn (Lee, 1994) argue that just teaching the students to master the facts is "history with the thinking taken out by reducing it to unhistorical political mythologizing" (p. 43). This is supported by some (e.g., DFEE \& QCA, 1999) who claim that history should be taught in a way that allows students to investigate the evidence, weigh it up and use the information to reach their own conclusions.

\section{Curriculum implementation}

Fullan (1988) states that implementation is not an 'event' but rather it is a 'process' -it is a process in which ideas, programmes, policies and structures are put into practice. It occurs "gradually and incrementally over a period of 2 or more years depending on the significance of the innovation" (Fullan, 1988, p. 204). However, he $(1991,1988)$ cautions that changes (to the curriculum) are often complex and for the most part challenging for all involved.

Successful curriculum implementation is dependent on many factors (Fullan, 1991; Hargreaves, 1998; Spady \& Marshall, 1991). The organisational structure of the school, the role of its principal and the commitment and attitude of its teachers are the most crucial elements in determining the success of any curriculum implementation (McCormick \& James, 1989; McGee, et al., 2004). McCormick and James (1989) stress the role of the school and its environment in determining the successful implementation of the curriculum. Changes in the curriculum will be accepted within the school when requirements have been made to suit the individual needs of the school. Within the school environment, the biggest determinant in ensuring the successful implementation of the curriculum is the level of support offered to teachers (Zeegers, 1995). Fullan and Pomfret (1977) support this by claiming that "...effective implementation of innovation requires time, personal interaction and contacts, in-service training and other forms of people-based support" (p. 391). Teachers need support to increase their understanding and familiarity with new curriculum documents as they will be responsible for the implementation of the new syllabus, and 
assessment of students (Peers, Diezmann \& Watters, 2003; Zeegers, 1995). This view is supported by Good (1989) who found that "despite the external forces that try to control the school curriculum, teachers must be learners, and the principals must actively support and strive to improve the instructional capacity of their schools" (p.11). Afamasaga (2002) supports this by stating that the understanding and perceptions by the teachers of the curriculum and what is expected of them as implementers is a crucial element in ensuring effective implementation.

Policies also have a big role to play in enabling a swift but smooth transition in changes to school curriculum. Hargreaves (1998) notes that in order to implement and make changes to the school curriculum, certain policies, guidelines and planning procedures are to be made clear and explicit. He goes on to note that changes in school curriculum policy are sometimes too broad and not clearly stated and this leads to problems which affect the implementation of the curriculum. Spillane, Reiser and Reimer (2002) emphasised that the "process of human sense-making" needs to be made clear and explicit in the accounts of policy implementation (p. 419). They noted that while teacher intentions are genuine when it comes to curriculum implementation, by trying to interpret how the document can be translated into classroom practice, they may misinterpret what is actually in the document. Spillane (2004) and Aitken (2006) caution that the danger in this predicament is that teachers may operate (unconsciously) on misunderstandings. Spillane (2004) states that this "unwitting and unknowing undermining" (p. 169) is a cognitive process in which implementing agents (teachers in this case) "first notice, then frame, interpret and construct meaning" (Spillane et al, 2002, p. 392). He goes on to explain that within this process of trying to understand a curriculum document there is an attempt to preserve an existing schema or ideals. By this they are referring to how teachers rely on "surface or superficial similarities between new knowledge about something and our existing scripts for that something" (p. 78). They note that teachers therefore use new information (in this case curriculum statements) to supplement existing understanding and practices. Given this predicament, they argue that policy and design need to: (1) be written in a way that communicates the reasoning 
behind the reform by getting teachers to obtain a deeper theoretical understanding of the reforms; and, (2) the new design needs to build on prior or existing knowledge. Hayward, Priestley and Young (2004) stress that external agencies have little influence in the understanding and acceptance of reform, therefore they need to ensure that design is explicit and well documented so problems such as that noted by Spillane et al. (2002) is avoided. Davis and Krajcik (2005) and Aitken (2006) emphasise that policy makers and curriculum designers should ensure that the "essence of intention" of the curriculum is relayed explicitly in the document for teachers, and that it fosters and promotes the pedagogical design capacity of teachers, so that teaching and learning is enhanced (p. 6). Spillane et al (2002), Aitken (2006) and Ball and Cohen (1996) therefore stress the significant contribution of design to ensure that the curriculum implements the essence of intention (Davis \& Krajcik, 2005).

Researchers have also noted the significant contribution of professional development and INSET workshops to effective curriculum implementation (Cohen \& Hill, 2001). They found that curriculum-based professional development that focused on the implementation of the curriculum was considered highly effective as teachers tend to embrace the practices and techniques used. Their large-scale study in California on professional development found that workshops that focused on pedagogical practices, the use of resources and designing assessments associated with particular curricula were more successful than those that merely focused on enhancing pedagogical strategies. Not surprisingly with regards to professional development for the implementation of the history curriculum, Penuel, Fishman, Yamaguchi and Gallagher (2007) note that workshops need to focus on both content knowledge and effective teaching strategies to deliver the curriculum.

\section{Chapter Summary}

This chapter provides a theoretical overview on the different areas of the research topic which include teacher INSET and professional development, teacher change, transfer of training, effective teaching pedagogies in history teaching, and curriculum implementation. The literature highlights the numerous benefits of professional development for teachers but there is still a 
need for more research in this area to ensure that teachers receive the most effective training. It is also evident from the review that teacher change is not a simple and linear process; it notes that teachers go through different stages and cycles before any real change occurs. Principals and educators expecting a swift change in teacher attitude and teaching practices need to understand the processes involved in teacher change. This review has also considered the issue of transfer of training and noted that this is a very complex issue. It highlights the fact that training does not necessarily equate to improved on the job practices and that there are numerous facilitating and inhabiting factors interacting that determine whether or not transfer occurs. The literature review also discussed effective teaching pedagogies. The literature revealed that there is no one effective teaching pedagogy for history. History teachers are encouraged to adopt more interactive and stimulating lessons to ensure that learning is more meaningful for students. For curriculum implementation, the literature cautions educators and curriculum designers to ensure that the language used is explicit thereby minimising different interpretations of the curriculum. The literature has highlighted that for curriculum implementation to be successful, there needs to be strong support structures in place. Teachers also need to be committed and enthusiastic in order for lasting changes to occur. 


\section{CHAPTER 4: METHODOLOGY}

\section{Introduction - 'Locating oneself' in the study}

I have been a history teacher for many years before embarking on postgraduate study. History has always fascinated me. This, combined with my involvement in developing the new history curriculum statements and being a trainer for various professional development activities for Samoan teachers paved the way for furthering my understanding, interest and passion into history education and teacher professional development. Despite continuous efforts, finances and resources from local and overseas consultants and educators to improve the performance of teachers' with regards to their pedagogical practices and subject content knowledge, recent MESC publications and reports state that not much has changed or improved. While I want to challenge these findings (MESC, 2005) by suggesting that student results should not be an indicator of teacher performance, it is important that research be undertaken to seek out and clarify other factors that may contribute to this. Because of this and my background it puts me in a challenging position to conduct a study that focuses on the facilitators and barriers for the transfer of INSET particularly as it relates to the teaching of history and the use of the curriculum documents in the classroom. One of my priorities however was to ensure that any preconceived assumptions I had would not impact on the study. However, being an insider there is opportunity for a wider understanding of the context. In a developing country, such as Samoa, although there is a need for quantitative data relating to educational outcomes and processes, there is also an urgent requirement for more qualitative research to provide richness and to ground findings within the experiences of the personnel on the ground who implements educational processes. Qualitative research can add to the validity and meaning of what is known and can provide more specific answers to problems of implementation.

\section{Methodology}

This research study adopted an interpretive phenomenological methodology using a case study approach. Phenomenology has its origins in philosophy (Giorgi, 1994). It is an approach which tries to understand the meanings and 
essence of an experience and how participants make sense of these (Grbich, 2007). The intention and adoption of this approach is to gain "insight into the world of [participants] and to describe their perceptions and reactions to a certain phenomena" (Fraenkel \& Wallen, 2006, p. 436).

Phenomenology was deemed the most appropriate research design for this study for the reasons outlined below:

(1) A phenomenological approach would allow differences in teachers' experiences and perceptions to emerge. It is particularly useful in capturing differences between teachers (Patton, 1990) as opposed to quantitative methods which consolidate teachers together as if they were all the same (Janesick, 2000). Guskey (1995) supports this in stating that teachers bring to workshops different experiences, different school environments and teaching beliefs, so a phenomenological approach is seen as the most appropriate to capture any commonality with the essences shared by the training participants (Patton, 1990).

(2) It can be used to describe a phenomena for which little is known (Strauss \& Corbin, 1990). Little is known about the phenomenon of INSET and its impact on Samoan history teachers in trying to implement a new curriculum.

Phenomenology has four key qualities, description, reduction, essences and intentionality (Ehrich, 2003). These four qualities help researchers to understand the theoretical underpinnings of phenomenology.

\section{Description}

Phenomenology comes from the Greek word, phainomenon, which translates to the way things appear, or a phenomenon (Spinelli as cited in Ehrich, 2003). The main aim of phenomenology is the description rather than the explanation of the phenomenon. The phenomenologist's main aim is to describe the phenomenon as accurately as possible. This means describing a phenomenon as one sees and experiences it. Patton (1990) states that phenomenology 
"focuses on descriptions of what people experience and how they experience it" (p. 71).

\section{Reduction}

By reduction, any assumptions and presuppositions about the phenomenon is suspended or bracketed. The main reason for this suspension or bracketing is to ensure that any preconceived ideas or prejudices are bracketed so as not to taint the description of the phenomenon (Merleau-Ponty as cited in Ehrich, 2003).

\section{Essences}

Essence is simply the core meaning of an individual's experience of any given phenomenon. The search for essences, involves the exploration of phenomena by using the "process of free imagination, intuition and reflection" (Ehrich, 2003, p. 46). Once a description is given, the phenomenologist tries to untangle the essential structure of the lived experience. Merleau-Ponty (as cited in Ehrich, 2003) argues that arriving at the essence of the phenomenon is not the final step, but is a way by which we understand the relationships of the experience.

\section{Intentionality}

Intentionality refers to consciousness, and the fact that individuals are always conscious of something (Merleau-Ponty as cited in Ehrich, 2003). The concept of noesis and noema was used by Husserl (1931) to reveal intentionality of consciousness. According to Husserl, "intentionality refers to the correlation between noema and noesis, both of which to the interpretation of an experience" (Sanders, 1982, p. 354). Noema is the objective statement of behaviour or the experience, while noesis is a subjective reflection of the objective statement (Sanders as cited in Ehrich, 2003, p. 354). The noema and the noesis lead each person to interpret an experience in a unique way.

This research is a case study of Samoan history teachers involved in the delivery of INSET and professional development since 2004. The case study method allows for a rich and vivid description (Cohen, Manion \& Morrison, 2000) of history teachers' perceptions and experiences of INSET to support curriculum reform. They state that a case study will allow for "important events and situations to speak for itself rather than to be interpreted, evaluated and 
judged by a researcher" (p. 182). Stouffer (as cited in Stake, 1998) states that case studies seek to find out what is common and particular about a certain case, with the result presenting something distinctive. Thus combined with phenomenological methodology, the researcher will adopt the practice of epoche, which will be an ongoing effort by the researcher to ensure that previous assumptions and ontological assumptions will be suspended and bracketed (Finlay, 2005).

\section{Data Collection}

The intent of a phenomenological study is to "understand the phenomena in [participants] own terms to provide a description of human experience as it is experienced by the person herself" (Bentz \& Shapiro, 1998, p. 96). Given this, the main form of data collection for this research was through the use of in depth, semi-structured face-to-face interviews with selected history teachers and Samoan MESC staff as this was seen as the "most effective type of qualitative interviews for Pacific peoples" (Auckland Uniservices, 2001). It provided insight into how they "think and feel in the most direct ways" (Bentz \& Shapiro, 1998, p. 96). This type of interview also "permits greater flexibility and permits a more valid response from the informant's perception of reality" (Burns, 1996, p. 330). It is the "most appropriate form of data collection for a phenomenological approach" (Fraenkel \& Wallen, 2006, p. 436) as I sought participant perceptions and experiences on the effectiveness of INSET in implementing new curriculum reforms. The questions were formulated and were 'directed to the participants' experiences, feelings, beliefs and convictions about the theme in question" (Welman \& Kruger, 1999, p. 196). In carrying out interviews I ensured that the participants were well-informed about the research and I created "a climate in which [each] research participant [felt] comfortable and [responded] honestly and comprehensively" (Moustakas, 1994, p. 114). With the participants consent all the interviews were tape-recorded to ensure that the interview proceeded smoothly and, more importantly, that it captured all the crucial information. 
In carrying out the interviews I ensured that any pre-conceived ideas and preconceptions I had about the effectiveness of INSET in implementing curriculum reform was bracketed (Moustakas, 1994). He notes that Husserl coined this practice "epoche, a Greek word meaning to stay away from or abstain" (p. 85). I also adopted the practice of "memoing" (Miles \& Huberman, 1984 , p. 69), by writing down what was occurring during the research process. By doing this I recorded my own experiences and thoughts on the interview process but not the content per se. These reflective field notes were dated and were later used to correlate information collected in the interviews.

Data was also collected from MESC and Government publications and other relevant documents pertinent to the study. The documents were not used to validate the findings from the participants but rather to gain a wider understanding of the issues that were identified or referred to during the interviews. At times I also used this data to probe in order to obtain teacher participant perspectives on issues relating to MESC or government policies on the training of teachers.

\section{Site and Sample Selection}

Hycner (1999) states that "the phenomenon dictates the method including even the type of participants" (p. 156) and not vice-versa. For this reason, this study used purposeful sampling in conjunction with the criterion to select history teachers and MESC personnel for an in depth study on the effectiveness of INSET in implementing curriculum reform (Merriam, 1998; Patton, 1990). Given this, I carefully chose the teachers and MESC staff for this research in line with Silverman's (2000) argument that participants be selected cautiously on the basis of the population the researcher is interested in. This type of sampling has also been selected as "it [served] the real purpose and objectives of the researcher for discovering, gaining insight and understanding into a particularly chosen phenomenon" (Burns, 1996, p. 370). The teachers and MESC staff for this study were not chosen to fabricate data generalisable to a larger population, but were selected on the basis that they would provide rich information on the phenomena and issues essential to the purposes of the 
research (Patton, 1990). As Burns (1996) argued, "case studies are focused on circumstantial uniqueness and not on the obscurities of mass representation" (p. 380). While the findings and explanations for this study are not generalisable to other teachers and their subject areas, it has wider resonance that can be applicable to other situations (Mason as cited in Silverman, 2000).

A sample of 6 teachers and 4 MESC personnel were selected. Boyd (2001) states that a range of participants from 2 to 10 is an adequate number to reach saturation. Creswell (1998) adds to this by stating that "long interviews with up to 10 people" is a recommended number to reach saturation (p. 65).

The 6 teachers selected for this study had the following characteristics:

- Each had attended various INSET sessions and professional development events since 2004, when the training for the new curriculum commenced;

- Each teacher had been teaching senior history classes for a period of more than five years prior to the implementation of the new curriculum in 2005;

- All of the teachers were teaching in schools that had become colleges since 2004 (explained in Chapter 2); and

- The schools selected had been offering senior history as a school subject since 2004

The four selected MESC personnel had been involved in teacher INSET and professional development since 2004. The MESC personnel selected were those in the School Operations Division (SOD), which dealt largely with teacher development and training and the Curriculum Materials and Assessment Division (CMAD) which dealt directly with curriculum and assessment matters.

\section{Data Use and Management}

The collection of multiple data are an important part of the research design and for this reason, steps were taken to ensure the security and confidentiality of the collected data. All data collected was organised under two headings: transcriptions and documents. All the data collected was stored in a protected password computer system which only I had access to and was made available 
for the supervisor to cite. All the data collected was used uniquely for the purposes of the research and will be destroyed 2 years after research has been completed for verification purposes. All the interviews were tape recorded so that I was able to take part in the conversation in a natural way although notes were also taken as a supplement to record non-verbal activity (Burns, 1996). All the interviews were transcribed after the interview sessions. I was aware of the time consuming nature of tape recordings but care was taken to minimise those effects.

\section{Data Analysis}

There are a number of procedures used by qualitative researchers to analyse their data. Miles and Huberman (1994) identified 3 major approaches to qualitative data analysis: interpretive approaches, social anthropological approaches and collaborative social research approaches. This research adopted the interpretive approach, whereby interviews were transcribed into written text for analysis. They note that the theoretical approach adopted for the study largely determines how the text is interpreted. Given this study adopted a phenomenological approach, the task was to avoid reducing and framing data by various categorization or coding operations. The main concern in this study was to discover and capture the essence of the phenomenon, and this was achieved in one way by bracketing out any preconceived ideas and assumptions I had. It is also important to note that during the data collection phase and the analysis phase, member checks were undertaken to ensure accuracy of information given during the interviews. I also strove to make certain that credibility for the study was enhanced by ensuring that the description and interpretation of the data clearly and explicitly reflected the participant perceptions and experiences (Grbich, 2007).

Thematic analysis was considered the most suitable method for analysis of the data as it dealt with naturally occurring events and it provided thick descriptions and information that lead to answers (Miles \& Huberman, 1994). Thematic analysis is also a suitable method for this research approach as it produces categories from the data, unlike quantitative strategies, which predetermine 
categories (Mutch, 2005). The thematic analysis in this study involved the following steps ( Miles \& Huberman cited in McDonald, 2002, p. 130):

a) Interview data was collected, recorded, and transcribed

b) Open coding took place. Strauss (as cited in Berg, 2007) refers to this process as an "unrestricted coding of the data" (p. 321). This was done by carefully and minutely going through each interview transcript to determine the concepts and categories that fit the data, which in turn also resulted in possible answers emerging. As a result of this process, codes were identified for all the data relating to the questions about INSET training strategies, barriers to the implementation of the new curriculum and policies regarding teacher development and professional development. Once specific ideas were identified, a reduction in items was carried out by collapsing them into categories / patterns. He refers to this process as axial coding, which consists of thorough coding around one category.

c) The last step involved clarifying specific themes across the patterns. These were located from the data and the memoing.

\section{Credibility and Trustworthiness in Qualitative Research}

In qualitative research, credibility, trustworthiness, transferability, dependability and confirmability ensures the worthiness of a research study (Krefting, 1991).

Credibility in this study was obtained by making sure the following was adhered to (Lincoln \& Guba, 1985):

a) Prolonged engagement in the field / collaboration: Given the phenomenological approach of this research study, I had to ensure that I obtained the participants subjective viewpoints on the topic and this was done by developing a trusting relationship with the participants. I also ensured that the interviews were carried out thoroughly so as to obtain a deep and complex understanding of the phenomenon under study, and that participants were given support and respect throughout the process of the study. 
b) Reflexivity: To achieve reflexivity, I kept a journal throughout the whole research study to track my own ideas, responses and 'biases' (Cohen, et al., 2000). This was done to ensure that my responses were kept separate from the responses of the participants.

c) Triangulation (of sources, methods and theory): This is the use of multiple data collection methods to verify or add credibility to the research (Cohen, et al., 2000). Given that this research study only collected data by conducting interviews with the participants, triangulation was carried out by comparing the participants' responses to the theoretical frameworks in the study, to identify what is common and to recognize the gaps in the research.

d) Member checking: This ensures that data is taken back to the participants to correct factual errors, to offer respondents the opportunity to add further information or to put information on record, to provide analysis and to check the adequacy of the analysis (Cohen, et al., 2000).

e) Peer debriefing: This includes the sharing of information of the research study (Cohen, et al., 2000). But given the confidentiality of the research participants, I was not able to discuss the data. I was able to discuss the analysis process with my colleagues to obtain their constructive feedback on ways to ensure that I was true to the data by ensuring that it was analysed thoroughly.

I ensured transferability by thoroughly explaining the steps and procedures taken to choose the sample for the study and that the sample chosen would enable me to answer the research questions posed (Cohen, et al., 2000). I also ensured that the research was carried out at a time appropriate to the research participants.

Dependability in a qualitative research study is ensuring that researchers provide a dense description of research methods, member checks are carried 
out, peer examination processes take place and the adoption of triangulation to further verify the data (Krefting, 1991). Dependability also refers to the coding and re-coding procedure. I ensured dependability was adhered to by carrying out member checks and providing a rich description of the research methods. I also ensured that the data was analysed and coded accurately. This was done by continuously coding and re-coding in order to highlight patterns that emerged from the research. I also made sure that I prevented the premature closure of the data by continuing to collect data and analyse until theoretical saturation was reached.

\section{Access, Entry and Ethical Considerations}

In undertaking this research, study I was constantly aware of the rigorous approach that the University requires with regards to ethics. The study was therefore guided by the four ethical frameworks for foreseeing ethical problems in research (Flinders 1992). These ethical frameworks are explained below:

a) Utilitarian ethics: Care was taken to ensure that participants were well-informed about the research and member checks were carried out to ensure this occurred. Informed consent forms were also prepared for the participants' perusal and approval. Considerable care was taken to ensure that during the fieldwork phase harm to the participants would be avoided (Bogdan \& Biklen, 2003). The data collected during the reporting phrase, was at all times considered confidential.

b) Deontological ethics: Care has been taken to ensure that I remained true to the research and that I conformed to ethical standards such as honesty, fairness and justice during the recruitment, collecting and reporting phase of the research.

c) Relational ethics: Relational ethics emphasises the researcher's relationship with the participants more than on rules and regulations. While my research took a rigorous approach by ensuring that rules 
and regulations were adhered to, care was also taken to establish a rapport with the participants. This I felt occurred as it contributed to the success of the research.

d) Ecological ethics: Given that the research (fieldwork) was to be undertaken in Samoa, considerable care was taken to ensure that cultural protocols and cultural sensitivity was adhered to. I was constantly aware of the difficulties of working within a 'western framework' and undertaking fieldwork in a Pacific island nation. Being a Pacific student however reduced these difficulties and care was taken to ensure that there was no harm caused to participants as a result of the study.

Apart from ensuring that the research undertook and adhered to the above ethical frameworks, negotiation of entry into the research sites also went through appropriate steps of authority. Before approaching the teachers and MESC staff about the research study, permission for entry into the schools was sought from the Samoan MESC. On approval from the Ministry, principals for the schools were contacted to ensure that there would be no disruption to staff and school activities. After receiving approval from all the concerned parties, teachers were then approached to take part in the study.

\section{Chapter Summary}

This chapter has discussed the methodological approach adopted for the study. It adopted an interpretive phenomenological methodology using a case study approach. This approach was deemed the most appropriate as the study sought to obtain Samoan educators' perceptions and experiences on the effectiveness of INSET in implementing curriculum reform. Purposeful sampling was used to select the ten educators for the study. The main form of data collection was through in depth, semi-structured face-to-face interviews. Given this study adopted a phenomenological methodology, thematic analysis was the most suitable method to analyse the data as it does not predetermine data categories. This research also took a very rigorous approach to ethical issues 
and concerns to ensure that participant confidentiality was adhered to throughout the research process. 


\section{CHAPTER 5: FACILITATION OF TRANSFER}

The approach of the INSET workshops and professional development activities was designed to overcome what has traditionally been the method of teaching and learning in Samoan schools. In this tradition teachers were the bearers and deliverers of knowledge and students were the passive learners. It was a teacher-dominated approach to teaching and learning. Given this, the new history curriculum demanded a more student-centred and vigorous approach to teaching and learning, which in turn meant that teachers required training on what were deemed effective teaching strategies, techniques and approaches to be able to deliver the curriculum in ways that were more meaningful.

Accordingly, this research question was designed to obtain the perceptions and experiences of the history teachers on the effectiveness of INSET workshops in helping them to implement the history curriculum document into classroom practice. The question was also provided to MESC staff involved with the training of teachers to obtain their views on the effectiveness of the training workshops in helping teachers to implement the new curriculum. The question sought to find what strategies, techniques and approaches were used in the training to help teachers improve their content knowledge and pedagogical skills in implementing the new Samoan history curriculum document into classroom practice?

\section{Effectiveness of Approaches and Strategies used in the training}

Teachers in the study identified the usefulness of the various teaching approaches, techniques and strategies used in the training to help them implement the curriculum into classroom practice. They noted that the trainers exemplified numerous ways in which the curriculum document could be translated into classroom practice by demonstrating to them and by giving them opportunities to design interactive and lively lessons, and also how to design improved assessment activities. Teachers also had opportunities to practice different teaching models that they could use in the classroom. 
...I have improved ways to plan a good history lesson and improved assessment and use of assessment information

...I found the training very useful as I improved planning, improved reporting techniques, I came up with different teaching techniques such as group activities, pictorial map, role play, mind map, puzzles, picture-word method and visual techniques and lesson examples which helped my students to learn

Yes...it has helped me reinforce my experience from the previous years in the sense that for example the focus of the new curriculum is more on interactive teaching

...previously teachers would just say, write your opinion about blah blah blah without providing models of how its structured, of how you make a coherence, of how you do the written model, the actual written model and for example what makes a good argumentum essay...but the workshops have changed that approach...teachers are now using the same practice to get students to produce work...

Teachers also found the strategies, techniques and approaches used in the training to be particularly useful for teaching history. They noted that history as a subject was a relatively uninteresting subject so the workshops assisted them in ensuring that the delivery of the curriculum would be more interesting and meaningful for the students. They also commented on the relevance of the training content as they were working directly with the curriculum documents. They noted that their content knowledge improved as a result of attending the training. Some of the typical comments are outlined below:

I have become equipped with other ways on how to teach history

We have to concentrate on methods, how to make history topics more interesting so students become more active, because what I found when I tried those teaching methods, it was so lively...especially as we know history it becomes boring

...Now I am able to plan my history classes to make them more meaningful for students...I plan lessons that will 
encourage my students to think critically and investigate different events in history...

...It was good how we were able to use the curriculum documents to work with...as it not only increased my content knowledge but I can apply what I have learnt directly into the classroom...

Teachers in the study also noted that the training workshops offered numerous strategies, techniques and approaches that they could use to help students of different abilities, levels and settings. It was also reported that students in the rural areas had very limited use and understanding of English so a variety of strategies and teaching techniques had to be employed to help them learn.

I select those appropriate to our learning context. There are many other methods for example like the speaking method of throwing a ball, like the throw and catch method using a ball or piece of paper...they like the picture method as they are not very vocal like the urban children.

A number of the teachers explained that the training should be on-going to ensure that they continued to receive assistance and help develop a variety of activities to help students of different abilities learn better.

At the moment in classrooms, its just the blackboard, duster and the textbook...but if this programme continues, there will be a variation of activities, for it to be easier because in the classroom, there are slow learners, and it be a way for teachers to know how to teach the subject and make the subject easier.

MESC staff highlighted the usefulness of the different strategies, techniques and approaches used in the training to help teachers effectively deliver the curriculum. MESC staff outlined that the whole approach for the training was to help teachers not only to understand the content but to be able to deliver it in meaningful ways.

The whole approach IST approach is really trying to overcome what's been traditionally the way of teaching which has been one-sided. 
Overall approach is we were trying to pinpoint the key areas that we were looking to implement changes in to help teachers with the academic side of it, certainly the content, then there was the other end of the triangle to do with language and the other point of the triangle was pedagogy, which encouraged teachers to look at interactive approaches for engaging student learning.

\section{Trainer Characteristics}

Teachers in the study felt that the trainers and their approach to the training were the biggest contributing factors in ensuring the success of the programme. The teachers in the study found the trainers to be very helpful and forthcoming in their approach, which in turn helped teachers to grasp important concepts of the training. Teachers also noted that trainers modelled various ways in which the content could be delivered and offered opportunities for them to practice designing a lively history lesson. Teachers in the study also observed the role the trainer played in supporting them when implementing a new teaching strategy. They went on to note that having trainer support influenced them to change their teaching behaviour as they had continuous monitoring and assistance.

The trainers are good...they are very helpful

This trainer, $X$, she did a perfect job this year...we find her very very helpful.

The trainer made us feel comfortable and to take pride in our learning...they motivated us to grasp the new ideas taught in the training so we can use it in the classroom

The trainer modelled the different strategies that we can use to deliver a lesson and make it more interesting

The trainer gave us opportunities to practice designing meaningful lesson in the training and got other teachers to assess its goodness

Having the trainer monitor and assist me with planning my lesson will mean that I can change my old boring ways of teaching and adopt and plan more lively lessons 
Teachers identified the importance trainers placed on explaining the workshop objectives and how they related to what should be occurring in the classroom. The emphasis the trainers placed on increasing teacher motivation and keenness to try out different approaches and strategies that they could use in the classroom was also considered important.

Our trainer was good...she explained the purpose of the training and the importance of being part of it... it made me understand better all the reforms and restructuring taking place at the moment...

At the beginning the trainer explained why the workshop was carried out and how that related to what we were doing in the classroom...I found this extremely helpful as I can now make the connections...

Our trainer was very good at getting us to try out new ways to teach history, this increased our confidence...I couldn't wait to try it out in the classroom...

The trainer made sure that all the teachers got involved...to try out different techniques to teaching... that by the end of the training all the teachers were motivated to try it out in their classrooms

However, the teachers also noted that not all the trainers used the same techniques. They felt that some trainers did not provide enough depth in helping them to translate the curriculum document into classroom practice. Some teachers felt that there was still a need to demonstrate more activities and lessons. In other words the teachers wanted additional demonstrations of practical activities to be included in the workshops. There was also the need to provide more techniques and approaches for helping student's comprehension.

...Not all trainers are the same, some trainers they do it just to get it done, they don't really go in-depth, and training is not consistent because all the trainers are different

...They [trainers] say that they don't want to spoon-feed teachers but they have to provide a lot of information for teachers and then demonstrate lessons for them help them as much as possible and so on 
...Well the...first thing that the presenters are junior...so there are other teachers...senior teachers who have been teaching in the field who may have a problem of receiving what is being explained...

They have strategies, they have strategies in helping you organise the content and delivering the content but for the reading component itself in dealing to or being part of is virtually absent virtually absent.'

Some teachers noted that trainers adopted a teacher-dominated style of delivery as opposed to an interactive consultative approach. There was also the need to ensure that all participants took part in the training as opposed to the trainers focusing on a few.

Its like a teacher-student type of thing rather than a consultative type of approach

There is a round robin type of show and tell method but still that is not enough'... and the method is not very effective

...Workshop participants should take a more active role in the training...because what is happening now is the training is dominated by the person doing the training...I feel it should be more consultative with the trainer being the facilitator...

...The trainer was very serious, and $X$ didn't seem so approachable so I never asked for any assistance...

There should be more activities, and make sure all the individuals involved are not just only in the group work so they understand the whole process of why they are there

...I felt that I didn't learn much, they talk about changing the way we teach but they don't do the same...they teach us like small children and not as adults...

...The Ministry should ensure that the trainers adopt interactive styles of teaching in the workshops...that way we can all take part and learn from one another instead of the trainer doing it all by themselves...

...The trainer should use a more facilitator role by helping us to adopt new practices then acting like a lecturer... 
MESC staff on the other hand noted that the pool of trainers was selected based on a set list of desirable qualities. The Ministry stressed that trainers are 'experts' in their field and that they go through an intensive programme to ensure that they are able to guide teachers through to ensure the curriculum is implemented effectively.

There is a criteria for the selection of trainers...they have to have first of all a good understanding of the curriculum reforms in secondary education. Second, they have to have thorough understanding of the use of the subject curriculum statements. Thirdly, they would have gone through an intensive train-the-trainer workshop...trainers were selected based on these set of criteria's...

.. Trainers are those teachers that have been teaching for many years in their specific subject areas, they have been involved in the external marking, moderating and assessment programmes of the Ministry...they have good knowledge of their subject areas...

The teachers that have been selected as trainers have also been teaching at the senior secondary level for many years and therefore have a good understanding of what is required of them at that level... they have also been chosen based on their leadership qualities within their own schools...

One of the interesting findings that emerged from the study was the need to provide more training for teachers who were teaching outside their subject areas. Participants noted that there needed to be a more vigorous practical approach for these teachers so that they were able to grasp the subject content with some level of confidence.

ITthey need more training in their teaching approach, pedagogy...there is still a significant number of teachers using the old way, the traditional approach to teaching...also, there is a lack of content knowledge and teachers are forced to teach subjects that are not their own.

...They should have more training for teachers teaching outside their subject areas...so that we are given opportunities to grasp the content information of the subject while at the same time showing us how to teach it... 
There should be intensive training carried out for teachers not teaching in their area so they can improve their content knowledge... history requires teachers to have an in-depth knowledge of the subject and there is real danger if teachers are not prepared for this...

\section{Discussion}

The international literature abounds with studies on the importance of professional development activities and INSET training that is designed to change pedagogical skills, knowledge and attitudes which in turn has a positive impact on student learning (Borko \& Putnam, 1995; Cohen \& Hill, 1997; Falk, 2001; Lam, 1998; Lamie, 1998; Sabri, 1997; Schober, 1984; Supovitz, et al., 2000; Supovitz \& Turner, 2000; Zeegers, 1995). The teachers in this research study found that their practices, skills, knowledge and beliefs changed as a result of attending the training. They found that they were able to improve both their content knowledge and pedagogical skills as a result of attending the workshops. The practical approach adopted by the trainers in the workshops worked to their advantage as it gave them opportunities to design, experiment and revise their approaches to lesson planning and design. Garet, et al. (2001) found that adopting a more practical approach to training was more effective and relevant for teachers. Pasikale (1996), in her study on Pasifika teachers, noted that preference for practical approaches in professional development workshops was evident. Timperley, et al. (2007) highlighted that engaging teachers in the learning process promotes their credibility as teachers which in turn leads to improved student outcomes.

While the teachers in the study noted marked improvements in both their content knowledge and pedagogical skills, there were still some concerns that the training did not adequately equip the teachers with the required knowledge, skills and attitude to effectively implement the history curriculum into classroom practice. There was a major concern that history teachers were still resorting to the traditional way of teaching. One explanation for this was that teachers felt that the workshops did not continue long enough, especially during the 
implementation phase to ensure the transfer of skills and knowledge learnt in the training transferred into classroom practice. The literature states that these short workshops are not sufficient to ensure that teachers grasp the necessary skills and knowledge to implement the new curriculum effectively (refer for example to Loucks-Horsley, 1997). Phillips (2003) supports this by arguing that that short workshops are inadequate for those teachers requiring stimulating and progressive instruction. Ball and Cohen (1999) condemn short-term professional development activities as "intellectually superficial, disconnected from deep issues of curriculum and learning, fragmented and non-cumulative" (p. 258). But Timperley, et al. (2007) found little evidence to suggest that giving teachers more time ensured better outcomes for students, it was how the time was used in facilitating the learning that was more important(Caulfield - Sloan \& Ruzicka, 2005; Maheady \& Harper, 1991 Timperley, et al., 2007). Some studies also showed that extended timeframes did not necessarily produce better student outcomes (Lipman, 1997).

Teachers in the study found that the workshop trainers adopted an authoritarian student-teacher type of approach to the delivery of the training. This problem is also highlighted in the literature in that the majority of INSET workshops adopt a lecture-like approach as opposed to a participatory interactive approach (Chadbourne, 1995; Day, 1999; Gravani, 2007; Ogletree \& Allen, 1976; Renyi, 1996). Researchers argue that adopting this approach lowers the motivation of teachers and limits their professionalism and security as educators (Kennedy, 2001). This low level of motivation can lead to the learner not applying the skills and knowledge learnt on the job into classroom practice (Foxon, 1993).

One of the major concerns found in the study was that teachers were forced to teach out of their subject area and for history, some teachers had to teach the subject as there was no other person able to do so. This overlooks the point that history is a complex subject requiring training to develop the skills and knowledge to teach the subject well. There is also the issue of pedagogy and how to deliver history so that it is meaningful for students (Wilson, 2001). There are significant and continuing complaints in the literature about the poor pedagogy secondary history teachers are using in the classroom (Bain, 2003; 
Cuban, 1984; Evans, 2004; Hootstein, 1994; Stearns et al., 2000; Cantu \& Warren, 2003). One of the concerns is that when teachers are forced to teach outside their subject area, the traditional approaches to learning are used. VanSledright (2007) has highlighted that history teachers relay large chunks of information for students to memorise and recall. He goes on to argue that this entire process is reinforced with tests that measure the ability of students to recall factual information.

\section{Chapter Summary}

This question sought to identify the effectiveness of INSET strategies, techniques and approaches in helping teachers to implement the new history curriculum into classroom practice. Teachers found the various strategies, techniques and approaches were very effective in helping them to implement the curriculum document into classroom practice. The workshops were particularly helpful for them to plan interactive and dynamic lessons, and formulate useful internal assessment activities. It was also noted that the various strategies, techniques and approaches used in the workshop enabled teachers to add ideas and teaching approaches to cater for students with different ability levels, ages and settings. Teachers highlighted the pivotal role of trainers in helping them to learn about new and different teaching approaches. Nevertheless, the study also highlighted the need for trainers to develop more activities that are practical for teachers. It has pinpointed the need for trainers to adopt more consultative approaches to teacher training as there was widespread concern with the style adopted by some of the trainers. The concern about teaching outside subject area expertise was identified; in relation to this, teachers noted that there needed to be continuous training to ensure support and assistance. 


\section{CHAPTER 6: BARRIERS OF TRANSFER}

Research question two was concerned with the barriers to implementation. Specifically it asked 'What are some of the barriers impeding on the successful implementation of the history curriculum document into the classroom?' It was formulated to obtain teachers perceptions and experiences of the barriers to the transfer of training and of course in doing this it identifies potential facilitative factors.

\section{Support structures}

Teachers in the study noted that receiving little or no support from their department heads was the biggest barrier to the implementation of the curriculum into classroom practice. They noted that because no support was received, they tended to revert to the traditional way of teaching. They felt that this lack of support and the lack of interest shown by department heads was the biggest impediment to their willingness to transfer what had been learnt in the training into the classroom. Some of the comments from the teachers included the following:

You want to discuss a certain strategy in teaching, but there's a lack of support from your department and it seems to turn you down so you go back to the traditional way of teaching because there is no help from other teachers

The problem in our department, when the in-service training finishes, is when I return and share what I have learnt, there is no support from the administration, there is no interest from staff as to what I have gained

You want to talk but there is no interest or keenness on their part to utilise what was learnt in the training...

MESC staff highlighted that support for teachers needs to be continuous; they commented that a lack of support for new teachers in implementing the curriculum document into classroom practice had resulted in teachers leaving 
the profession. Therefore continuous support and training was viewed as important especially during the curriculum reform period.

There still needs to be continuous support especially when new teachers graduating. Turnover in the system, that's why it's important to have that on-going support and training

...Sustainability and on-going support was not offered to teachers which in turn resulted in teachers leaving the profession...sustainability was not sustained...

Teachers were not getting the support they needed...therefore most would teach using the blackboard and chalk with no real initiative

\section{Monitoring and Evaluation}

Teachers in the study noted that the lack of monitoring and evaluation on the transfer of skills and knowledge into the classroom, both at the school and national level was one of the biggest impediments to the transfer of training. Many teachers stated that monitoring of performance and application of skills into the classroom had to be consistent and on-going to ensure that the training was implemented. The following comments reflect this:

There should be a person to make sure that there is a follow-up...monitoring is the most important...if there is consistency with monitoring, I'm sure the teachers will work towards making sure that training is being implemented

Willingness of the HOD to really implement and to ensure that transfer is taking place and also its being monitored...it is monitored but it needs to be on a regular basis on a periodic basis but not on a daily basis as it imposes on the teaching and feeling of the teacher.

Teachers stressed that monitoring within the schools needed to be carried out both at the national level by the Ministry and at the school level by the principal. This they argued would ensure that teachers were doing what they were supposed to be doing and ensured that the skills and knowledge learnt in the training was being transferred into classroom practice. 
If there was somebody that works in the Ministry, probably once or twice a year, to screen whether we are doing what we are supposed to be doing, there's no use having training but no one comes

I feel there should be regular monitoring...although we try our best to do it in the school, teachers don't realize its importance but if the Ministry come they put more importance on it.

There is also no support nor monitoring for implementation from the principal

There is no close monitoring, NOTHING, there should be close monitoring of all these training, just to make sure the teachers are doing what they are supposed to be doing.

Some MESC staff also support claims highlighted by teachers in stating that although there is monitoring by the Ministry it is inadequate. They go on to note that monitoring at the school level by principals and at the school committee level is weak. MESC staff claim that school committees were not asking schools to be more accountable for teaching and learning. Some teachers noted that although principals and SROs were trained to carry out the monitoring of teachers that when the project and training ended, so did the monitoring.

There's the absence of monitoring...there's monitoring from MESC but it is inadequate.

Weakness in terms of that National structure for monitoring, we come down to the school level and there's a weakness at the principal level...there's also weakness with the management of the school.

Weakness at the school committee level, because they themselves, they don't understand they haven't had the opportunity...their work mainly revolves around festivities and one of the weakness I find is they don't ask for accountability

I think that area needs strengthening...and that's why when we first implemented the new secondary curriculum, we had a leadership training for SROs and school principals... and there was a template prepared for them to use when they are monitoring the performance of teachers in the classrooms...but when the project ended that ended 
too...so I think there's an issue there with monitoring at the school level

Schools are getting away with National Policy on Monitoring, the Policy on Teaching and Learning

...I have just gone out to schools and the monitoring is not good, there's no correlation between what's in teachers plan book and what they're doing in the classroom

Our evaluation system is weak, everyone does their own thing until someone comes into the room and they perform.

While the MESC team is aware of weaknesses in the monitoring and evaluation of INSET, they are also adamant that they have played a vital role in ensuring that the training is being transferred into the classroom. Ministry staff claim that they have, to a certain extent, played their part but now it is up to principals to monitor their teachers. They claim that training for SROs and principals was undertaken and therefore schools should ensure that monitoring is being carried through.

\begin{abstract}
Monitoring visits from the $X$ staff and we also have verification visits...that's the support we offer...if they want more training on the content, we also organise that and arrange for training...everything is covered in these training, content, pedagogy and we even bring them in and have them talk...but principals and SRO's should also play their part in ensuring that monitoring and evaluation of teacher practices is taking place...

If the monitoring is not good then implementation doesn't take place... the ministry have done their job but its now up to schools, the principals and the SRO's...our role is to help
\end{abstract}

But these comments conflict with some of the respondents from the Ministry of Education were saying about the capabilities of the SRO. It was reported that their knowledge was not up-to-date and they were not able to offer teachers their full support in offering suggestions and feedback on the evaluation.

We got our school review officers to do the monitoring but...because of the limited time and numbers and also because of where they're at, none of our school review 
officers had worked at...secondary level within the curriculum...

...Their understanding of curriculum is very weak in terms of implementation...they would know what your year plan looks like but they wouldn't be able to give support to the teacher

...Training of SRO's not up-to-date with curriculum

\section{Resources}

Teachers in the study noted that a lack of resources was one of the biggest barriers to the implementation of the curriculum into classroom practice. The training provided many examples of how to make the learning more meaningful for the students but the teachers felt that after the training they could not use these ideas as there were few if any resources.

There a varied and good methods shown in the training but the problem is we don't have the resources, like video, pictures and posters... and if we find a video... we turn it on and it doesn't work.

We have the visual equipment but you know the tapes and all are not available. It would have made it easier. The relevant tapes and all these should be on stock.

... There is no library for student research

... There is no photocopy machine

Teachers sought supplies of resources for the schools especially given that there was a new curriculum to be implemented.

The unavailability of text, the audio-visual material...this should be available in our school from the Ministry

Some of our textbooks that were ordered...don't know if they are here in the office or we have to go ALL THE WAY TO APIA to find texts for students, collect or photocopy them.

...They [Ministry] said that they will give out teachers handbooks to assist teachers with the new curriculum but 
they have not done that...we only have the student textbooks that we all use...

...The other thing is you travel to look for your own resources and they don't care about you

However, MESC staff stated that schools were given the curriculum statements and an ample supply of student textbooks and the teachers would need to find other resources to further assist them.

We just give them the curriculum statement and the student books that were produced. Additional resources they have to look for those themselves. But there are additional resources that the teachers can use but they have to find that themselves

...Teachers have to be more active and use the internet and library to look for additional resources... we have given them all the resources that were produced here in the Ministry...

Teachers also reported that principals and heads of departments held on to resources for fear of students damaging them. Furthermore, it was identified that there was a lack of school funds to support extra curricula activities, such as class field trips.

No money for funding fieldtrips and workshop

But if there are resources but they hold onto it, they don't want to, they cautions not to spoil the resources

If we want to use the photocopy, they say it is bad, or no ink, or we are not allowed to use it

I don't understand why they hold onto the resources...it was given out to schools to be used in the teaching of children...so I don't understand why they should hold on to it...they afraid we might ruin it, I don't know

\section{Teacher Quality}

Research has indicated that teacher quality and their receptiveness to new ideas largely determines the success or failure of any training (Timperley, et al., 
2007). MESC staff noted that one of the biggest barriers to the implementation of the curriculum into classroom practice is poor teacher performance and an unwillingness to apply the ideas.

The other thing is teacher laziness, to be quiet honest. There are a lot of uncommitted teachers out there. Its teacher attitude towards all the reforms...it's the attitude of teachers, that's the biggest barrier that I know of... we have provided the training, they got the on-going support and we've them and provided them with all the resources but its really up to them and how they do their stuff...they know there are support services if they need it

If the teacher is not willing, not interested, the programme will fall through and learning is NOT TRANSFERRED!

You want to talk but they is no interest or keenness on their part to utilize what was learnt in the training

It's the teachers attitude. Now we have given them everything, resources and all...now it's up to them to implement it and that's another issue

An issue that emerged from the research was that teachers who attended training did not readily share ideas and training with colleagues upon their return to school.

Some of the teachers that come here are s:::0 greedy they don't want to share information (teacher apathy)

There is no feedback to ensure that there is continuous flow for the success of the programme (not willing)

There is no mechanism for teachers to work together to come up with outcomes for their subject

...No network...maybe they can't share their ideas or they don't understand what was taught in the training

MESC staff highlighted that teachers did not take extra measures to ensure that they thoroughly understood their subject matter, which resulted in teachers reverting to the traditional approach of teaching and learning. 
When they don't really understand things they just drop it...they don't do it...there are too many of them...they are too difficult for them...they are all new for them...so they fall back to the traditional method

If they don't understand the books, they just give it to the kids to COPY COPY COPY and explain and then that's it...there is no discussion, there is no actual teaching.

Another issue is with the teachers who cannot cover the curriculum...they don't cover the curriculum

With that teacher with just limited knowledge on the content, limited knowledge in the skills and that determines the way they teach

Teachers in the study highlighted that teacher overload was the biggest contributor to them not implementing ideas into the classroom. There are a lot of extra curricular activities that take away valuable time from the classroom and hence the teachers did not have enough time to deliver the lessons in more meaningful ways.

The volume of work given to teachers sometimes blogs the teachers out that you find that you have a heavy workload and all these things

...There are so many other things going on in school, like practice for cultural day and sports, which blocks the teacher from implementing what was learnt in the training into the classroom...there's just too much things teachers have to do...

50 minutes in a period and by that time you haven't gotten around to all the 30 students

So the teacher does what's easy for her hence, the traditional approach, give out the

Furthermore, MESC staff suggested that pre-service education of teachers was ineffective and did not prepare the teachers to teach the curriculum adequately.

the teachers coming from FOE are not good...they don't know how to plan, they don't know the content, the content and pedagogy are bad...because if they were good, we just give them the stuff and they do it' 
the quality of teachers we have now is not up to standard...I believe that it largely has to do with their preservice education...they were not trained to teach the curriculum and to teach it in meaningful ways...

An issue that also came through the interviews from teachers was that they were required to teach outside their subject areas. This resulted in teachers not having a solid understanding of the content which in turn led them to rely on the traditional method of teaching and learning. The learning process was further blunted when the teachers indicated that at times they did not teach students the concepts and terminology because it was difficult for the students to understand.

No background of a teacher to take the course they were force

Teachers have not had the training they need to teach the history curriculum...they just use what's in the textbook as they don't have enough content knowledge and pedagogical skills to teach it to students...

The vocabs too hard and the students do not understand some of history vocab so I just leave it for later

MESC staff also noted that the majority of teachers were still using the traditional approach because only a few teachers from the schools had attended the training and if they did turn up, they also left early. There is also the issue of teachers from schools absenting themselves from the workshops, which in turn has led to a lack of teacher understanding when delivering the curriculum into classroom practice.

few turn up to workshops and there also has been a high turnover of staff but there is also a degree of arrogance because of the status of the school

the teachers that come to the training leave after morning tea or lunch...they are not there for the duration of the training so they miss out on important teaching skills and knowledge 
non-attendance and absence of a whole school approach which is in fact a reflection of leadership, management within the school

An interesting finding that emerged from the study was the role culture plays in blocking a teacher from seeking more assistance. Teachers in the study have noted that they do not want to ask for further assistance as it may imply that the trainers did not explain things properly so they revert to using the traditional approach of teaching.

Culture dictates how we think, how we behave whether we are aware of it or not but it has a bearing on what we do to the point where it does not bring out the true picture

Because of our culture, they just want to praise people, they don't want to go against the people...they don't want to ask questions as it might mean that the trainers did not deliver the training properly

\section{Leadership within the schools}

One of the pressing issues that came across as a barrier to the successful implementation of the curriculum into classroom was the role of the principal and heads of departments in supporting teachers. Teachers and MESC staff alike noted that principals were not monitoring the performance of their teachers and offering critical support and assistance to ensure the success of the training. MESC staff also reported that principals are not implementing follow-up training for their staff to ensure sustainability and consistency of the professional development. MESC staff believe that there is a heavy reliance on the Ministry when it should be the school assisting, appraising and offering support to teachers.

Yes, that's right, that's another big concern of the Ministry is the leadership and its reflected in the IAs...the principals need to sign before coming in to the Ministry but most schools don't sign... and when we give students zero they complain and that's because they not doing their work of monitoring teachers

We have noticed principals who are not doing their jobs, they don't have $P D$ programmes to give their 
schools...they don't visit classrooms and appraise teachers...

The principals have to monitor. We first trained the principals and the SRO's. Its the leadership and how they manage the school...this is the biggest barrier because if the principal doesn't do their job then teachers morale is affected...because teachers say that there is no support from principal'

The biggest problem we have is there is no supervision from principals, they rely too much on the ministry... wait for us to come out and then do some work

\section{Curriculum}

Teachers have noted that one of the barriers to the implementation of the curriculum into classroom practice is that teachers did not have a thorough understanding of what is required of them - many teachers believed the curriculum was the same as the previous one.

the curriculum is still the same...it's the way we teach it that's changed

its nothing new, the same old same old thing, they say its different but l'm still teaching the same history topics in Year 12, like the different kinds of government, wars in Samoa and so on...

they have just included more activities and internal assessments but it is still all the same...

There is also the need to ensure that there is a consistent understanding of the curriculum across the education sector. There are varying degrees of understanding of what the curriculum is and how it should be delivered. For example, the Ministry have a different perception of the curriculum to teachers. The policies need to be outlined explicitly so that there is no confusion for the teachers and policy-makers.

There's a lot of national level policies that are contributing very differently at school level and there is no follow-up on what actually is school level policy 
Teachers really need to be prepared, to really understand the curriculum...they believe it's the same as the old one but the Ministry say it is different...

The Ministry says we have to teach this amount of topics but teachers are only teaching a fraction of this...there is no clear understanding of the curriculum

Teachers commented on the time span in which the curriculum is being implemented into classroom practice, they believe they were not given sufficient training and, most importantly, time to implement the new curriculum. They believe the new curriculum, introduction of assessments, etc. have all been introduced simultaneously and so teachers have not implemented many aspects adequately. Furthermore, because everything is exam-oriented teachers are teaching just enough to get students through.

Too much in a short time...it should be spread out, because it takes time to implement...as a result the activities were rushed...sometimes when we finish the training I have learnt only probably $60 \%$ of the whole thing because there is a timing to finish doing certain activities

Everything was rushed...we should have been given time to get used to the new curriculum before assessments are introduced...just leading to an overload in teacher work and end up we resort to the old way of teaching just to cover everything...

Teachers are teaching to the assessment...its all examoriented...out of 6 topics only 4 are examinable...so when the exams come, teacher only teach 4 and student has no choice

There is also the issue of sustainability where teachers are trained to implement the curriculum but after a year or two they leave the education system, sustaining an effective curriculum implementation in such situations becomes problematic.

Turnover, sustainability was not maintained in terms of curriculum implementation 


\section{Network}

Teachers also noted that there should be more interaction amongst staff from within the school and between schools. This they believed would enhance the sharing of training ideas which in turn would lead to the curriculum being implemented effectively. MESC staff also believe that working independently does not help the teacher to develop both professionally and socially. In addition, the sharing of ideas and understanding would eliminate barriers and difficulties teachers were experiencing when implementing the curriculum.

I think there currently needs to be a networking of all history teachers under the umbrella of the History Association for them to share information using the internet, to access and communicate with them...this will help us to understand and teach our subject more thoroughly

...Constant communication with other teachers will not only get resources to them but help them out in various ways...it will reinforce the training that's given by those who organize them...

Start transferring teachers...teachers come from Apia, come here [rural area] and help out with schools here and teachers in rural areas go to Apia...that has been suggested but never done because of time consumes and all...

\section{Discussion}

The results discussed in this chapter were concerned with the barriers to the implementation of the history curriculum. There were a range of issues identified including leadership, resources, a lack of understanding of the curriculum and support. Teachers in the study have noted that lack of support from principals and heads of departments is one of the biggest barriers to implementing the skills and knowledge learnt from the training into classroom practice. Fullan (1982) supports this by stating that follow-up for teachers upon their return to the classroom and during the implementation phase of change has long been recognised as a critical element to ensure change in their practices. This widespread problem of insufficient support to teachers to implement ideas in the classroom has been highlighted in the international 
literature (Barak \& Waks, 1997; Fullan, 1982; Huberman \& Miles, 1984; Lamie, 1998; le Roux \& Ferreira, 2005; Zeegers, 1995).

Foxon (1993) in conducting a content analysis on more than 30 articles identified an unsupportive organisational climate accounted for $42 \%$ of the inhibiting factors. Showers, et al. (1987) argue that support for teachers is crucial to ensure that they continuously develop new skills and integrate them into their teaching practice. In studies carried out by Ediger (2003), Slater (2006) and $\mathrm{Ha}$, et al. (2004), they concluded that principals, trainers and colleagues need to offer continuous support to ensure ideas learnt in training are being implemented into the classroom. Lieberman (1996) argues that involving the whole community in supporting teachers will lead to continuous learning and changed practices on the part of the teacher. Broad and Newstrom (1992) have proposed that there should be a partnership between trainees, their heads of departments and trainers at all stages of the training process to ensure support while the trainee undergoes training. For history teachers, receiving this support would ensure that teachers transfer what has been learnt into classroom practice (Hill, 1995; Pendry et al, 1998). Fullan (1993) highlights the need for teachers to "actively improve the conditions for learning in his or her immediate environment" (p. 6).

Teachers in the study also noted that there was a lack of monitoring and evaluation after the training workshops. There have been strong criticisms with regard to this lack of monitoring and evaluation (Ediger, 2003; Ha, et al., 2004; Huberman \& Miles, 1984; Ingvarson, et al., 2003; OECD, 1998; Ogletree \& Allen, 1976; Slater, 2006;). Teachers and MESC staff have noted that the present system of monitoring and evaluation is neither adequate nor properly implemented and as a result gaps in teacher performance and practice are not identified. The OECD (1998) and Slater (2006) claims that the majority of evaluations are poorly conducted, analysed and disseminated. Slater (2006) suggests that this limits access by policy makers to models of best practice. Ingvarson, et al. (2003) stress that teacher practices should be carefully monitored during the difficult implementation phase to offer support and assistance to the teacher. 
Teacher quality has also been highlighted in this study as one of the major impediments to the transfer of skills into the classroom. This study has found that their unwillingness to share and try out new ideas leads to lack of transfer to the classroom. It was also found that some teachers lacked the motivation and the willingness to ensure transfer of training. Foxon (1993) has noted that learner characteristics accounted for $21 \%$ of the inhibiting factors to the transfer of training into the classroom. Foxon (1993), Subedi (2004) and Wlodkowski (1985) highlighted that low level of learner motivation led to low or zero levels of transfer. Foxon (1993) argued that this low level of motivation can be attributed to the difficulty for the learner to grasp skills and knowledge from the training or the learner simply did not see the relevance of the training to job requirements.

Teachers in this study also noted that there were too many extra curricular activities operating in the schools that prevented teachers from implementing the training. Foxon (1993) highlighted that work demands also inhibited the participants from applying training and as a result they resorted to old ideas and ways of doing things. Bartlet (2004) adds that teachers are always genuine about what they do, but in instances where they are forced to do more as a result of reforms, they tend to overwork. This study also found that culture impacted significantly on the willingness of teachers to ask for assistance. Teachers would comment that the training was clear and that they understood it when in fact there were numerous areas of assistance needed. It is a cultural norm in Samoa not to ask for assistance frequently as this implies that the trainer is not delivering the training well.

The study also identified that teacher's inability to perform and transfer skills into the classroom was blamed on their pre-service training. The study found that teachers are not equipped with the content knowledge and pedagogical skills to be able to deliver it well. Wilson (2001), in reviewing the literature on the teaching of history has highlighted the need for teachers to have a sound knowledge and understanding of the history curriculum in order to deliver it in meaningful ways for the students. Cantu and Warren (2003) supports this by stating that if teachers are not exposed to the varied historical enquiry teaching 
methods in college they fail to recognise the value and use of such teaching methods. Another striking finding in this study was that teachers were teaching outside their subject area which helps to explain why they were not taking any further initiative to improve or learn more about the subject. They cautioned that this attitude and approach to the teaching of history forces teachers to resort to the traditional ways of teaching.

The lack of resources to aid teachers with the teaching and learning was an additional impediment to the implementation of the curriculum into classroom practice. Teachers in the study noted that their willingness and ability to try out new ideas in the classroom was hindered on return to the schools because resources were not readily available or if resources were available use was limited because of fear of damage. Foxon's (1993) analysis of the literature found that failure to provide sufficient resources also hindered the transfer of training into the classroom.

A lack of leadership within the schools was another one of the major concerns highlighted by teachers in the study. Teachers noted that principals were not taking a more active role to ensure that training was transferred into the classroom, but that they should be taking this role to ensure that teachers utilise the skills and knowledge learnt in the training to improve their teaching practices. Numerous studies (Backhouse, 1987; Barak \& Waks, 1997; Foxon, 1993; Fullan, 1982; Huberman \& Miles, 1984; Lamie, 1998; le Roux \& Ferreira, 2005; McDonald, 2002; Zeegers, 1995) have identified the need for support from top management in order for teachers to transfer the training into classroom practice. Timperley, et al. (2007) highlighted that effective leaders vigorously supported the professional learning of their staff by ensuring teachers were given opportunities to learn. There were numerous studies which also highlighted the positive effects for both students and teachers as a result of principals developing a learning culture within their schools (Davis, 2006; French, 2001, Hirshman, 1996).

Another major concern and finding that emerged was that teachers were not totally clear about the curriculum and what was expected of them. The majority 
of teachers noted that the curriculum was the same as the previous one, and hence this was a good reason for not altering teaching practices and approaches. This confusion is also highlighted in the literature - policies and changed practices not being made explicitly clear (Aitken, 2006; Spillane et al, 2002). There should be explanation notes in the documents so teachers are able to make clear distinctions between old and new knowledge. Hargreave (1998) goes on to note that changes in school curriculum policy are sometimes too broad and not clearly stated, which leads to problems in the implementation of the curriculum. Spillane et al (2002) stated that teacher intentions are genuine when it comes to implementation by trying to understand how the curriculum can be translated into classroom practice, but cautions that they may in the event misinterpret, rather than undermine policy documents (Spillane et al, 2002). Davis and Krajcik (2005) and Aitken (2006) emphasised that policy makers and curriculum designers should ensure that the "essence of intention" of the curriculum is relayed explicitly in the document for teachers, and that it fosters and promotes the pedagogical design capacity of teachers, so that the teaching and learning is enhanced (p. 6). But Robinson and Lai (2006) also highlight the need and relevance of getting teachers to engage in their prior knowledge in order for them to understand the changes taking place. Timperley et al (2007) states that problems are usually solved by teachers' past beliefs and experiences which enables them to understand and accept the changes.

\section{Chapter Summary}

This research question sought to identify the barriers teachers considered were impeding the successful implementation of the history curriculum into classroom practice and by default facilitators were also recognised. Educators noted that there are numerous barriers to the implementation of the curriculum into classroom practice. One of the most notable and striking was the lack of support systems in place both at the school and national level. Teachers highlighted that they were not being given the level of support they needed from heads of departments and principals. There was also the lack of and inadequate monitoring and evaluation of training practices, this concern was 
highlighted by both teachers and MESC staff. The need to train SROs on how best to monitor and evaluate teachers was seen as urgent as was the need to maintain their up-to-date knowledge about the curriculum. The provision and use of adequate resources by the teachers was another important factor identified as contributing to the implementation of ideas. The teachers themselves, their performance and their unwillingness to implement training ideas into the classroom was identified as being significant. Some noted that a contributing factor in teacher unwillingness was due to the work overload. There was also the need to ensure that teachers fully understood the curriculum so that they were able to teach it. The study noted the numerous benefits of teacher networking. As McGee et al (2004) noted, while a great deal of effort went into providing schools with resources, facilities and strategic plans, it was the teacher who ultimately integrated these into classroom practice. 


\section{CHAPTER 7: A SHIFT TOWARDS SCHOOL - BASED PROFESSIONAL DEVELOPMENT}

This chapter focuses upon teachers' views and understanding of policies and structures put in place to ensure on-going professional support for them. The question seeks to clarify, what are teacher's views or understanding on any policies or structures in place to ensure on-going professional support for teachers while implementing the new curriculum changes?

\section{School-based}

Past professional development training and workshops have all been carried out by MESC at its headquarters, but there has now been a move towards school-based professional development. Teachers have noted that this shift has been very positive as the workshops are now planned around their practical needs. Furthermore, teachers are now having more say in their training needs, or in other words, schools are now adopting a bottom-up approach to professional development.

We have seen positive results with school-based training...so the team go out into the schools or the districts and do the training there rather than have the teachers come here because they can use the students for their training and do it in their classroom...and also some teachers when they come here for the training, they stay for 2-3 hours then they disappear for their personal stuff

Moving the training to the schools have been a positive and better move as we teachers are now able to work in our own environment...its more practical and realistic

This move to school-based training is better as the whole school gets involved...its all towards the improvement of the whole school

We have the school improvement programme of professional development programme of teachers teaching the other teachers or demonstrating the lessons

That's the requirement from the Ministry, that each school has to have a PD programme, an on-going PD programme 
and if they would like or if they require assistance from the Ministry then we go out and help them.

The teachers are the ones implementing and teaching in the classroom so any change needs to come from them...maybe it be easier because the ideas, problems are theirs

The Ministry also has a new appraisal system to assess the performance of teachers; this system enables teachers to list their training needs so future professional development activities can be planned to assist them with any areas of weakness.

We have a new appraisal system for teachers and in that new system, appraisal forms that teachers fill out, they list down their training needs....we get the needs from them, we discuss then we plan...we're trying to encourage the bottom-up approach

There are teachers who want to go on holiday but need to come back for appraisal...the weakness is that it is not continuous because it's a set period just to satisfy the requirements of the annual plans.

The Ministry have also seen positive changes emerge as a result of the schoolbased training. They stress that it is less expensive for both the Ministry and the teachers because there is no travel involved and allowances and meals do not need to be provided. The Ministry note that if there is a need for extra assistance from the department then trained and specialised staff is allocated to run the training for the schools.

Its cheaper if its school-based because if teachers come we need to provide refreshments and bus-fare...more cheaper, more practical and realistic and within teachers own environment

The schools run their own workshops...but they write to the Ministry if they need someone to come in

The expectation of the Ministry is that schools will continue to provide PD and if they need help from the Ministry they come and ask for it 
For the first three years of the implementation we had heaps of request but I think now there's hardly any request

Another Ministry policy encourages schools to network and provide assistance to each other. Teachers from different schools have been trained to conduct and carry out the training, but each school is responsible for organising such training and its frequency. There have been concerns raised by teachers as they note that not all schools take this initiative seriously and that the Ministry does not monitor and offer on-going support to schools to ensure that it continues.

Its all school-based now...there's no more training at the Ministry...they using those that have been trained to do the training or whoever can do the training for their department. the other thing is schools assist each other...the Ministry initiates but schools do it...it's a sort of network and it really works

The networking with schools is good but the interest and motivation dies down after awhile...also if the Ministry continues to provide on-going support to schools, they will continue to do it but once the Ministry leaves, the network goes up in the air

Despite the benefits of school-based professional development, like any new initiative there are always concerns and issues raised. There is the urgent need to bring in trainers for different subject areas as teachers claim that everyone is grouped together.

Need people who specialized in different areas so training be effective and enhanced

We all attend the training in schools. If it is for the Math's department, we all attend...the problem is I don't know if it is carried out properly by the administration, there's no logic, or maybe they don't understand what the department want

...If its English, we all attend, Maths, we all attend, Accounting, we all attend...

They have a policy, that PD be school-based. But with school based, there's no one who can do it, then what? 
Concerns were also raised about the time allocated for professional development activities. Teachers note that they have a very heavy teaching load which impacts upon the time they need for their professional development. They note that the workload should be decreased so that they have time for professional development activities.

...Teachers' already have a heavy workload especially
junior teachers...so I suggest that teachers have a
workload less than at least 15 to make time for their
counterparts in the subject and to plan their department
meeting...
'...The availability of themselves and myself on top of our
teaching load is another factor that needs to be
considered...

Teachers also raised concerns that despite school-based professional development, there is still a need for centralised INSET, especially for new teachers. Some respondents remarked that there is insufficient INSET provided for teachers, especially during this curriculum implementation phase.

I have suggested to the principal to take the new teachers to be in-serviced, so when they come back they have the same knowledge as I do so we can liaise

More IST for teachers...its not enough

We need more [professional development] in the beginning of the year and at times when we are free

\section{Discussion}

The results discussed in this chapter highlighted the benefits of school - based professional development. While there is still a need for centrally - based professional development activities, this study has found that this shift in policy to conduct training in teachers own environment has many benefits.

Before the implementation of the new history curriculum, all INSET and professional development activities were centrally controlled and administered by MESC. Now all training and professional development activities are the responsibility of the individual schools; in other words, all professional activities 
are now school-based. The majority of the teachers noted that this has been a realistic and practical move as they are trained in their own environment. They noted the benefits of having training in their own environment enabling all staff to work towards school improvement projects without any teachers feeling isolated or left out. Veenman and Denessen (2001) note that this move towards professional development provides guidance and assistance at the school level using approaches such as coaching, collaboration, inquiry and reflection. Teachers in the study noted that this approach has enabled them to identify their own learning needs within their own environment, in what is referred to as a bottom-up approach (Saito, et al., 2006). This approach also enables them to obtain the support they need from principals and top management (Lieberman, 1996). Timperley et al (2007) in their synthesis study found that an individual's learning is strongly influenced by the socio-cultural context in which the learning or training is taking place (p. 25).

The Ministry has also arranged for different schools to network with each other. Teachers have noted that this has been a positive move as they can share resources and collaborate with each other on different levels. It has also been highlighted in the literature as having a very positive impact on teachers (Darling-Hammond, 1998a; Hargreaves \& Fink, 2000; Lieberman, 1996; Saito, et al., 2006).

As with any new initiative, there are always concerns and problems; one of the main concerns was that training in the schools was not conducted properly. Teachers claimed that they are all grouped together for professional development activities. Teachers claimed that these workshops were not well managed and were not consistent. They highlighted the need to design different workshops catering to the individual needs of the teacher in their own subject area. There is also the need for specialised trainers to visit schools to ensure that learning needs are catered to.

Another concern that came through the study was the sustainability of the collaboration and networking between schools. They noted that there was no serious continuity with the programmes and it is evident that when the Ministry 
leave, the schools do not follow through with the networking and training. This has been highlighted in a study by Coburn (2003) who questions the sustainability of reforms and initiatives. She goes on to highlight that a common scenario for these reforms is that there is a short-term influx of resources and professional development training, which then disappears once external support is withdrawn. It is highlighted in the literature that for teacher networking to work, there needs to be effective leadership or the existence of a key person (Hattam \& Mclnerney, 2000; Saito, et al., 2006). The existence of a key person or leader ensures that professional development efforts are recognised and fostered by all (Saito, et al., 2006).

\section{Chapter Summary}

The purpose of research question three was to obtain teachers' views and understanding about policies or structures in place to ensure on-going professional support for teachers while implementing the new curriculum changes. Educators in the study noted the numerous benefits of school-based training. They were very pleased with the bottom-up approach to professional development as it enabled them to identify their specific training needs within their own teaching environment. School-based professional development also enabled schools to work together towards school improvement goals and activities. Teachers were also happy with policies that encouraged people to work together and network, it gave them the opportunity to share and assist each other with teaching and learning concerns. But teachers in the study also highlighted the need to utilise more qualified and specialised trainers for different subject areas. There was also the issue of timing of workshops to ensure that their other responsibilities were not disrupted when they were engaged in training. It has been highlighted that principals need to take a more active role in school-based professional development; this will help to ensure that professional development is effective as teachers and principals will be pursuing school issues and problems together while addressing their own individual professional needs. 


\section{CHAPTER 8: CONCLUSION AND RECOMMENDATIONS}

\section{Introduction}

This research study was undertaken in Samoa. In the last five years the Samoan education system has undergone numerous reforms. These reforms have included the restructuring of the single-stream curriculum into a dualeducation system where the same curricula and assessments apply to all students. Given this, a new curriculum and supporting teaching documentation were established for all subjects. Central to these reforms has been the training of teachers to help them implement the curriculum document into classroom practice. This study has focussed on obtaining Samoan educators' perspectives and experiences on the effectiveness of INSET in helping teachers to implement curriculum reforms in history. It sought to obtain teachers perceptions and experiences

1) the strategies, techniques and approaches used in the in-service training to help teachers improve their content knowledge and pedagogical skills in implementing the new Samoan history curriculum document into classroom practice?

2) some of the barriers impeding the successful implementation of the history curriculum document into the classroom

3) any policies or structures in place to ensure on-going professional support while implementing the new curriculum changes

Given the nature of the research study, the study adopted an interpretive phenomenological methodology using a case study approach. Purposeful sampling was used to select the history teachers and the MESC staff for the study. Data was collected through the use of in depth, semi-structured face-toface interviews with the participants and thematic analysis was used to analyse the results. 


\section{Findings}

The purpose of this research study was to obtain educator's perceptions and experiences on the effectiveness of INSET in helping them to translate and implement the curriculum into classroom practice. While the majority of the teachers found the techniques, strategies and approaches in the workshops helpful to translate the curriculum into classroom practice, there were numerous barriers that prevented them from effectively implementing the. One of the widespread concerns and barriers was the level of support received by teachers from school principals, heads of departments and MESC. Teachers noted that not receiving this support upon their return to school which was the most significant barrier in impeded the successful implementation of the curriculum document into classroom practice. The literature on INSET highlights support as the most essential ingredient in ensuring transfer of ideas into classroom practice (Lieberman, 1996; McDonald, 2002). The literature on transfer of training and curriculum implementation also highlights support from both local and national level as critical if learning is to take place (Foxon, 1993; Spillane et al, 2002; Timperley et al, 2007).

Another key finding was the lack of monitoring and evaluation both by the school and at the national level. There was inadequate follow-up of workshops and teachers were not made aware of gaps and weaknesses in their practise, which in turn did not provide any avenues for improving their teaching practices. This finding related to another finding - the quality of the teachers. For various reasons, a number of teachers were reported to lack motivation or the initiative to implement training ideas into classroom practice (Foxon, 1993; McDonald, 2002). Undoubtedly however, teacher workload was one of the main factors that contributed to teachers not effectively using training techniques and strategies in the classroom to help students understand the curriculum (Bartlet, 2004; Gewirtz, 1997). There was also the issue of teachers not fully and explicitly understanding the curriculum document (Spillane et al., 2002).

Given the concerns and barriers raised by teachers, present-day professional workshops are now conducted at schools. These workshops have shown to be more effective and efficient as all teachers work towards school improvement 
programmes Veenman \& Denessen, 2001; Saito et al., 2006). But again, results from the study show that these school-based training programmes are not adequately planned and resourced. Teachers note that there needs to be more specialised training so that they are able to upgrade their practices and content knowledge in their own specialised areas. Teachers in the study have also noted that the Ministry should take more measures to ensure that the networking of teachers takes place to ensure that learning and training is continuous and on a timely basis.

\section{Limitations}

While engaged in this research study and subsequent to the data gathering, I have been made aware of several limitations that could have hindered the credibility of the findings especially if caution was not exercised.

One of the notable limitations of this research study was the adoption of western research paradigms to carry out a research study in a Pacific nation, which has different cultural practices and norms. As Tupuola (1993) noted, utmost caution needs to be taken when western practices are adopted to carry out research in non-western settings. While I was aware of this, given my wellgrounded understanding of my own culture I was confident that I was able to eliminate any such problems that might arise. Adopting a phenomenological research approach helped me to minimise this problem. Embedded in the phenomenology design is the obtaining of participants views and perceptions by means of talking, which is the most appropriate way of obtaining island views and ways of working and this was especially relevant in the Samoan context.

Another limitation was the small number of participants selected for the study; but this was balanced by the selection of the respondents - they brought with them strong views and opinions, which provided a measure of saturation. Boyd (2001) and Creswell (1998) state that a range of participants from 2 to 10 is sufficient to reach saturation. 
There were also potential problems based on the type of questions asked during the interviews. However in the development of the questions and subsequent probes, utmost care and precaution was taken to ensure that leading and double questions were avoided.

On the issue of generalisability; while the intention is that the findings are not generalisable and applicable to a wider population, the findings highlight some issues that can have relevance in other settings and contexts. Schofield (1992 cited in Cohen, et al., 2000) argues that in qualitative research, it is important to provide a clear, "detailed and in-depth description so that others can decide the extent to which findings from one piece of research are generalisable to another situation such as to address the issue of comparability and translatability" (p. 109). Lincoln and Guba (1985) argued against this by stating that it is not the researcher's responsibility to provide an indicator of transferability but should otherwise ensure if transferability is possible by providing readers with adequately rich data. But caution should still be exercised in generalising from this study as considerably more research is needed.

Another major limitation in this research concerns the level and appropriateness of the interview transcripts. While the interviews were undertaken in English, some teachers relied heavily on Samoan language interpretation and interaction. Caution and the utmost care were taken during the transcribing to ensure that the translation and choosing of appropriate words remained true to what was actually referred to by the participants.

\section{Recommendations}

Given the findings of this study a number of recommendations are applicable:

1) One of the major concerns that has come out of the study is the lack of support received by teachers at both the school and national level. Given this, the Samoan Ministry of Education should take measures to ensure that support is offered to teachers before, during and after the training period. There should be more workshops for senior management, 
principals and SRO's not only to ensure that they are equipped with the required and necessary skills to help teachers implement the curriculum document into classroom practice but also to ensure they are made fully aware of the importance of support that is needed for change to occur.

2) There needs to be a review of monitoring and evaluation policies. One issue raised by the research participants was that SROs were not adequately trained nor did they have up-to-date knowledge of the new curriculum, which in turn affected their ability to offer constructive feedback to teachers. Given this situation, there needs to be on-going and continuous training for SROs, principals and those involved in monitoring and evaluation to ensure that teachers not only receive the support they need but also that they are able to identify gaps in their practices.

3) MESC needs to play a more active and vigorous role in ensuring continuous and interactive networking of teachers within and between schools. Teachers felt that the Ministry only initiates these networks, then leaves it to teachers; they felt that teachers become more active and involved in these partnerships and networking only when they know that the Ministry is behind it.

4) Another issue that was raised by teachers was the quality of the workshop trainers. While content knowledge and pedagogical skills are important, teachers noted that trainers should also be more aware of cultural and contextual settings. Trainers should ensure the training programme is culturally and contextually situated to ensure that training is effective.

5) Careful attention should be given to the design of professional development workshops. This should include careful scrutiny of the content to be delivered and the activities to enhance learning. Attention should also be given to ensuring that the training is appropriate for a diverse range of teachers. Aligned to this, is the need to ensure that barriers to the transfer of training are minimised. This will ensure that training is transferred into the classroom.

6) An issue that was brought up in the study was that teachers were teaching outside their subject areas. The Ministry of Education should 
ensure that a needs analysis is carried out on these teachers to ensure that gaps in their content knowledge and pedagogical skills are being addressed through a vigorous professional development programme.

7) One of the biggest impediments to the implementation of the curriculum highlighted by the teachers was the lack of resources to deliver the programme. The Ministry of Education and school principals should ensure that adequate resources are provided for teachers in order to assist them with their teaching.

8) One of the issues that emerged from the study was the need to ensure the linkages between pre-service education and what is being taught at schools. The Ministry of Education and the Faculty of Education of the National University of Samoa need to work closely together to ensure that pre-service teachers are well equipped with the content knowledge and pedagogical skills required to teach in schools.

9) The Ministry of Education should conduct continuous training for principals. One of the notable issues that came across in the study was the need for principals to play a more central role in promoting and encouraging a community of learners within the school. There was also the need to ensure the continuous networking of teachers within their own schools and between schools. This would ensure a community of learning is fostered and encouraged.

\section{Issues for further research}

Given this research study was introductory and limited in scope it is important that further research be considered. The following highlights some of the research gaps.

1) One of the key findings was the level of support that should be offered to teachers. There still needs to be research into how much support is appropriate to ensure transfer occurs. There is also the question of the kind and nature of support that should be offered and to what extent.

2) More research should also be carried out on the most suitable training design for a Pacifica setting. What kind of training would be more appropriate for Pacific island teachers? What strategies and approaches 
would provide teachers with the opportunity to enhance their professional skills and understanding

3) There should also be more research into how Pacifica peoples learn? What are the conditions needed for enhanced learning of Pacific people? While there is considerable research into how adults learn best, more research should be geared towards how Pacific island people learn, incorporating the theories of adult learning. Understanding this will ensure that training design and workshops will be developed to help Pacific teachers learn.

4) There should be research into the sustainability of training workshops. How do we ensure that the workshops and training we are implementing will be sustained? What do we need to do to ensure that it leads to improved student outcomes? What qualities are associated with sustainability?

Given the findings of this research study, it is important to note that more research in different cultural settings needs to be carried out to ensure the generalisability and transferability of findings in this study. But it has shed light on the barriers that educators need to minimise in order for teacher training workshops and professional developed to be more effective. It is only when these problems are minimised and addressed that teaching and learning can be more effective and stimulating for our children. 


\section{APPENDICES}

\section{Appendix One: Participant Information Sheet}

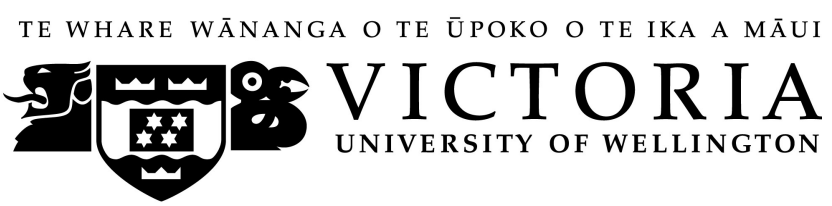

\section{PARTICIPANT INFORMATION SHEET}

Talofa lava. My name is Maimoana Petaia and I'm in my second year of postgraduate study at Victoria University of Wellington, New Zealand. I have formerly been a teacher at Robert Louis Stevenson Secondary School and have done numerous tasks in relation to teacher training and curriculum development within the Ministry of Education, Sports and Culture. Due to my involvement in these areas, this research seeks to further my understanding on teacher in-service training and curriculum development. The following information pertains to the study.

Purpose of the research

The purpose of the research is primarily to complete a thesis and fulfil requirements for a Masters Degree in Education. It is also the hope that the findings will provide valuable information for the Ministry of Education, Sports and Culture (MESC) in the development of future in-service teacher training so that teachers will be better equipped to transfer what has been learnt in the trainings into their classrooms.

Procedure for the study

In the event that you do agree to take part in the study, interviews will be carried out (at a time convenient to you) to obtain your views on the effectiveness of in-service trainings in helping you deliver the curriculum. The interviews will seek to identify what are the strategies that have been employed in the trainings to ensure that training is transferred into the classroom. The interviews will also seek to identify the barriers to the transfer of training. Your views and understanding in regards to in-service trainings and professional development policies will also be sought.

Please note that your participation is voluntary and you may withdraw from the study at any time. It is anticipated that 1 interview session will take place but in the event that clarity is needed, subsequent interviews may be requested at a time convenient to you. The information you provide in the interviews will be held in strict confidence and you will not be identified in any way. All the information collected will be kept in a protected password computer system for which only myself and my supervisor will have access to. All the information collected in the interviews will be made available for you to comment on within the next week. 
It is also important to note that you will be able to obtain a copy on the outcome of the study if so requested. All the data collected will be kept for a period of 2 years after the research has been completed and this is mainly for academic verification purposes. Once this has been completed all the information will be destroyed and tapes used in the interviews will be electronically wiped or if so requested may be returned to you.

If you have any queries or concerns regarding the conduct of this research, please do not hesitate to contact myself or my supervisor, Dr. Lex McDonald at the given contact details below. Also note that your receipt of this information sheet on a university letterhead confirms that ethical approval to conduct the research has been given by the Victoria University Wellington College of Education Ethics Committee. A pre-interview information sheet will be posted out to you once your acceptance to take part in this study has been received.

Sincerely,

Maimoana Petaia

(Student researcher)

Samoa contact details:

$\mathrm{XXX}$
Dr. Lex McDonald

(Supervisor)

Contact details: 


\section{Appendix Two: Consent Form}

\section{CONSENT FORM FOR RESEARCH PROJECT ON EDUCATORS' PERCEPTIONS and EXPERIENCES OF IN- SERVICE TRAINING TO SUPPORT CURRICULUM REFORM}

I have read all the information relating to this research. I understand that by signing this form I give my consent to take part in this study. (Please tick each item if you agree).

I understand that the following principles apply to this study:

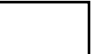

I have been provided with adequate information relating to the purpose of the research and I have understood the information given

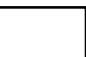

My participation is voluntary and I agree to take part. I do not have to take part in this study.

I understand that I may withdraw from this study at any time without providing reasons. I understand that in the event of withdrawal from the study, all the information I have given will be destroyed

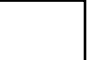

I understand that all the information or opinions I provide will be kept confidential and no one will know what I have said or written

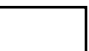

All the information I provide will be kept in a secure place, for which only the researcher and supervisor will have access to

I understand that all the information for the study will be destroyed 2 years after the report has been written.

understand that I will be given the opportunity to comment on the information that I provide and may change any of the information if I wish to

I understand that the information I provide will be used for the purposes of the study. It may also be used for a conference or publication.

I can meet with the researcher at an arranged time to discuss the study

I have read all of the above statements and give my consent to take part in this study

Name:

School:

Date:

Signature: 


\section{Appendix Three: Pre-interview Information Sheet}

Pre-interview information on Educators' perceptions and experiences of in-service training to support curriculum reform: A case study of Samoan history teachers.

Talofa lava teachers, principals and teacher educators.

Thank you again for agreeing to participate in this research. Your participation in this study is highly valued and appreciated. I thank you for taking time out of your busy schedule to complete the interview. It is anticipated that the interview session will take about 50 minutes.

At this stage you would have read and received all information pertaining to the study and its purpose. This sheet will give you some information on the interview session and asks you to give some thought to the questions that will be asked. Please note that your participation is voluntary and you may withdraw from the study, but I hope that you will be able to take part.

All the information you provide will be confidential and you will not be identified in any way. The interviews will be audio recorded so as to allow the interview to proceed in a conversational manner and also so that it can be analysed at a later date. You will also be given a copy of the interview transcript in the following week for you to check for accuracy. All the transcripts and the audio tapes will be kept for a period of 2 years for academic verification purposes before being destroyed and electronically wiped or if so requested be returned to you.

The major questions to be considered during the interview include the following:

Question 1

\section{For teachers}

How has the in-service training helped you to teach the history curriculum effectively in the classroom?

For this question you may like to consider things such as:

- What strategies/techniques/ approaches have been used in the training to help you improve your content knowledge of the history curriculum?

- What strategies have assisted you in improving your teaching styles to better deliver the curriculum?

- Overall, the focus of this questions is obtaining your perceptions and experiences on what strategies used in the training has worked well for you and why?

\section{For MESC personnel}

What strategies / techniques / approaches have you adopted and used in the trainings to help teachers implement the curriculum document into classroom practice?

Question 2 (applies to both teachers and MESC personnel).

What barriers do you see as impeding on the successful implementation of the history curriculum document into the classroom? 
For this question you may like to consider the barriers that stop you (teachers) from implementing the history curriculum in the classroom.

Question 3 (applies to both teachers and MESC personnel).

What are your views or understanding on any policies or structures in place to ensure on-going professional support for you as teachers / educators' in implementing the new curriculum changes?

Please note for this question that you do not have to have any knowledge of policies on in-service training or professional development.

Once again, I thank you for agreeing to take part in this interview session. Please find the interview consent forms attached for your perusal and approval.

If you have any queries or concerns regarding the conduct of this research, please contact myself or my supervisor, Dr. Lex McDonald on the contact details given below.

Faafetai tele lava,

Maimoana Petaia

(Student researcher)

Samoa contact details:

$\mathrm{XXX}$
Dr. Lex McDonald

(Supervisor)

Contact details: 


\section{Appendix Four: Consent form - Interview}

\section{CONSENT FORM: INTERVIEW}

Consent form for interview session on educators' perceptions and experiences of in-service training to support curriculum reform: A case study of Samoan history teachers.

I have read all the information relating to this research. I understand that by signing this form I give my consent to take part in the interview sessions. (Please tick each item if you agree).

I understand that the following principles apply to the interview sessions:

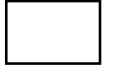

I choose to take part in the interview sessions. It is voluntary and I may withdraw from taking part.

All the information and comments I give will be confidential and I will not be identified in any way.

I do not have to answer all the questions in the interview if I so wish not to comment on.

All the information given will be kept in a protected password computer system for which only the researcher and supervisor will have access to. All the information will be destroyed after a period of 2 years

All the audio tapes used in the interviews will be electronically wiped after a period of 2 years

I will be given the opportunity to comment upon the information given in the interviews and can change any of it if I so wish

I would like to obtain a brief summary on the outcome of the research study.

I can meet with the researcher at an arranged time to discuss the study

I have read all of the above statements and give my consent to take part in the interview sessions

Name:

School:

Date:

Signature: 


\section{Appendix Five: Application letter to carry out research in schools}

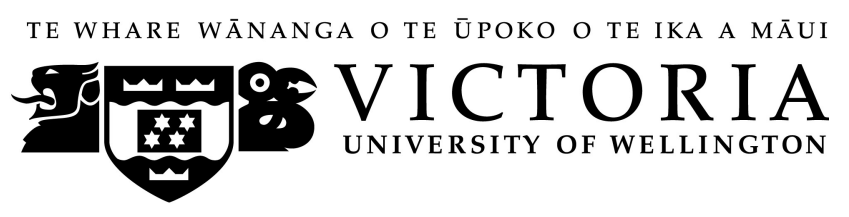

Victoria University

Wellington

New Zealand

18 November 2007

Tautapilimai Levaopolo Tupae Esera

Chief Executive Officer

Ministry of Education, Sports and Culture

APIA

\section{RE: Approval to carry out research with history teachers in selected Government schools and MESC personnel involved with teacher professional development and in-service training.}

Dear Sir,

My name is Maimoana Petaia and I'm in my second year of postgraduate study at Victoria University of Wellington, New Zealand. I have formerly been a teacher at Robert Louis Stevenson School and have been largely involved with the Ministry in the development of the new History curriculum and in-service training.

I'm writing to seek your permission and approval to conduct a study amongst history teachers in selected Government schools. The study seeks to obtain educators' perceptions and experiences of in-service trainings (or related professional development activities) in implementing the history curriculum into classroom practice. It seeks to identify both the facilitators and the barriers to the transfer of training into the classroom.

I'm also seeking your permission to interview MESC personnel largely involved with teacher professional development and in-service training within the Ministry on their views of the training and how it prepares teachers to implement the curriculum document into classroom practice. I'm also seeking your permission to work closely with the following Divisions (Curriculum, Materials and Assessment Division, Policy, Planning and Research Division, School Operations Division) within the Ministry so as to obtain any documents pertinent to the study and also their views on teacher professional development and curriculum implementation. 
The purpose of the research is to primarily complete a thesis and fulfil the requirements for a Masters Degree in Education but it is also the hope that the outcome of the research will provide valuable information in the development of future in-service teacher training so teachers are better equipped to transfer what has been learnt from the training into the classroom.

Information will be collected by conducting interviews with history teachers from the selected government schools and MESC personnel. It is anticipated that the research will in no way interfere with participants daily classes and responsibilities as interview sessions will take place at a time convenient to them. All the information collected will be strictly confidential but teachers will have access to the information provided to check for accuracy. The outcomes of the study will be made available to the teachers and the Ministry upon request.

If you have any queries or concerns regarding the conduct of this research, please contact myself or my supervisor, Dr. Lex McDonald on the contact details given below. Also note that your receipt of this letter on a university letterhead confirms that ethical approval has been given by the Victoria University of Wellington College of Education Ethics Committee. Please find attached a participant information sheet and consent forms that be given to selected teachers and MESC personnel upon approval to proceed with the study.

I look forward to your favourable response to this humble request.

Sincerely,

Maimoana Petaia

Dr. Lex McDonald

(Student researcher)

(Supervisor)

Samoa contact details:

XXX

Contact details:

XXX 


\section{REFERENCES}

Afamasaga, T. (2002). Personal reflections on education in Samoa. In F. Pene, A.M. Taufe'ulungaki \& C. Benson (Eds.). Tree of Opportunity. Suva, Fiji: Institute of Education.

Aitken, G. (2006). Signalling shifts in meaning: The experience of social studies curriculum design. Curriculum Matters, 2, 6-25.

Alexander, J. (2006). Letting students choose their own history. And why the Commonwealth is all wrong about the teaching of history. Professional Educator, 5(4), 27-33.

American Educational Research Association (2005). Essential Information for Educational policy. In Research Points, 3(1).

Anderson, S.E. (1997). Understanding teacher change: Revisiting the concerns based model. Curriculum Inquiry, 27, 331-367.

Asia Development Bank Report (2005). Summary poverty reduction and social analysis SAM: Educator Sector Project II. Apia, Samoa: Author.

Auckland Uniservices Ltd. (2001). Pasifika education research guidelines. (Report to the Ministry of Education). Wellington: Ministry of Education.

Backhouse, J.K. (1987). Changing teaching methods through INSET. British Journal of Inservice Education 14(1), 25-28.

Bain, R.B. (2003). Putting the pieces together (again?): History teacher education as a university wide task. (Reforming History Education Briefing Paper). Washington, DC: University of Michigan.

Baldwin, T.T., \& Ford, J.K. (1988). Transfer of training: A review and directions for future research. Personnel Psychology, 41, 63-105.

Ball, D., \& Cohen, D. (1996). Reform by the book: What is-or might be-the role of curriculum materials in teacher learning and instructional reform? Educational Research, 25(9), 6-14.

Ball, D., \& Cohen, D. (1999). Developing practice, developing practitioners: Toward a practice based theory of professional education. In L. DarlingHammond \& G. Sykes (Eds.). Teaching as a Learning Professional: Handbook of Policy and Practice. (pp. 3-32). San Francisco: Jossey-Bass.

Barak, M., \& Waks, S. (1997). An Israeli study of longitudinal in-service training mathematics, science and technology teachers. Journal of Education for Teaching, 23(2).

Barth, R.S. (1990). Improving schools from within: Teachers, parents and principals can make the difference. San Francisco: Jossey-Bass.

Bartlet, L. (2004). Expanding teacher workloads: A resource for retention or a recipe for overwork? Journal of Education Policy. 15(5), 565-582.

Barton, K. (1996). Narrative simplifications in elementary students Historical thinking. In J. Brophy (Ed.), Advances in research on teaching. Greenwich, CT: JAI.

Barton, K.C., \& Levstik, L.S. (1998). "It wasn't a good part of history". National identity and students' explanations of historical significance. Teachers College Record 99(3), 478-513.

Ben-Chaim, D., Fresko, B., \& Carmeli, M. (1998). In-service mathematics teacher education: A comprehensive approach, Journal of Education for Teaching, 14, 267-276

Benejam, P., \& Espinet, M. (1992). Spain. In H. B. Leavitt (Ed). Issues and Problems in Teacher Education: An International Handbook. New York: Greenwood. 
Bentz, V.M., \& Shapiro, J.J. (1998). Mindful inquiry in social research.Thousand Oaks, CA: Sage.

Berg, B.L. (2007). Qualitative research methods for the social sciences $\left(6^{\text {th }}\right.$ ed.). Boston: Allyn \& Bacon.

Bogdan, R.C., \& Biklen, S.K. (2003). Research for education: An introduction to theories and methods ( $\left.4^{\text {th }} \mathrm{Ed}\right)$. Boston: Pearson Education.

Bolam, R. (1982). In-service education and training of teachers: A condition of educational change. Final Report of CERI Project on INSET. Paris: OECD

Borko, H., \& Putnam, R.T. (1995). Expanding a teachers' knowledge base: A cognitive psychological perspective on professional development. In T.R. Guskey \& M.Huberman (Eds.). Professional development in education: New paradigms and practices. New York: Teachers College Press

Borko, H., \& Putnam, R. (1996). Learning to teach. In D. Berliner, \& R. Calfee (Eds.), Handbook of educational psychology (pp. 673-708). New York: Macmillan.

Boyd, C.O. (2001). Phenomenology the method. In P. L. Munhall (Ed), Nursing research: A qualitative perspective ( $3^{\text {rd }}$ ed.) pp. 93-122. Sudbury, MA: Jones \& Bartlett.

Broad, M.L., \& Newstrom, J.W. (1992). Transfer of training. Massachusetts: Addison-Wesley.

Burns, R.B. (1996). Introduction to Research Methods (3 ${ }^{\text {rd }}$ ed.). Melbourne: Longman Australia.

Cantu, D.A., \& Warren, W.J. (2003). Teaching history in the digital classroom. New York: M.E. Sharpe.

Caulfield-Sloan, M.B., \& Ruzicka, M.F. (2005) The effect of teachers' staff development in the use of higher-order questioning strategies on third grade students' rubric science assessment performance. Planning and Changing, 36(3-4), 157-175.

Chadbourne, R. (1995). Student reluctance to take up school-based teacher education: One university's experience. Journal of Education for Teaching: International Research and Pedagogy, 21(2), 219-226.

Coburn, C.E. (2003). Thinking scale: Moving beyond numbers to deep and lasting change. Educational Researcher. 32(6), 3-12.

Cohen, D., \& Hill, H. (1997). Policy, practice and learning. Paper presented at the annual meeting of the American Educational Research Association, March 1997. Chicago, IL.

Cohen, D.K., \& Hill, H.C. (2000). Instructional policy and classroom performance: The mathematics reform in California. Teachers College Record, 102(2).

Cohen, D.K., \& Hill, H.C. (2001). Learning policy: When state education reform works. New Haven, CT: Yale University.

Cohen, L., Manion, L., \& Morrison, K. (2000). Research methods in education $\left(5^{\text {th }}\right.$ ed). London: Routledge \& Falmer

Cole, E.A., \& Barsalou, J. (2006). Unite or Divide? The challenges of teaching history in societies emerging from violent conflict, Special Report: United States Institute of Peace. Washington..

Combs, M., \& Beach, J.D. (1996). Stories and Storytelling: Personalising the social studies. Reading Teacher, 47(6).

Corcoran, T.B. (1995). Transforming conceptions of professional learning. In M.W. McLaughlin, \& I. Oberman (Eds.), Teacher Learning: New policies, new practices (pp.185-201). New York: Teachers College. 
Cordeiro, P.A., Kraus, C., Hastings, S., \& Binkowski, K. (1997). A problembased learning approach to professional development: Supporting learner transfer. Paper presented at the annual meeting of the American Educational Research Association, Chicago, IL.

Cree, V., \& Macauley, C. (2000). Transfer of learning in professional and vocational education. New York: Routledge.

Creswell, J.W. (1998). Qualitative enquiry and research design: Choosing among five traditions. Thousand Oaks, CA: Sage.

Cuban, L. (1984). How teachers taught: Constancy and change in American classrooms 1890 - 1980. New York: New York University.

Cuban, L. (1991). History of teaching in social studies. In J. Shaver (Ed). Handbook of research on social studies teaching and learning (pp.197209). New York: Macmillan.

Curry, D. (2001). Evaluating transfer of learning in human services. Journal of Child and Youth Care Work, 15-16, 155-170.

Darling-Hammond, L. (1998a). Teacher learning that supports student learning. Educational Leadership, 55(5), 6-11.

Darling-Hammond, L. 1998b). Policy and change: getting beyond bureaucracy. In A. Hargreaves, A.Lieberman, M.Fullan, \& D.Hopkins (Eds), International handbook of educational change (pp.482-616). UK: Kluwer Academic.

Davis, A. (2006). Characteristics of teacher expertise associated with raising the reading comprehension abilities of Years 5-9 students. Unpublished doctoral thesis, University of Auckland, Auckland, New Zealand.

Davis, E., \& Krajcik, J. (2005). Designing educative curriculum materials to promote teachers learning. Educational Researcher, 34(3), 3-14

Day, C. (1999). Developing teachers: The challenges of life-long learning. London: Falmer Press.

Department of Education, (1995). Western Samoa education policies 19952005: Education policy and planning development project. Samoa: Author.

DFEE \& QCA (1999). History: The national curriculum for England. London: The author.

Donovan, J., Sousa, D., \& Walberg, H. (1987). The impact of staff development on implementation and student achievements. Journal of Educational Research, 80, 348-351.

Ediger, M. (2003). Data driven decision-making. College Student Journal, $37(1), 1-9$.

Education Review Office (2000). In-service training for teachers in New Zealand schools. Wellington: The author.

Egan, K. (1989). Layers of historical understanding. Theory and Research in Social Education, 17(4), 280-294.

Ehrich, L.C. (2003). Phenomenology: The quest for meaning. In T. O'Donoghue, \& K. Punch (Eds.). Qualitative educational research in action: Doing and reflecting (pp. 42-69). London: Routledge Falmer.

Epstein, T.L. (1994). The arts of history: An analysis of secondary school students' interpretations of the arts in historical contexts. Journal of Curriculum and Supervision, 9(2), 174-194.

Evans, R.W. (1988). Lessons from history: Teacher and student conceptions of the meaning of history. In Theory and Research in Social Education, XVI (3), 203-225.

Evans, R.W. (2004). The social studies wars: What should we teach the children? New York: Teachers College Press. 
Falk, B. (2001). Professional learning through assessment. In A. Lieberman, \& L. Miller (Eds.). Teachers caught in the action: professional development that matters. NY: Teachers College Press.

Finlay, L. (2005). Reflexive embodied empathy: A Phenomenology of participant-researcher intersubjectivity. Methods Issue: The Humanistic Psychologist 33(4), 271-292.

Fletcher, C.L., \& Barufaldi, J.P. (2002). Evaluating professional development with student data: Challenges and successes for project ESTT. Paper presented at the annual meeting of the National Association of Research in Science Teaching, New Orleans, LA .

Flinders, D.J. (1992). In search of ethical guidance: Constructing a basis for dialogue. Qualitative Studies in Education 5(2), 101-115.

Foxon, M. (1993). A process approach to the transfer of training Part 1: The impact of motivation and supervisor support on transfer maintenance. In Australian Journal of Education Technology, 9(2), 130-143.

Fraenkel, J.R., \& Wallen, N.E. (2006). How to design and evaluate research in education. ( $6^{\text {th }}$ ed.) McGraw Hill: New York.

French, R. (2001). Great job, now do it better. Journal of Staff Development, 22(4) $26-28$.

Fullan, M. (1982). The meaning of educational change. NY: Teachers College Press.

Fullan, M. (1985). Change process and strategies at the local level. Elementary School Journal, 3, 391-421.

Fullan, M. (1988). Research into educational innovation. In R. Glatten, M. Preddy, C. Riches, \& M. Masterton, (Eds.), Understanding school management. Milton Keynes: Open University Press.

Fullan, M. (1991). The new meaning of educational change. New York: Teachers College Press.

Fullan, M. (1993). Why teachers must become change agents. Educational Leadership, 50, 12-17.

Fullan, M., \& Pomfret, A. (1977). Research on curriculum and instruction implementation. Review of Education Research, 5, 391-392.

Gabella, M.S. (1994). Beyond the looking glass: Bringing students into the conversation of historical inquiry. Theory and Research in Social Education. 22(3), 340-363.

Gardner, R. (1995). On-service teacher education. In L. Anderson (Ed). International encyclopedia of teaching and teacher education $\left(2^{\text {nd }} \mathrm{ed}\right)$. London: Pergamon Press.

Garet, M., Porter, A., Desimone, L., Birman, B., \& Yoon, K. (2001). What makes professional development effective? Results from a National Sample of Teachers. American Educational Research Journal, 38(4), 915-945.

Gewirtz, S. (1997). Post-welfarism and the reconstruction of teachers' work in the UK. 12(4), 217-231.

Giorgi, A. (1994). A phenomenological perspective on certain qualitative research methods. Journal of Phenomenological Psychology, 25, 190220.

Good, T.L. (1989). Using classroom and school research to professionalise teaching. In B, Creemers, T Peters, \& T. Reynolds (Eds.). School effectiveness and school improvement (pp. 3-22), Amsterdam: Swets \& Zeitlinger. 
Government of Samoa. (2006). Joint Samoa programme strategy 2006-2010: Government of Samoa, government of Australia and government of New Zealand. Apia: Author.

Gravani, M.N. (2007). Unveiling professional learning: Shifting from the delivery of courses to an understanding of the processes. Teaching and Teacher Education. 23, 688-704.

Grbich, C. (2007). Qualitative data analysis: An introduction. CA: Thousand Oaks.

Greenland, J. (Ed) (1983). The in-service training of primary school teachers in English-speaking Africa: A report. London: Macmillan.

Grosso de Leon, A. (2001). Higher education's challenge: New teacher education models for a new century. New York: Carnegie Corporation.

Guskey, T.R. (1995). Professional development in education: In search of the optimal mix. In T.R. Guskey, \& M. Huberman (Eds.). Professional development in education: New Paradigms and Practices. New York: Teachers College Press.

Guskey, T.R. (1997). Research needs to link professional development and student learning. Journal of Staff Development, 18, 36-40.

Ha, A., Lee, J., Chan, D., \& Sum, R. (2004). Teacher perceptions of in-service teacher training to support curriculum change. In Physical Education: the Hong Kong experience. In Sport, Education and Society, 9(3), 421-438.

Hargreaves, A. (1995). Development and desire: A post-modern perspective. In T.R. Guskey, \& A.M. Huberman (Eds.). Professional development in education: New paradigms \& practice (pp. 9-34). New York: Teachers College Press.

Hargreaves, A. (1997). From reform to renewal: A new deal for a new age. In A. Hargreaves, \& R. Evans (Eds.), Beyond educational reform: Bringing teachers back in (pp.105-125).. Buckingham, UK: Open University Press.

Hargreaves, A. (1998). Pushing the boundaries of educational change. In A. Hargreaves, A. Lieberman, M. Fullan, \& D. Hopkins (Eds.), International Handbook of educational change: part one (pp.281-294), Dordrecht: Kluwer Academic.

Hargreaves, A., \& Fink, D. (2000). Three dimensions of Reform. In Educational Leadership, 57(7), 30-34.

Hargreaves, A., \& Fullan, M. (Eds.) (1992). Understanding teacher development. New York: Teachers' College.

Harris, M., \& Fasano, C. (1988). Towards a policy of continuing professional development of teachers: An Australian perspective. Journal of Educational Policy, 3(3), 291-300.

Hattam, R., \& Mclnerney, P. (2000). Proper teacher training holds the answers to 'whole school reform'. Education Review, 4(2), 14.

Haydn,T. (2004). What pupils dislike about teachers, school subjects, being in classrooms and school in general: A view from five secondary schools, presented at Widening participation: Research, policy and practice. Conference, University of Warwick, 17 March, 2004. Available online at http://www.uea.ac.uk/ m242/nasc//cross/cman/quest/htm.

Hayward, L., Priestley, M., \& Young, M. (2004). Ruffling the calm of the ocean floor: Merging practice, policy and research in assessment in Scotland. Oxford Review of Education, 30(3), 397-415.

Hill, D. (1995). The strong department: Building the department as a learning community. In L. Santee Siskin, \& J. Warren Little (Eds.). The subjects in 
question: Department organisation and the high school. New York: Teachers' College Press.

Hirshman, J. (1996). Lingelbach Elementary School: A case study of a chapter 1 school wide project. Journal of Education for Students Placed at Risk, 1(2), 135-146.

Hootstein, E.W. (1994). Motivating students to learn. Clearing House. 67(4), 213-216.

Huberman, M., \& Miles, M. (1984). Innovation up close. NY: Plenum Press.

Hucznski, A.A., \& Lewis, J.W. (1980). An empirical study into the learning transfer process in management training. The Journal of Management Studies, 17(2), 227-240.

Husserl, E. (1931) Ideas: General introduction to pure phenomenology, translated by W.R. Boyce Gibson (p. 133). London: George Allen \& Unwin.

Hycner, R.H. (1999). Some guidelines for the phenomenological analysis of interview data. In A. Bryman, \& R.G. Burgess (Eds.), Qualitative Research (Vol. 3, pp.143-164). London: Sage.

Hynds, A. (1997). Perceptions on transfer of training strategies for teacher inservice within New Zealand. Wellington, NZ: Wellington College of Education.

Ingvarson, L. (1998a). Professional development as a pursuit of professional standards: The standard-based professional development system. Teaching and Teacher Education, 14(1), 127-140.

Ingvarson, L.C. (1998b). Teaching standards: Foundations for the reform of professional development. In A. Hargreaves, A. Lieberman, M. Fullan, \& D. Hopkins (Eds.). International Handbook of Educational Change. Dordrecht: Kluwer.

Ingvarson, L.C. (2002). Building a Learning Profession. Paper No 1, Commissioned Research Series, Australian College of Education. Canberra: Australian College of Education.

Ingvarson, L., Meiers, M., \& Beavis, A. (2003). Evaluating the quality and impact of professional development programs. In M. Meiers (Ed.), ACER Research Conference (pp.28-34), Melbourne: ACER.

Janesick, V.J. (2000). The choreography of qualitative research design. In N.K. Denzin, \& Y.S. Lincoln (Eds.) Handbook of Qualitative Research (pp.379399). Thousand Oaks, CA: Sage.

Karagiorgi, Y., \& Symeou, L. (2006). Teacher Professional Development in Cyprus: Reflections on Current Trends and Challenges in Policy and Practices, Journal of In-Service Education, 32(1), 47-61.

Kelly, H.B. (1982). A primer on transfer of training. Training and Development Journal, 36(11), 102-106.

Kennedy, D.M. (1998). The art of the tale: Storytelling and history teaching. The History Teacher, 31(3), 319-330.

Kennedy, K. (2001). The teacher quality debate: Focusing on the professional and personal dimensions. In K. Kennedy (Ed.). Beyond the rhetoric: Building a teaching profession to support quality teaching (pp. 2-11). Eakin west, ACT: Australian College of Education.

Kieviet, F.K. (1990). A decade of research on teacher education in the Netherlands. In R. Tisher, \& M. Wideen, (Eds.). Research in teacher education: International perspectives. London: Falmer Press. 
Kozlowski, S.W.J., \& Salas, E. (1997). An organizational systems approach for the implementation and transfer of training. In J.K. Ford, S.W.J. Kozlowski, K. Kraiger, E. Salas, \& M. Teachout (Eds.), Improving training effectiveness in work organizations (pp.247-287). Mahwah, NJ: Lawrence Erlbaum.

Krefting, L. (1991). Rigor in qualitative research: The assessment of trustworthiness. The American Journal of Occupational Therapy. 45(3), 214-222.

Lam, W.Y.K. (1998). How sustainable are in-service teacher training courses? Asia-Pacific Journal of Teacher Education, 26(1), 65-74.

Lamie, J.M. (1998). Teacher education and training in Japan. Journal of Inservice Education, 24(3), 515-535.

Lawlor, S. (1989). Correct Core, in B. Moon, P. Murphy \& J. Raynor (Eds.) Policies for the curriculum. Buckingham: Open University.

Leberman, S., McDonald, L., \& Doyle, S. (2006). The transfer of learning: Participants' perspectives of adult education and training. Hampshire, England: Gower.

le Roux, C., \& Ferreira, J.G. (2005). Enhancing environmental education teaching skills through in-service education and training. Journal of Education for Teaching, 31(1), 3-14.

Lee, P. (1994). Historical knowledge and the national curriculum. In H. Bourdillon (Ed.), Teaching history (pp. 41-48). London: Routledge.

Lewin, K. (1951). Field theory in social science. New York: Harper and Row.

Lieberman, A. (1996). Practices that support teacher development: Transforming conceptions of professional learning. In M. W. McLaughlin \& I. Oberman (Eds.), Teacher learning: New policies, new practices. New York: Teachers College Press.

Lincoln, Y.S., \& Guba, E.G. (1985). Naturalistic Inquiry. Newbury Park, CA: Sage.

Lipman, P. (1997). Restructuring in context: A case study of teacher participation and the dynamics of ideology, race and power. American Educational Research Journal, 34(1), 3-37.

Loucks-Horsley, S. (1997). Teacher change, staff development and systematic change: Reflections from the eye of a paradigm shift. In G.W.B.S. Friel (Ed.). Reflecting on our work: NSF teacher enhancement in $k-6$ mathematics (pp. 113-132). Lanham, MD: University Press of America.

Maheady, L., \& Harper, G.F. (1991). Training and implementation requirements associated with the use of a classwide peer tutoring system. Education and Treatment of Children, 14(3), 177-198.

Marx, R.D. (1986). Self-managed skill retention. Training and Development Journal, 40(1), 54-57.

Mayer, D., Mitchell, J., Macdonald, D., \& Bell, R. (2005). Professional standards for teachers: A case study of professional learning. Asia-Pacific Journal of Teacher Education, 33(2), 159-179.

McCormick, R., \& James, M. (1989). Curriculum and Evaluation in Schools. $\left(2^{\text {nd }}\right.$ ed). New York: Routledge.

McDonald, B.L. (2002). Transfer of training in a cultural context: A Cook Islands study. Unpublished doctoral dissertation, Victoria University of Wellington, New Zealand. 
McDonald, L., \& Melchior, E. (2008). Investing in transfer of learning: Dancing the talk. In I. Livingston (Ed.), New Zealand Annual Review of Education, 17 (pp. 73-90). Wellington: Victoria University of Wellington.

McGee, C., Hill, M., Cowie, B., Miller, T., Lee, P., Milne, L., et al. (2004). Case studies of schools: Implementation of national curriculum. New Zealand: Ministry of Education.

Merriam, S.B. (198). Qualitative Research and Case Study Applications in Education. Revised and Expanded from 'Case Study Research in Education'. San Francisco, CA: Jossey-Bass.

Miles, M. B., \& Huberman, A.M. (1984). Qualitative data analysis: A sourcebook of New Methods. Newbury Park, CA: Sage.

Miles, M.B., \& Huberman, A.M. (1994). Qualitative data analysis (2 ${ }^{\text {nd }}$ ed.). Thousand Oaks, CA: Sage.

Millan, J. (2000). Story-telling: An effective strategy for teaching history in the English as a second language classroom, and beyond. Rapport, 24(Spring), 2000.

Ministry of Education. (2007). Education for all. Apia, Samoa: Author.

Ministry of Education, Sports and Culture. (1995). Strategic policies and plan: July 1995 - June 2005. Apia, Samoa: Author.

Ministry of Education, Sports and Culture. (2006). Strategic policies and plan: July 2006 - June 2015. Apia, Samoa: Author.

Ministry of Finance. (2005). Strategy for the Development of Samoa 2008 2012. Apia, Samoa: Author.

Moustakas, C. (1994). Phenomenological Research Methods. Thousand Oaks, CA: Sage.

Mutch, C. (2005). Doing educational research: A practitioner's guide to getting started. Wellington, New Zealand: NZCER.

National University of Samoa (2004). A study of the implementation of the new Samoa secondary curriculum: A preliminary report. Apia, Samoa: The author

Niemi, R.G., \& Smith, J. (2001). Learning history in schools: The impact of course work and instructional practices on achievement. Theory and Research in Social Education, 29(1), 18-42.

OECD, (1998). Staying ahead: In-service training and professional development, Paris, France: The author.

Ogletree, E., \& Allen, B. (1976). Opinions of inner-city teacher of in-service meetings. Peabody Journal of Education. 54(1), 47-52.

Pasikale, A. (1996). Seen but not heard: Voices of Pacific Island learners. Wellington, New Zealand: Wright \& Carman.

Patton, M. (1990). Qualitative evaluation and research methods. Newbury Park, CA: Sage.

Peers, C., Diezmann, C., \& Watters, J. (2003). Supports and concerns for teacher professional growth during the implementation of a science curriculum innovation. Research in Science Education, 33, 89-110.

Pendry, A., Husbands, C., Arthur, J., \& Davison, J. (1998). History teachers in the making: Professional learning. Philadelphia, PA: Open University.

Penuel, W.R., Fishman, B.J., Yamaguchi R.Y., and Gallagher, L.P. (2007). What makes professional development effective? Strategies that foster curriculum implementation. American Education Research Journal, 44(4), 921-958. 
Perry, S. (1990). Ideas for improving transfer of training. Adult Learning, 1, 1923.

Phillips, J. (2003). Powerful learning: Creating learning communities in urban school reform. Journal of Curriculum and Supervision, 18(3), 240-258.

Pitt, J. (2000). Computing on a shoestring: Extending pupils historical vision with limited resources. Teaching History, 101, p.12.

Renyi, J. (1996). Teachers take charge of their learning: Transforming professional development for student success. Washington, DC: National Foundation for the Improvement of Education.

Robinson, V.M.J., \& Lai, M.K. (2006). Practitioner research for educators: $A$ guide to improving classrooms and schools. Thousand Oaks, CA: Corwin.

Sabri, K.S. (1997). In-service teacher training programmes: The case of Palestine. Journal of In-service Education, 23(1), 113.

Saito, E., Hendayana, S., Imansyah, H., Ibrohim., Isamu, K., \& Hideharu, T. (2006). Development of school-based in-service training under the Indonesian mathematics and science teacher education project. Improving Schools, 9(1), 47-59.

Sanders, P. (1982). Phenomenology: A new way of viewing organizational research. The Academy of Management Review 7, 353-360.

Schober, H.M. (1984). The effects of in-service training on participating teachers and students in their economic classes. The Journal of Economic Education, 15(4) 282-295.

Schofield, K. (2004). Samoa secondary education curriculum and resources project phase two: Final quarterly report July 01 - September 30. Uniservices Ltd, Auckland, New Zealand: Auckland Uniservices.

Scott, C., Coxon, E., \& Lameta, E. (2004). Samoa secondary education curriculum andrResources project: Phase 2. Auckland, New Zealand: Auckland Uniservices.

Seixas, P. (1999). Beyond content and pedagogy: In search of a way to talk about history education. Journal of Curriculum Studies, 31(3), 317-337.

Showers, B., Joyce, B., \& Bennett, B. (1987). Synthesis of research on staff development: A framework for future study and state of the art analysis. Educational Leadership, 45(3), 77-87.

Silverman, D. (2000). Doing Qualitative Research: A Practical Handbook. Thousand Oaks, CA: Sage.

Slater, J. (2006). The Times Educational Supplement, No 4694, p. 12.

Spady, W.G., \& Marshall, K.J. (1991). Beyond traditional outcome-based education. Educational Leadership 49(2) 67-72.

Spillane, J.P. (2004). Standards deviation: How schools misunderstood education policy. Cambridge, MA: Harvard University Press.

Spillane, J.P., Reiser, B., \& Reimer, T. (2002). Policy implementation and cognition. Reframing and refocusing implementation research. Review of Educational Research. 72(3), 387-431.

Stake, R.E. (1998). Case studies. In N.K. Denzin, \& Y.S. Lincoln (Eds.), Strategies of qualitative inquiry (pp.86-109). Thousand Oaks, CA: Sage.

Stearns, P., Seixas, P., \& Wineburg, S. (Eds.)(2000). Knowing, teaching and learning history: National and international perspectives. New York: New York University Press.

Stoskopf, A. (2001). Reviving Clio: Inspired history teaching and learning (without high-stakes tests). Phi Delta Kappan, 82(6), 468-473. 
Strauss, A., \& Corbin, J. (1990). Basics of Qualitative Research, Newbury Park, CA: Sage.

Stronkhorst, R., \& van den Akker, J. (2006). Effects of in-service education in improving science teaching in Swaziland. International Journal of Science Education, 28(15), 1771-1794.

Subedi, B.S. (2004). Emerging trends of research on transfer of learning. International Education Journal, 5(4), 591-599.

Supovitz, J.A., Mayer, D.P., \& Kahle, J.B. (2000). Promoting inquiry-based instructional practice: The longitudinal impact of professional development in the context of systemic reform. Educational Policy, 14(3), 331-356.

Supovitz, J.A., \& Turner, H.M. (2000). The effects of professional development on science teaching practices and classroom culture. Journal of Research in Science Teaching, 39(9), 963-980.

Taplin, M., Ng Fung Ping, D., \& Fuqian, H. (2007). The impact of a collaborative model for curriculum restructuring on teachers' professional growth. In T. Townsend, \& R. Bates (Eds.) Handbook of teacher education: Globalisation, standards and professionalism in times of change. Netherlands: Springer.

Thompson, K. (2001). Constructivist curriculum design for professional development: A review of the literature. Australian Journal of Adult Learning, 41(1), 94-109.

Timperley, H., Wilson, A., Barrar, H., \& Fung, I. (2007). Teacher professional learning and development: Best evidence synthesis iteration. Wellington, New Zealand: Ministry of Education.

Tufue, R. (1998). Perceptions of Pacific Island New Zealand resident educator's on transfer of training strategies, Unpublished doctoral dissertation, Victoria University of Wellington, New Zealand.

Tupuola, A. (1993). Raising research consciousness the Fa'a Samoa way. New Zealand Review of Education, 3, 175-189.

VanSledright, B.A. (1996). Closing the gap between school and disciplinary history? Historian as high school history teacher. Advances in Research on Teaching. 6, 257-289.

VanSledright, B.A. (2002). Fifth graders investigating history in the classroom: Results from a research-practitioner design experiment. The Elementary School Journal, 103(2), 131-160.

VanSledright, B.A. (2007). Why should historians care about the history teaching? Perspectives Online. Accessed on January 23, 2009. http://www.historians.org/perspectives/issues/2007/0702/0702tea2.cfm.

Veenman, S., \& Denessen, E. (2001). The coaching of teachers: Results of five training studies. Educational Research and Evaluation, 7(4), 385-417.

Villegas-Reimers, E. (2003). Teacher professional development: An international review of the literature. Paris: International Institute for Educational Planning.

Vonk, J.H.C. (1995). Teacher education and reform in Western Europe: sociopolitical contexts and actual reform. In N. K. Shimahara, \& I. Z. Holowinsky (Eds.). Teacher Education in Industrialised Nations. New York: Garland.

Voss, J.F. (1998). Issues in the learning of history. Issues in Education 4(2), 163-210.

Warren, W.J. (2003). Teaching Authentic History. In D.A. Cantu \& W.J. Warren (Eds.). Teaching History in the Digital Classroom (pp. 167-179). New York: M. E. Sharpe,. 
Weiss, I.R., Montgomery, D.L., Ridgway, C.J., \& Bond. S.L. (1998). Local systemic change through teacher enhancement: Year three cross-site report. Chapel Hill, NC: Horizon Research.

Weissglass, J. (1994). Deepening our dialogue about equity. Educational Leadership, 54(7), 78-81

Welman, J.C., \& Kruger, S.J. (1999). Research methodology for the business and administrative sciences. Johannesburg, South Africa: International Thompson.

White, J. (2003). Rethinking the school curriculum: Values, aims and purposes. London: Rutledge Flamer.

Willink, R.J. (1959). In-service training of junior high school teachers of New York State. NASSP Bulletin, 43(13) 222.

Wilson, S.M. (2001). Research on history teaching. In Richardson, V. (Ed.) Handbook of Research on Teaching (pp. 527-544) (4 ${ }^{\text {th }}$ ed.). Washington, DC: American Educational Research Association,.

Wlodkowski, R.J. (1985). Enhancing adult motivation to learn. San Francisco: Jossey-Bass.

World Bank Report (1992). Western Samoa - rebuilding the education system: Education sector review. Apia, Samoa: The author

Zeegers, Y. (1995). Supporting teachers to implement the national curriculum: A New Zealand perspective. Australian Science Teachers Journal, 41(4), $45-48$. 